Article

\title{
Predictive Modeling of a Buoyancy-Operated Cooling Tower under Unsaturated Conditions: Adjoint Sensitivity Model and Optimal Best-Estimate Results with Reduced Predicted Uncertainties
}

\author{
Federico Di Rocco ${ }^{1}$ and Dan Gabriel Cacuci ${ }^{2, *}$ \\ 1 Department of Astronautic, Electric and Energy Engineering (DIAEE), "Sapienza"-University of Rome, \\ 00185 Roma, Italy; federicodirocco@alice.it \\ 2 Center for Nuclear Science and Energy, Department of Mechanical Engineering, \\ University of South Carolina, 300 Main Street, Columbia, SC 29208, USA \\ * Correspondence: cacuci@cec.sc.edu; Tel.: +1-803-777-9751
}

Academic Editor: Hiroshi Sekimoto

Received: 18 October 2016; Accepted: 28 November 2016; Published: 8 December 2016

\begin{abstract}
Nuclear and other large-scale energy-producing plants must include systems that guarantee the safe discharge of residual heat from the industrial process into the atmosphere. This function is usually performed by one or several cooling towers. The amount of heat released by a cooling tower into the external environment can be quantified by using a numerical simulation model of the physical processes occurring in the respective tower, augmented by experimentally measured data that accounts for external conditions such as outlet air temperature, outlet water temperature, and outlet air relative humidity. The model's responses of interest depend on many model parameters including correlations, boundary conditions, and material properties. Changes in these model parameters induce changes in the computed quantities of interest (called "model responses"), which are quantified by the sensitivities (i.e., functional derivatives) of the model responses with respect to the model parameters. These sensitivities are computed in this work by applying the general adjoint sensitivity analysis methodology (ASAM) for nonlinear systems. These sensitivities are subsequently used for: (i) Ranking the parameters in their importance to contributing to response uncertainties; (ii) Propagating the uncertainties (covariances) in these model parameters to quantify the uncertainties (covariances) in the model responses; (iii) Performing model validation and predictive modeling. The comprehensive predictive modeling methodology used in this work, which includes assimilation of experimental measurements and calibration of model parameters, is applied to the cooling tower model under unsaturated conditions. The predicted response uncertainties (standard deviations) thus obtained are smaller than both the computed and the measured standards deviations for the respective responses, even for responses where no experimental data were available.
\end{abstract}

Keywords: cooling tower; adjoint sensitivity analysis; adjoint cooling tower model solution verification; data assimilation; model calibration; best-estimate predictions; reduced predicted uncertainties

\section{Introduction}

Nuclear and other energy-producing large-scale industrial installations must include systems that guarantee the safe discharge of residual heat from the industrial process into the atmosphere. In the case of nuclear power plants, the residual heat is discharged into the atmosphere by using cooling towers. The amount of heat released into the external environment can be quantified by using a numerical simulation model of the physical processes that take place within the respective cooling tower, complemented by experimentally measured data that characterize external conditions such 
as outlet air temperature, outlet water temperature and outlet air relative humidity. Based on the flow regime occurring in the fill section, the cooling towers are generally divided in two categories: cross-flow towers and counter-flow towers. A model for the steady-state simulation of both cross-flow and counter-flow wet cooling towers has been presented in [1]. The natural draft cooling tower model presented in [1] was validated against experimental data in [2,3] under partially and totally saturated conditions. This work also analyses a natural draft cooling tower, but, in contradistinction with the work in [2,3], the draft cooling tower analyzed in this work operates always under unsaturated conditions. Thus, just as in [2,3], the cooling tower analyzed in this work is operated with the tower's fan turned off, causing the air mass flow rate to be an unknown state variable to be determined by solving the underlying set of governing equations. In contradistinction to [2,3], however, the unsaturated operating conditions analyzed in this work are modeled by governing equations that differ from the ones presented in [2,3].

The work in $[2,3]$ used a considerably more accurate and efficient numerical method than was used in [1], thereby overcoming all of the non-convergence issues that had plagued some of the computations in [1]. The accurate and efficient numerical method introduced in [2,3] is also used in this work for computing the following quantities: (i) The water mass flow rates at the exit of each control volume along the height of the fill section of the cooling tower; (ii) The water temperatures at the exit of each control volume along the height of the fill section of the cooling tower; (iii) The air temperatures at the exit of each control volume along the height of the fill section of the cooling tower; (iv) The humidity ratios at the exit of each control volume along the height of the fill section of the cooling tower; (v) The air relative humidity at the exit of each control volume; and (vi) the air mass flow rate at the outlet of the cooling tower.

This work is organized as follows: Section 2 presents the mathematical model of a mechanical draft counter-flow cooling tower operating under unsaturated conditions, along with the numerical solution for the quantities (state functions) mentioned above in items (i) through (vi). Section 3 presents the development of the adjoint sensitivity model for the counter-flow cooling tower operating under unsaturated conditions using the general adjoint sensitivity analysis methodology (ASAM) for nonlinear systems [4-6]. Using a single adjoint computation enables the efficient and exact computation of the sensitivities (functional derivatives) of the model responses to all of the 47 model parameters, thus alleviating the need for repeated forward model computations in conjunction with finite difference methods. Sensitivities are subsequently used for ranking the contributions of the single model parameters to the model responses variations, computing the propagated uncertainties of the model responses, and for the application of the "predictive modeling for coupled multi-physics systems" (PM_CMPS) methodology [7], aimed at yielding best-estimate predicted nominal values and uncertainties for model parameters and responses.

Section 4 presents the results of applying the PM_CMPS methodology, which simultaneously combines all of the available computed information and experimentally measured data for the buoyancy-operated counter-flow cooling tower operating under unsaturated conditions. The best-estimate results predicted by the PM_CMPS methodology reveal that the predicted values of the standard deviations for all the model responses, even those for which no experimental data have been recorded, are smaller than either the computed or the measured standards deviations for the respective responses. After discussing the significance of these predicted results, this work concludes by indicating possible further generalizations of the adjoint sensitivity analysis and PM_CMPS methodologies.

\section{Mathematical Model of a Mechanical Draft Counter-Flow Cooling Tower Operating under Unsaturated Conditions}

The experimental measurement used for this study have been performed at Savannah River National Laboratory (SRNL) for F-Area Cooling Towers in the period going from April, 2004 to August, 2004; this data collection comprises a total of 8079 benchmark data sets [8], each one containing the 
following (four) measured quantities: (i) Exhaust air temperature according to the "Tidbit" sensor, which will be denoted in the following as $T_{a, o u t}($ Tidbit $)$; (ii) Exhaust air temperature according to the "Hobo" sensor, which will be denoted in the following as $T_{a, o u t(H o b o)}$; (iii) Outlet water temperature, which will be denoted in the following as $T_{w, o u t}^{\text {meas }}$ (iv) Exhaust air relative humidity, which will be referred to as $R H^{\text {meas }}$. For a data set to be intended as unsaturated is required that the value of the exhaust air relative humidity $(R H)$, computed by making use of the SNRL simulation code CTTool [1], is smaller than $100 \%$, while the threshold is set on correspondence of the saturation line $(R H=100 \%)$. With this standard set, 6717 data sets among the total 8079 measured have matched the requirement above and have been therefore identified as "unsaturated", leading to include them in the present study. Histogram plots and analyses of the statistical moments of the selected 6717 data sets have been gathered in Appendix A. The state functions chosen for the analysis of the cooling tower mathematical model hereby considered have been selected according to the quantities comprised in the experimentally measured data sets. A numerical method, which has been presented in detail in [2], has been implemented to improve both the accuracy and the efficiency in the solution of the constitutive equations system governing the counter-flow cooling tower model.

The cooling tower model analyzed in this work has been originally presented in [1] and has been thoroughly described in [2], from which Figures 1-3 have been taken. Natural draft air enters the tower just below the fill section, through which it passes flowing upwards along the height of the tower finally exiting at the top, through an exhaust comprising a fan. Inlet water enters the tower below the drift eliminator, and is sprayed downwards over the fill section, leading to the creation of a uniform film flow through the fill.

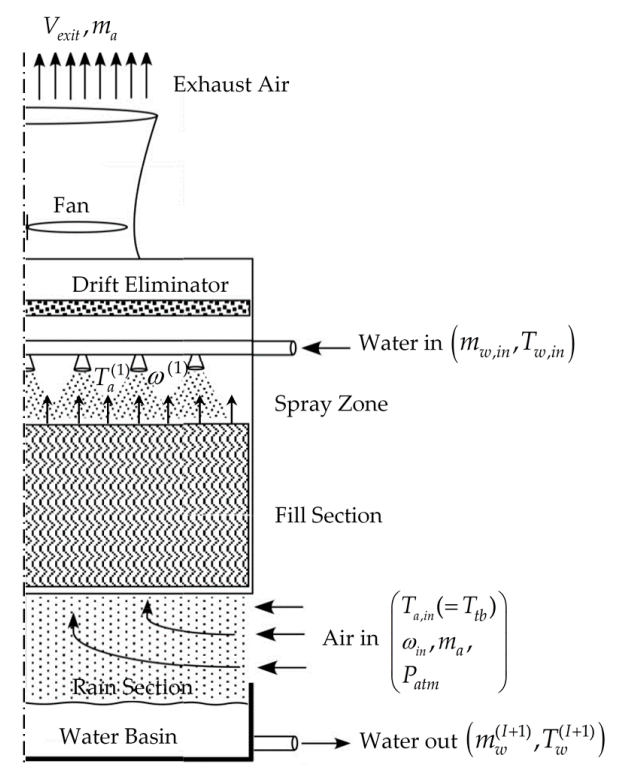

Figure 1. Flow through a counter-flow cooling tower.

The magnitude of the heat and mass transfer processes occurring in the counter-flow cooling tower of interest can be mathematically determined by obtaining the solution of the nonlinear system comprising the following balance equations: (A) Liquid continuity; (B) Liquid energy balance; (C) Water vapor continuity; (D) Air/water vapor energy balance; (E) Mechanical energy balance. In the derivation process of these equations, the cooling tower model has undergone several assumptions, such as:

1. air and water stream temperatures are uniform at any cross section;

2. the cross-sectional area of the cooling tower is assumed to be uniform;

3. the heat and mass transfer only occur in the direction normal to flows;

4. the heat and mass transfer through tower walls to the environment is neglected; 
5. the heat transfer from the cooling tower fan and motor assembly to the air is neglected;

6. the air and water vapor is considered a mixture of ideal gasses;

7. the flow between flat plates is unsaturated through the fill section.

It is worth specifying that this work applies to cooling towers of moderate size, for which it is possible to neglect the occurrence of the heat and mass transfer phenomena in the rain section. Figure 2 displays the vertical nodalization chosen for the fill section. Figure 3 offers a more detailed description of the heat and mass transfer processes occurring at the interface between the water film and the air flow within a single control volume.

As reminded above, when the cooling tower is operated in natural draft/wind-aided mode the mass flowrate of dry air becomes an additional unknown. Even with the fan off though, hot water flowing through the cooling tower will cause air to continue to flow through the tower due to buoyancy, with possible flow enhancements caused by the wind pressure at the air inlet to the cooling tower. The state functions underlying the cooling tower model (cf., Figures 1-3) are as follows:

1. the water mass flow rates, denoted as $m_{w}^{(i)}(i=2, \ldots, 50)$, at the exit of each control volume, $i$, along the height of the fill section of the cooling tower;

2. the water temperatures, denoted as $T_{w}^{(i)}(i=2, \ldots, 50)$, at the exit of each control volume, $i$, along the height of the fill section of the cooling tower;

3. the air temperatures, denoted as $T_{a}^{(i)}(i=1, \ldots, 49)$, at the exit of each control volume, $i$, along the height of the fill section of the cooling tower;

4. the humidity ratios, denoted as $\omega^{(i)}(i=1, \ldots, 49)$, at the exit of each control volume, $i$, along the height of the fill section of the cooling tower.

5. the air mass flow rates, denoted as $m_{a}$, constant along the height of the fill section of the cooling tower.

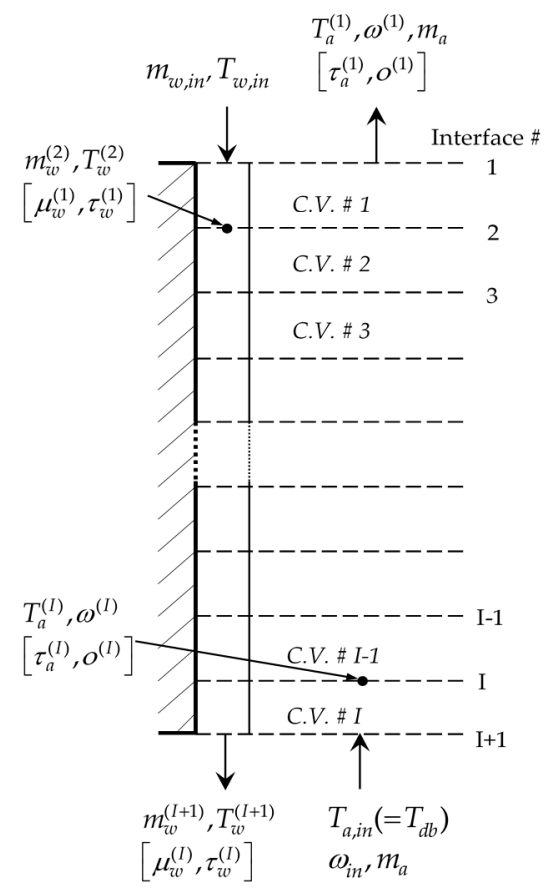

Figure 2. Fill section nodalization comprising 49 control volumes $(i=1, \ldots, I=49)$; both the forward state functions $\left(m_{w}^{(i)}, T_{w}^{(i)}, T_{a}^{(i)}, \omega^{(i)}, m_{a} ; i=1, \ldots, I\right)$ and the adjoint state functions selected $\left(\mu_{w}^{(i)}, \tau_{w}^{(i)}, \tau_{a}^{(i)},(i), \mu_{a} ; i=1, \ldots, I\right)$ are shown in the picture. 


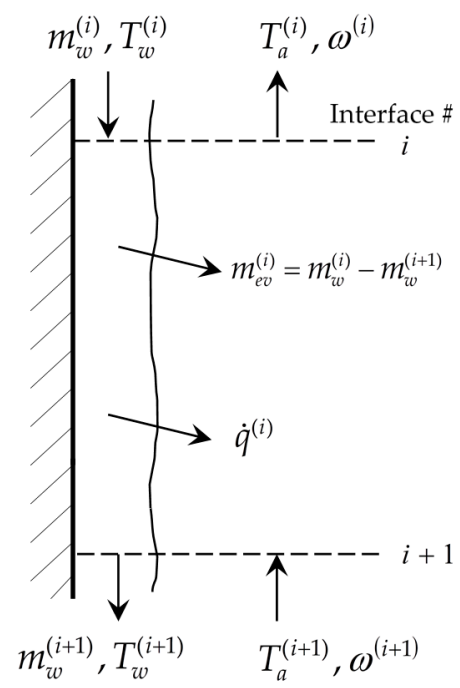

Figure 3. Heat and mass transfer phenomena at the interface between downward water film and upward air within a single control volume of the cooling tower's fill section.

Here and in the following, the above state functions are assumed to be components of the following (column) vectors:

$$
\mathbf{m}_{w} \equiv\left[m_{w}^{(2)}, \ldots, m_{w}^{(I+1)}\right]^{\dagger}, \mathbf{T}_{w} \equiv\left[T_{w}^{(2)}, \ldots, T_{w}^{(I+1)}\right]^{\dagger}, \mathbf{T}_{a} \equiv\left[T_{a}^{(1)}, \ldots, T_{a}^{(I)}\right]^{\dagger}, \boldsymbol{\omega} \equiv\left[\omega^{(1)}, \ldots, \omega^{(I)}\right]^{\dagger}, m_{a}
$$

In this paper's notation, the dagger ${ }^{(+)}$is used to denote "transposition", and all vectors in this work are column vectors. Because of the aforementioned similarities with the partially saturated case in [2], the constitutive equation system governing the cooling tower model of interest is closely comparable with the one provided in Equations (2)-(15) in [2]. For this unsaturated analysis, the governing equations within the total of $I=49$ control volumes represented in Figure 2 are as follows [1]:

A. Liquid Continuity Equations:

(i) Control Volume $i=1$ :

$$
N_{1}^{(1)}\left(\mathbf{m}_{w}, \mathbf{T}_{w}, \mathbf{T}_{a}, \boldsymbol{\omega}, m_{a} ; \boldsymbol{\alpha}\right) \triangleq m_{w}^{(2)}-m_{w, i n}+\frac{M\left(m_{a}, \boldsymbol{\alpha}\right)}{\bar{R}}\left[\frac{P_{v s}^{(2)}\left(T_{w}^{(2)}, \boldsymbol{\alpha}\right)}{T_{w}^{(2)}}-\frac{\omega^{(1)} P_{a t m}}{T_{a}^{(1)}\left(0.622+\omega^{(1)}\right)}\right]=0 ;
$$

(ii) Control Volumes $i=2, \ldots, I-1$ :

$$
N_{1}^{(i)}\left(\mathbf{m}_{w}, \mathbf{T}_{w}, \mathbf{T}_{a}, \boldsymbol{\omega}, m_{a} ; \boldsymbol{\alpha}\right) \triangleq m_{w}^{(i+1)}-m_{w}^{(i)}+\frac{M\left(m_{a}, \boldsymbol{\alpha}\right)}{\bar{R}}\left[\frac{P_{v s}^{(i+1)}\left(T_{w}^{(i+1)}, \boldsymbol{\alpha}\right)}{T_{w}^{(i+1)}}-\frac{\omega^{(i)} P_{a t m}}{T_{a}^{(i)}\left(0.622+\omega^{(i)}\right)}\right]=0 ;
$$

(iii) Control Volume $i=I$ :

$$
N_{1}^{(I)}\left(\mathbf{m}_{w}, \mathbf{T}_{w}, \mathbf{T}_{a}, \boldsymbol{\omega}, m_{a} ; \boldsymbol{\alpha}\right) \triangleq m_{w}^{(I+1)}-m_{w}^{(I)}+\frac{M\left(m_{a}, \boldsymbol{\alpha}\right)}{\bar{R}}\left[\frac{P_{v s}^{(I+1)}\left(T_{w}^{(I+1)}, \boldsymbol{\alpha}\right)}{T_{w}^{(I+1)}}-\frac{\omega^{(I)} P_{a t m}}{T_{a}^{(I)}\left(0.622+\omega^{(I)}\right)}\right]=0 ;
$$

B. Liquid Energy Balance Equations: 
(i) Control Volume $i=1$ :

$$
\begin{gathered}
N_{2}^{(1)}\left(\mathbf{m}_{w}, \mathbf{T}_{w}, \mathbf{T}_{a}, \boldsymbol{\omega}, m_{a} ; \boldsymbol{\alpha}\right) \triangleq m_{w, i n} h_{f}\left(T_{w, i n}, \boldsymbol{\alpha}\right)-\left(T_{w}^{(2)}-T_{a}^{(1)}\right) H\left(m_{a}, \boldsymbol{\alpha}\right) \\
-m_{w}^{(2)} h_{f}^{(2)}\left(T_{w}^{(2)}, \boldsymbol{\alpha}\right)-\left(m_{w, i n}-m_{w}^{(2)}\right) h_{g, w}^{(2)}\left(T_{w}^{(2)}, \boldsymbol{\alpha}\right)=0
\end{gathered}
$$

(ii) Control Volumes $i=2, \ldots, I-1$ :

$$
\begin{gathered}
N_{2}^{(i)}\left(\mathbf{m}_{w}, \mathbf{T}_{w}, \mathbf{T}_{a}, \boldsymbol{\omega}, m_{a} ; \boldsymbol{\alpha}\right) \triangleq m_{w}^{(i)} h_{f}^{(i)}\left(T_{w}^{(i)}, \boldsymbol{\alpha}\right)-\left(T_{w}^{(i+1)}-T_{a}^{(i)}\right) H\left(m_{a}, \boldsymbol{\alpha}\right) \\
-m_{w}^{(i+1)} h_{f}^{(i+1)}\left(T_{w}^{(i+1)}, \boldsymbol{\alpha}\right)-\left(m_{w}^{(i)}-m_{w}^{(i+1)}\right) h_{g, w}^{(i+1)}\left(T_{w}^{(i+1)}, \boldsymbol{\alpha}\right)=0
\end{gathered}
$$

(iii) Control Volume $i=I$ :

$$
\begin{gathered}
N_{2}^{(I)}\left(\mathbf{m}_{w}, \mathbf{T}_{w}, \mathbf{T}_{a}, \boldsymbol{\omega}, m_{a} ; \boldsymbol{\alpha}\right) \triangleq m_{w}^{(I)} h_{f}^{(I)}\left(T_{w}^{(I)}, \boldsymbol{\alpha}\right)-\left(T_{w}^{(I+1)}-T_{a}^{(I)}\right) H\left(m_{a}, \boldsymbol{\alpha}\right) \\
-m_{w}^{(I+1)} h_{f}^{(I+1)}\left(T_{w}^{(I+1)}, \boldsymbol{\alpha}\right)-\left(m_{w}^{(I)}-m_{w}^{(I+1)}\right) h_{g, w}^{(I+1)}\left(T_{w}^{(I+1)}, \boldsymbol{\alpha}\right)=0 ;
\end{gathered}
$$

C. Water Vapor Continuity Equations:

(i) Control Volume $i=1$ :

$$
N_{3}^{(1)}\left(\mathbf{m}_{w}, \mathbf{T}_{w}, \mathbf{T}_{a}, \boldsymbol{\omega}, m_{a} ; \boldsymbol{\alpha}\right) \triangleq \omega^{(2)}-\omega^{(1)}+\frac{m_{w . i n}-m_{w}^{(2)}}{\left|m_{a}\right|}=0
$$

(ii) Control Volumes $i=2, \ldots, I-1$ :

$$
N_{3}^{(i)}\left(\mathbf{m}_{w}, \mathbf{T}_{w}, \mathbf{T}_{a}, \boldsymbol{\omega}, m_{a} ; \boldsymbol{\alpha}\right) \triangleq \omega^{(i+1)}-\omega^{(i)}+\frac{m_{w}^{(i)}-m_{w}^{(i+1)}}{\left|m_{a}\right|}=0 ;
$$

(iii) Control Volume $i=I$ :

$$
N_{3}^{(I)}\left(\mathbf{m}_{w}, \mathbf{T}_{w}, \mathbf{T}_{a}, \boldsymbol{\omega}, m_{a} ; \boldsymbol{\alpha}\right) \triangleq \omega_{i n}-\omega^{(I)}+\frac{m_{w}^{(I)}-m_{w}^{(I+1)}}{\left|m_{a}\right|}=0
$$

D. The Air/Water Vapor Energy Balance Equations:

(i) Control Volume $i=1$ :

$$
\begin{gathered}
N_{4}^{(1)}\left(\mathbf{m}_{w}, \mathbf{T}_{w}, \mathbf{T}_{a}, \boldsymbol{\omega}, m_{a} ; \boldsymbol{\alpha}\right) \triangleq\left(T_{a}^{(2)}-T_{a}^{(1)}\right) C_{p}^{(1)}\left(\frac{T_{a}^{(1)}+273.15}{2}, \boldsymbol{\alpha}\right)-\omega^{(1)} h_{g, a}^{(1)}\left(T_{a}^{(1)}, \boldsymbol{\alpha}\right) \\
+\frac{\left(T_{w}^{(2)}-T_{a}^{(1)}\right) H\left(m_{a}, \boldsymbol{\alpha}\right)}{\left|m_{a}\right|}+\frac{\left(m_{w, i n}-m_{w}^{(2)}\right) h_{g, w}^{(2)}\left(T_{w}^{(2)}, \boldsymbol{\alpha}\right)}{\left|m_{a}\right|}+\omega^{(2)} h_{g, a}^{(2)}\left(T_{a}^{(2)}, \boldsymbol{\alpha}\right)=0 ;
\end{gathered}
$$

(ii) Control Volumes $i=2, \ldots, I-1$ :

$$
\begin{gathered}
N_{4}^{(i)}\left(\mathbf{m}_{w}, \mathbf{T}_{w}, \mathbf{T}_{a}, \boldsymbol{\omega}, m_{a} ; \boldsymbol{\alpha}\right) \triangleq\left(T_{a}^{(i+1)}-T_{a}^{(i)}\right) C_{p}^{(i)}\left(\frac{T_{a}^{(i)}+273.15}{2}, \boldsymbol{\alpha}\right)-\omega^{(i)} h_{g, a}^{(i)}\left(T_{a}^{(i)}, \boldsymbol{\alpha}\right) \\
+\frac{\left(T_{w}^{(i+1)}-T_{a}^{(i)}\right) H\left(m_{a}, \boldsymbol{\alpha}\right)}{\left|m_{a}\right|}+\frac{\left(m_{w}^{(i)}-m_{w}^{(i+1)}\right) h_{g, w}^{(i+1)}\left(T_{w}^{(i+1)}, \boldsymbol{\alpha}\right)}{\left|m_{a}\right|}+\omega^{(i+1)} h_{g, a}^{(i+1)}\left(T_{a}^{(i+1)}, \boldsymbol{\alpha}\right)=0
\end{gathered}
$$

(iii) Control Volume $i=I$ :

$$
\begin{gathered}
N_{4}^{(I)}\left(\mathbf{m}_{w}, \mathbf{T}_{w}, \mathbf{T}_{a}, \boldsymbol{\omega}, m_{a} ; \boldsymbol{\alpha}\right) \triangleq\left(T_{a, i n}-T_{a}^{(I)}\right) C_{p}{ }^{(I)}\left(\frac{T_{a}^{(I)}+273.15}{2}, \boldsymbol{\alpha}\right)-\omega^{(I)} h_{g, a}^{(I)}\left(T_{a}^{(I)}, \boldsymbol{\alpha}\right) \\
+\frac{\left(T_{w}^{(I+1)}-T_{a}^{(I)}\right) H\left(m_{a}, \boldsymbol{\alpha}\right)}{\left|m_{a}\right|}+\frac{\left(m_{w}^{(I)}-m_{w}^{(I+1)}\right) h_{g, w}^{(I+1)}\left(T_{w}^{(I+1)}, \boldsymbol{\alpha}\right)}{\left|m_{a}\right|}+\omega_{i n} h_{g, a}\left(T_{a, i n}, \boldsymbol{\alpha}\right)=0 .
\end{gathered}
$$


E. The Mechanical Energy Balance Equation:

$$
\begin{aligned}
& N_{5}\left(\mathbf{m}_{w}, \mathbf{T}_{w}, \boldsymbol{\omega}, \mathbf{T}_{a}, m_{a} ; \boldsymbol{\alpha}\right) \triangleq \\
& {\left[\frac{1}{2 \rho\left(T_{d b}, \boldsymbol{\alpha}\right)}\left(\frac{1}{A_{\text {out }}(\boldsymbol{\alpha})^{2}}-\frac{1}{A_{\text {in }}(\boldsymbol{\alpha})^{2}}+\frac{k_{\text {sum }}}{A_{\text {fill }}{ }^{2}}\right)+\frac{f}{2 \rho\left(T_{\text {tdb }}, \boldsymbol{\alpha}\right)} \frac{96}{R_{e}\left(m_{a}, \boldsymbol{\alpha}\right.} \frac{L_{\text {fill }}(\boldsymbol{\alpha})}{A_{\text {fill }}{ }^{2} D_{h}}\right]\left|m_{a}\right| m_{a}} \\
& -g Z(\boldsymbol{\alpha}) \rho\left(T_{d b}, \boldsymbol{\alpha}\right)-\frac{V_{w w}{ }^{2}\left(T_{d b}, \boldsymbol{\alpha}\right)}{2}+\Delta z_{\text {rain }} g \rho\left(T_{d b}, \boldsymbol{\alpha}\right)+g \rho\left(T_{a}^{(1)}, \boldsymbol{\alpha}\right) \Delta z_{4-2}(\boldsymbol{\alpha}) \\
& +g \Delta z(\boldsymbol{\alpha}) \frac{P_{a t m}}{R_{a i r}}\left[\frac{1}{2 T_{a, i n}}+\frac{1}{2 T_{a}^{(1)}}+\sum_{i=2}^{I} \frac{1}{T_{a}^{(i)}}\right]=0 ;
\end{aligned}
$$

The vector $\alpha$, which appears in Equations (2)-(14), comprises as its components the 47 model parameters, which will be denoted in the following as $\alpha_{i}$, i.e.,

$$
\alpha \triangleq\left(\alpha_{1}, \ldots, \alpha_{N_{\alpha}}\right)
$$

where $N_{\alpha}=47$ represents the total number of model parameters. These model parameters value and standard deviations have been experimentally derived, causing their statistical distributions not to be completely known; the first four statistical moments (means, variance/covariance, skewness, and kurtosis) of each of these parameter distributions have nevertheless been quantified, as presented in Appendix B.

As discussed in [2], the numerical method used in the original work [1] to solve Equations (2)-(14) failed to achieve convergence for all the considered data sets, and for this reason it was substituted with a more accurate and efficient one, based on Newton's method together with the GMRES linear iterative solver for sparse matrices [9] comprised in the NSPCG package [10]. This method has been thoroughly described in [2], Section 2.1.

The Jacobian matrix of derivatives of Equations (2)-(14) with respect to the state functions is denoted as:

$$
\mathbf{J}\left(\mathbf{u}_{n}\right) \triangleq\left(\begin{array}{ccccc}
\mathbf{A}_{1} & \mathbf{B}_{1} & \mathbf{C}_{1} & \mathbf{D}_{1} & \mathbf{E}_{1} \\
\mathbf{A}_{2} & \mathbf{B}_{2} & \mathbf{C}_{2} & \mathbf{D}_{2} & \mathbf{E}_{2} \\
\mathbf{A}_{3} & \mathbf{B}_{3} & \mathbf{C}_{3} & \mathbf{D}_{3} & \mathbf{E}_{3} \\
\mathbf{A}_{4} & \mathbf{B}_{4} & \mathbf{C}_{4} & \mathbf{D}_{4} & \mathbf{E}_{4} \\
\mathbf{A}_{5} & \mathbf{B}_{5} & \mathbf{C}_{5} & \mathbf{D}_{5} & \mathbf{E}_{5}
\end{array}\right),
$$

The majority of the components of this block matrix remain unaltered from the Jacobian matrix in [2], Equation (20), whose components are detailed in [2], Appendix C; the components which are caused by the unsaturated operating conditions to be different from the study in [2] are separately detailed in Appendix $C$ of this paper. The above matrix $\mathbf{J}\left(\mathbf{u}_{n}\right)$ is a non-symmetric sparse matrix of order 197 by 197; the diagonal storage method used in NSPCG to relevantly reduce the matrix size, together with the approximation introduced by setting the column vectors $\left(\mathbf{E}_{1}, \ldots, \mathbf{E}_{4}\right)$ and the row vectors $\left(\mathbf{A}_{5}, \ldots, \mathbf{D}_{5}\right)$ to zero, are discussed in [2], Section 2.1.

As detailed in Appendix A, each of these data sets comprises measurements of the following quantities: (i) Outlet air temperature measured with the "Tidbit" sensor; (ii) Outlet air temperature measured with the "Hobo" sensor; (iii) Outlet water temperature; (iv) Outlet air relative humidity.

Accordingly to the aforementioned quantities contained in the benchmark data sets, the following responses of interest have been chosen for this work:

(a) the vector $\mathbf{m}_{w} \triangleq\left[m_{w}^{(2)}, \ldots, m_{w}^{(I+1)}\right]^{\dagger}$ of water mass flow rates at the exit of each control volume $i$, $(i=1, \ldots, 49)$;

(b) the vector $\mathbf{T}_{w} \triangleq\left[T_{w}^{(2)}, \ldots, T_{w}^{(I+1)}\right]^{\dagger}$ of water temperatures at the exit of each control volume $i$, $(i=1, \ldots, 49)$;

(c) the vector $\mathbf{T}_{a} \triangleq\left[T_{a}^{(1)}, \ldots, T_{a}^{(I)}\right]^{\dagger}$ of air temperatures at the exit of each control volume $i$, $(\mathrm{i}=1, \ldots, 49)$; 
(d) the vector $\mathbf{R} \mathbf{H} \triangleq\left[R H^{(1)}, \ldots, R H^{(I)}\right]^{\dagger}$, having as components the air relative humidity at the exit of each control volume $i,(i=1, \ldots, 49)$;

(e) the scalar $m_{a}$, representing the air mass flow rate along the height of the cooling tower the value of the air mass flowrate.

It is important to note that the water mass flow rates $m_{w}^{(i)}$, the water temperatures $T_{w}^{(i)}$, the air temperatures $T_{a}^{(i)}$ and the air mass flow rate $m_{a}$ are computed by solving Equations (2)-(14), while the air relative humidity value, $R H^{(i)}$, is obtained through the following expression:

$$
R H^{(i)}=\frac{P_{v}\left(\omega^{(i)}, \boldsymbol{\alpha}\right)}{P_{v s}\left(T_{a}^{(i)}, \alpha\right)} \times 100=\frac{\left(\frac{\omega^{(i)} P_{a t m}}{\omega^{(i)}+0.622}\right)}{\left(e^{a_{0}+\frac{a_{1}}{T_{a}^{(i)}}}\right)} \times 100
$$

For the unperturbed base case, all model parameters $\left(\alpha_{i}\right)$ are used in solving Equations (2)-(14) with their nominal values, which are listed in Appendix B. It is worth specifying that the nominal values for parameters $\alpha_{1}$ through $\alpha_{5}$ (i.e., the dry bulb air temperature, dew point temperature, inlet water temperature, atmospheric pressure and wind speed) are statistically computed by averaging the values of the respective quantities in the 6717 data sets considered for this study.

The bar plots displayed below in Figures 4-7 show, at the exit of each of the 49 control volumes, the values of the water mass flow rates $m_{w}^{(i)}$, the water temperatures $T_{w}^{(i)}$, the air temperatures $T_{a}^{(i)}$, and the air relative humidity, $R H^{(i)}$, respectively.

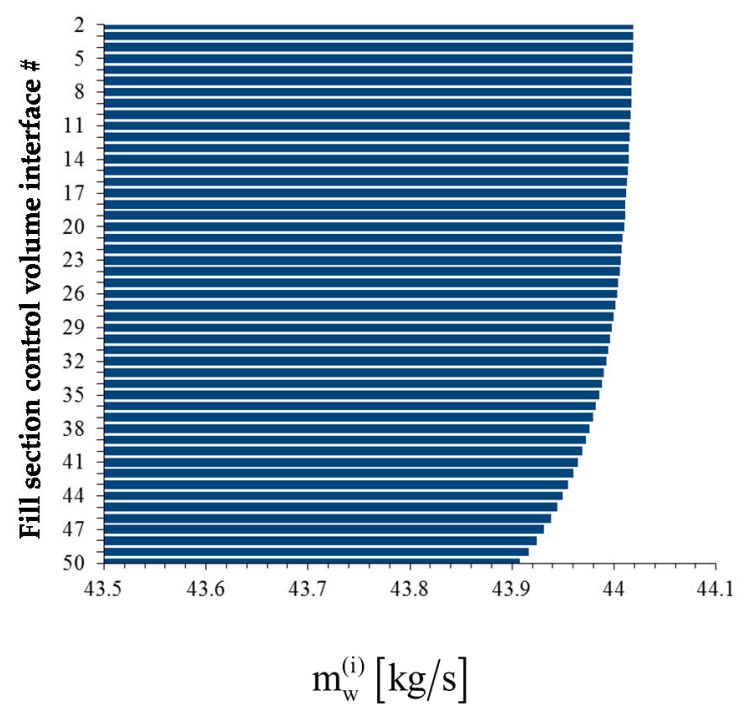

Figure 4. Bar plot of the water mass flow rates $m_{w}^{(i)},(i=2, \ldots, 50)$, at the exit of each control volume along the height of the fill section of the cooling tower. 


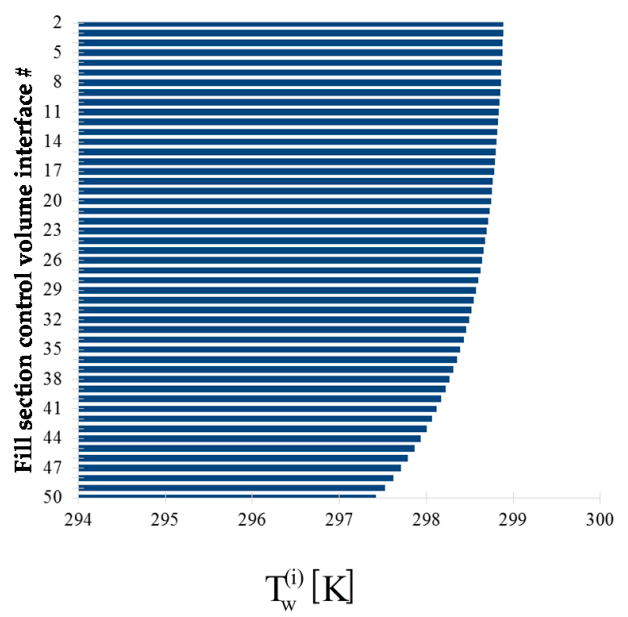

Figure 5. Bar plot of the outlet water temperature $T_{w}^{(i)},(i=2, \ldots, 50)$, at the exit of each control volume along the height of the fill section of the cooling tower.

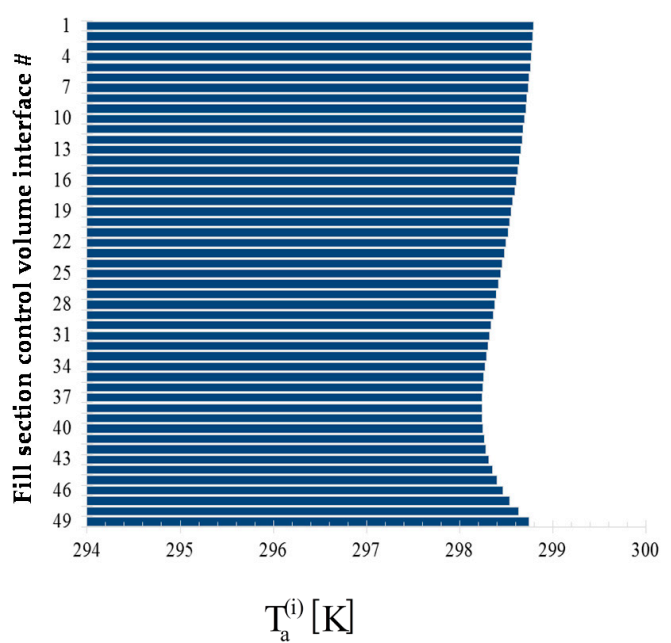

Figure 6. Bar plot of the outlet air temperature $T_{a}^{(i)},(i=1, \ldots, 49)$, at the exit of each control volume along the height of the fill section of the cooling.

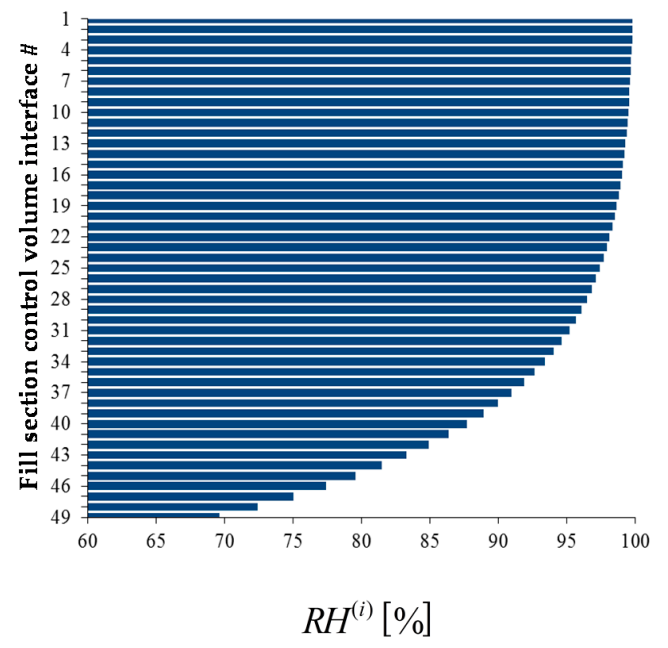

Figure 7. Bar plot of the outlet air relative humidity $R H^{(i)},(i=1, \ldots, 49)$, at the exit of each control volume along the height of the fill section of the cooling. 


\section{Development of the Cooling Tower Adjoint Sensitivity Model}

The development of the cooling tower adjoint sensitivity model follows the same path as in [2], Section 3.1, where the topic is discussed more in detail. The total sensitivity of a model response $R\left(\mathbf{m}_{w}, \mathbf{T}_{w}, \mathbf{T}_{a}, \boldsymbol{\omega}, m_{a} ; \boldsymbol{\alpha}\right)$, with respect to arbitrary variations in the model's parameters $\delta \boldsymbol{\alpha} \equiv\left(\delta \alpha_{1}, \ldots, \delta \alpha_{N_{\alpha}}\right)$ and state functions $\delta \mathbf{m}_{w}, \delta \mathbf{T}_{w}, \delta \mathbf{T}_{a}, \delta \boldsymbol{\omega}, \delta m_{a}$, around the nominal values $\left(\mathbf{m}_{w}^{0}, \mathbf{T}_{w}^{0}, \mathbf{T}_{a}^{0}, \boldsymbol{\omega}^{0}, m_{a}^{0} ; \boldsymbol{\alpha}^{0}\right)$ of the parameters and state functions, is obtained by means of the G-differential of the model's response to these changes. This G-differential is referred to as $D R\left(\mathbf{m}_{w}^{0}, \mathbf{T}_{w}^{0}, \mathbf{T}_{a}^{0}, \boldsymbol{\omega}^{0}, m_{a}^{0} ; \boldsymbol{\alpha}^{0} ; \delta \mathbf{m}_{w}, \delta \mathbf{T}_{w}, \delta \mathbf{T}_{a}, \delta \boldsymbol{\omega}, \delta m_{a} ; \delta \boldsymbol{\alpha}\right)$, and introducing the adjoint sensitivity functions it becomes:

$$
D R\left(\mathbf{m}_{w}^{0}, \mathbf{T}_{w}^{0}, \mathbf{T}_{a}^{0}, \boldsymbol{\omega}^{0}, m_{a}^{0} ; \boldsymbol{\alpha}^{0} ; \delta \mathbf{m}_{w}, \delta \mathbf{T}_{w}, \delta \mathbf{T}_{a}, \delta \boldsymbol{\omega}, \delta m_{a} ; \delta \boldsymbol{\alpha}\right)=\sum_{i=1}^{N_{\alpha}}\left(\frac{\partial R}{\partial \alpha_{i}} \delta \alpha_{i}\right)+D R_{\text {indirect }}
$$

where the "indirect effect" term, $D R_{\text {indirect }}$, is obtained as:

$$
D R_{\text {indirect }} \equiv \boldsymbol{\mu}_{w} \cdot \mathbf{Q}_{1}+\boldsymbol{\tau}_{w} \cdot \mathbf{Q}_{2}+\boldsymbol{\tau}_{a} \cdot \mathbf{Q}_{3}+\mathbf{o} \cdot \mathbf{Q}_{4}+\mu_{a} \cdot Q_{5}
$$

and where the vector $\left[\boldsymbol{\mu}_{w}, \boldsymbol{\tau}_{w}, \boldsymbol{\tau}_{a}, \mathbf{o}, \mu_{a}\right]^{\dagger}$ is required to be the solution of the following adjoint sensitivity system:

$$
\left(\begin{array}{ccccc}
\mathbf{A}_{1}^{\dagger} & \mathbf{A}_{2}^{+} & \mathbf{A}_{3}^{\dagger} & \mathbf{A}_{4}^{+} & \mathbf{A}_{5}^{\dagger} \\
\mathbf{B}_{1}^{\dagger} & \mathbf{B}_{2}^{\dagger} & \mathbf{B}_{3}^{\dagger} & \mathbf{B}_{4}^{\dagger} & \mathbf{B}_{5}^{\dagger} \\
\mathbf{C}_{1}^{\dagger} & \mathbf{C}_{2}^{\dagger} & \mathbf{C}_{3}^{\dagger} & \mathbf{C}_{4}^{\dagger} & \mathbf{C}_{5}^{\dagger} \\
\mathbf{D}_{1}^{\dagger} & \mathbf{D}_{2}^{\dagger} & \mathbf{D}_{3}^{\dagger} & \mathbf{D}_{4}^{\dagger} & \mathbf{D}_{5}^{+} \\
\mathbf{E}_{1}^{\dagger} & \mathbf{E}_{2}^{\dagger} & \mathbf{E}_{3}^{\dagger} & \mathbf{E}_{4}^{\dagger} & \mathbf{E}_{5}^{\dagger}
\end{array}\right)\left(\begin{array}{c}
\boldsymbol{\mu}_{w} \\
\boldsymbol{\tau}_{w} \\
\boldsymbol{\tau}_{a} \\
\mathbf{o} \\
\mu_{a}
\end{array}\right)=\left(\begin{array}{c}
\mathbf{R}_{1} \\
\mathbf{R}_{2} \\
\mathbf{R}_{3} \\
\mathbf{R}_{4} \\
R_{5}
\end{array}\right),
$$

The vectors $\mathbf{R}_{\ell} \equiv\left(r_{\ell}^{(1)}, \ldots, r_{\ell}^{(I)}\right), \ell=1,2,3,4$ in Equation (20) comprise the functional derivatives of the model responses with respect to the state functions, i.e.,:

$$
r_{1}^{(i)} \equiv \frac{\partial R}{\partial m_{w}^{(i+1)}} ; \quad r_{2}^{(i)} \equiv \frac{\partial R}{\partial T_{w}^{(i+1)}} ; \quad r_{3}^{(i)} \equiv \frac{\partial R}{\partial T_{a}^{(i)}} ; \quad r_{4}^{(i)} \equiv \frac{\partial R}{\partial \omega^{(i)}} ; \quad i=1, \ldots, I .
$$

and where $R_{5}$ is defined as follows:

$$
R_{5} \equiv \frac{\partial R}{\partial m_{a}}
$$

while the vectors $\mathbf{Q}_{\ell} \equiv\left(q_{\ell}^{(1)}, \ldots, q_{\ell}^{(I)}\right), \ell=1,2,3,4$ in Equation (19) comprise the derivatives of the model's equations with respect to model parameters, i.e.,:

$$
q_{\ell}^{(i)} \equiv \sum_{j=1}^{N_{\alpha}}\left(\frac{\partial N_{\ell}^{(i)}}{\partial \alpha_{j}} \delta \alpha_{j}\right) ; i=1, \ldots, I ; \quad \ell=1,2,3,4 .
$$

and where $Q_{5}$ is defined as follows:

$$
Q_{5} \equiv \sum_{j=1}^{N_{\alpha}}\left(\frac{\partial N_{5}}{\partial \alpha_{j}} \delta \alpha_{j}\right)
$$

It is worth reminding that the adjoint sensitivity system in Equation (20) is independent of parameter variations. This feature allows the selected adjoint functions $\left[\boldsymbol{\mu}_{w}, \boldsymbol{\tau}_{w}, \boldsymbol{\tau}_{a}, \mathbf{o}, \mu_{a}\right]^{\dagger}$ to be computed by solving the adjoint sensitivity system just once. 
Dimensional analysis allows determining the units of the adjoint functions from Equation (19). Namely, the units for the adjoint functions must satisfy the following relations:

$$
\left[\mu_{w}^{(i)}\right]=\frac{[R]}{\left[N_{1}\right]} ; \quad\left[\tau_{w}^{(i)}\right]=\frac{[R]}{\left[N_{2}\right]} ; \quad\left[\tau_{a}^{(i)}\right]=\frac{[R]}{\left[N_{3}\right]} ; \quad\left[o^{(i)}\right]=\frac{[R]}{\left[N_{4}\right]} ; \quad\left[\mu_{a}\right]=\frac{[R]}{\left[N_{5}\right]}
$$

where $[R]$ denotes the unit of the response $\mathrm{R}$, while the units for the respective equations are as follows:

$$
\left[N_{1}\right]=\frac{k g}{s} ;\left[N_{2}\right]=\frac{J}{s} ;\left[N_{3}\right]=[-] ; \quad\left[N_{4}\right]=\frac{J}{k g} ; \quad\left[N_{5}\right]=\frac{J}{m^{3}}
$$

Table 1 below lists the units of the adjoint functions for five responses: $R \triangleq T_{a}^{(1)}, R \triangleq T_{w}^{(50)}$, $R \triangleq R H^{(1)}, R \triangleq m_{w}^{(50)}$ and $R \triangleq m_{a}$, respectively, in which, $T_{a}^{(1)}$ denotes exit air temperature; $T_{w}^{(50)}$ denotes exit water temperature; $R H^{(1)}$ denotes exit air relative humidity; $m_{w}^{(50)}$ denotes exit water mass flow rate; and $m_{a}$ denotes air mass flow rate.

Table 1. Units of the adjoint functions for different responses.

\begin{tabular}{cccccc}
\hline Responses & {$\left[\boldsymbol{\mu}_{w}^{(i)}\right]$} & {$\left[\boldsymbol{\tau}_{w}^{(i)}\right]$} & {$\left[\boldsymbol{\tau}_{\boldsymbol{a}}^{(i)}\right]$} & {$\left[\boldsymbol{o}^{(i)}\right]$} & {$\left[\boldsymbol{\mu}_{\boldsymbol{a}}\right]$} \\
\hline$R \triangleq T_{a}^{(1)}$ & $\mathrm{K} /(\mathrm{kg} / \mathrm{s})$ & $\mathrm{K} /(\mathrm{J} / \mathrm{s})$ & $\mathrm{K}$ & $\mathrm{K} /(\mathrm{J} / \mathrm{kg})$ & $\mathrm{K} /\left(\mathrm{J} / \mathrm{m}^{3}\right)$ \\
$R \triangleq T_{w}^{(50)}$ & $\mathrm{K} /(\mathrm{kg} / \mathrm{s})$ & $\mathrm{K} /(\mathrm{J} / \mathrm{s})$ & $\mathrm{K}$ & $\mathrm{K} /(\mathrm{J} / \mathrm{kg})$ & $\mathrm{K} /\left(\mathrm{J} / \mathrm{m}^{3}\right)$ \\
$R \triangleq R H^{(1)}$ & $(\mathrm{kg} / \mathrm{s})^{-1}$ & $(\mathrm{~J} / \mathrm{s})^{-1}$ & - & $(\mathrm{J} / \mathrm{kg})^{-1}$ & $\left(\mathrm{~J} / \mathrm{m}^{3}\right)^{-1}$ \\
$R \triangleq m_{w}^{(50)}$ & - & $(\mathrm{J} / \mathrm{kg})^{-1}$ & $\mathrm{~kg} / \mathrm{s}$ & $(\mathrm{kg} / \mathrm{s}) /(\mathrm{J} / \mathrm{kg})$ & $(\mathrm{kg} / \mathrm{s}) /\left(\mathrm{J} / \mathrm{m}^{3}\right)$ \\
$R \triangleq m_{a}$ & - & $(\mathrm{J} / \mathrm{kg})^{-1}$ & $\mathrm{~kg} / \mathrm{s}$ & $(\mathrm{kg} / \mathrm{s}) /(\mathrm{J} / \mathrm{kg})$ & $(\mathrm{kg} / \mathrm{s}) /\left(\mathrm{J} / \mathrm{m}^{3}\right)$ \\
\hline
\end{tabular}

Figures 8-12 below display the bar plots of the adjoint functions corresponding to the five measured responses of interest, namely: (i) The exit air temperature $R \triangleq T_{a}^{(1)}$; (ii) The outlet (exit) water temperature $R \triangleq T_{w}^{(50)}$; (iii) The exit air humidity ratio $R \triangleq R H^{(1)}$; (iv) The outlet (exit) water mass flow rate $R \triangleq m_{w}^{(50)}$; and (v) the air mass flow rate $R \triangleq m_{a}$.

Let $S_{j}$ denote the "absolute sensitivity" of the response $R$ with respect to the parameter $\alpha_{j}$, and is defined as:

$$
S_{j} \triangleq \frac{\partial R}{\partial \alpha_{j}}-\left[\sum_{i=1}^{I}\left(\mu_{w}^{(i)} \frac{\partial N_{1}^{(i)}}{\partial \alpha_{j}}+\tau_{w}^{(i)} \frac{\partial N_{2}^{(i)}}{\partial \alpha_{j}}+\tau_{a}^{(i)} \frac{\partial N_{3}^{(i)}}{\partial \alpha_{j}}+o^{(i)} \frac{\partial N_{4}^{(i)}}{\partial \alpha_{j}}\right)+\mu_{a} \frac{\partial N_{5}}{\partial \alpha_{j}}\right]
$$

An independent method to compute absolute response sensitivities $S_{j}$ is by making use of perturbative finite difference methods, such as:

1. considering an arbitrarily small perturbation $\delta \alpha_{j}$ to the model parameter $\alpha_{j}$;

2. re-computing the perturbed response $R\left(\alpha_{j}^{0}+\delta \alpha_{j}\right)$, where $\alpha_{j}^{0}$ denotes the unperturbed parameter value;

3. using the finite difference formula

$$
S_{j}^{F D} \cong \frac{R\left(\alpha_{j}^{0}+\delta \alpha_{j}\right)-R\left(\alpha_{j}^{0}\right)}{\delta \alpha_{j}}+O\left(\delta \alpha_{j}\right)^{2}
$$

4. using the approximate equality between Equations (27) and (28) to obtain independently the respective values of the adjoint function(s) being verified.

The independent verification methodology discussed in steps (1)-(4) above will be clearly illustrated in Appendix D, where the adjoint functions depicted in Figures 8-12 will be verified. 


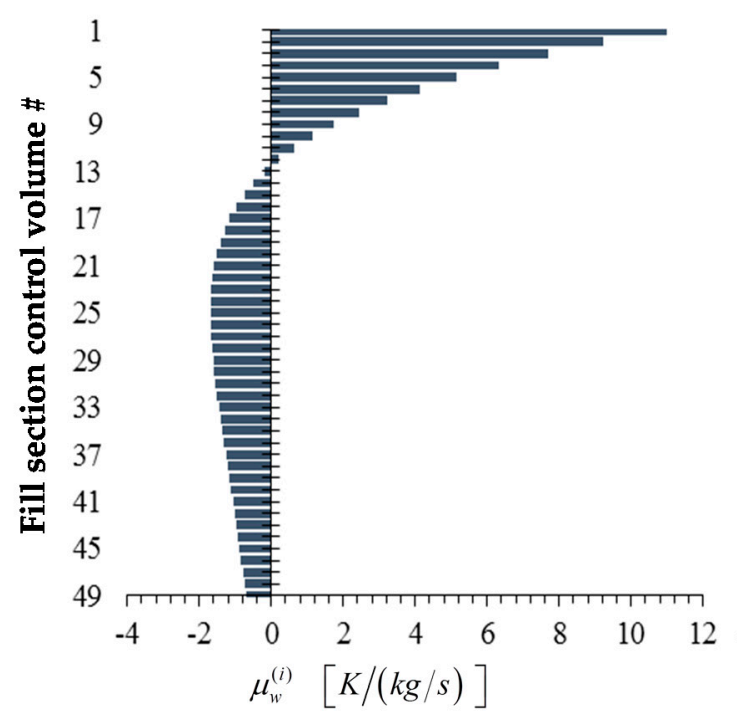

(a)

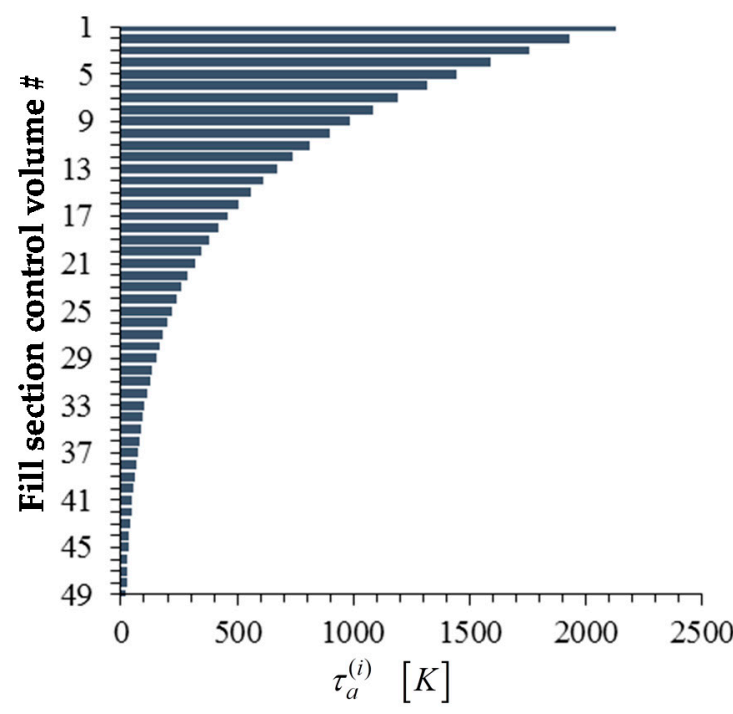

(c)

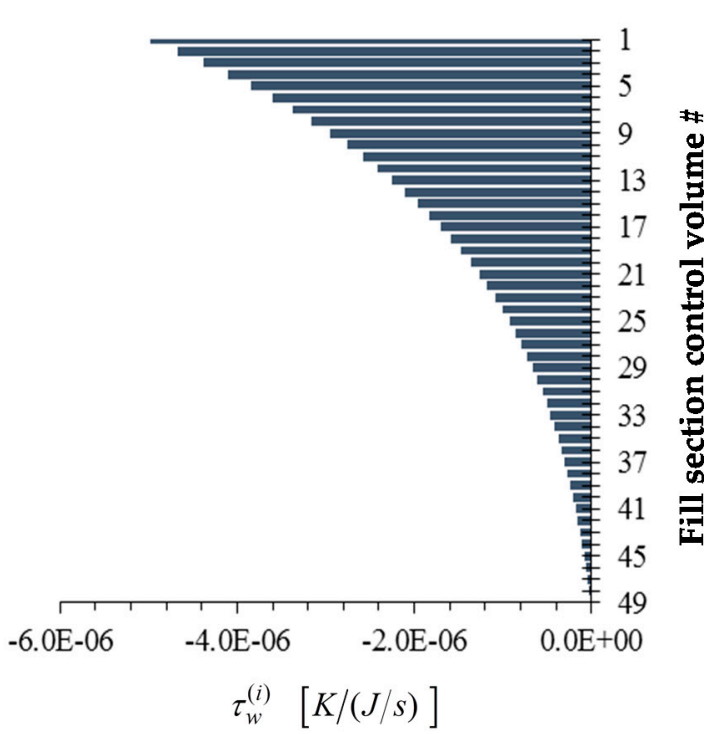

(b)

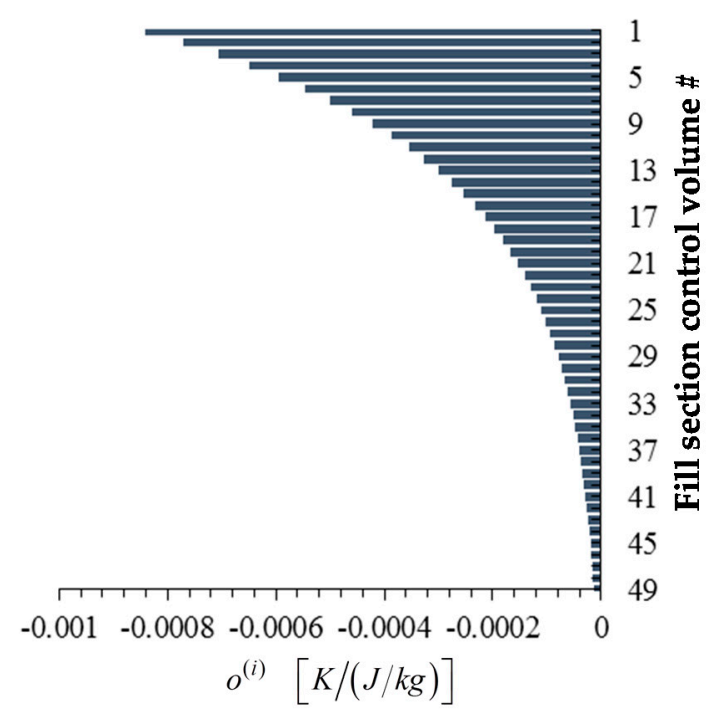

(d)

Figure 8. Bar plots of adjoint functions for the response $R \triangleq T_{a}^{(1)}$ as functions of the height of the cooling tower's fill section: (a) $\boldsymbol{\mu}_{w} \triangleq\left(\mu_{w}^{(1)}, \ldots, \mu_{w}^{(49)}\right) ;(\mathbf{b}) \boldsymbol{\tau}_{w} \triangleq\left(\tau_{w}^{(1)}, \ldots, \tau_{w}^{(49)}\right) ;(\mathbf{c}) \boldsymbol{\tau}_{a} \triangleq\left(\tau_{a}^{(1)}, \ldots, \tau_{a}^{(49)}\right)$; (d) $\mathbf{o} \triangleq\left(o^{(1)}, \ldots, o^{(49)}\right)$. For the response $R \triangleq T_{a}^{(1)}$, the value of the adjoint function $\mu_{a}$ is -0.12651 . 


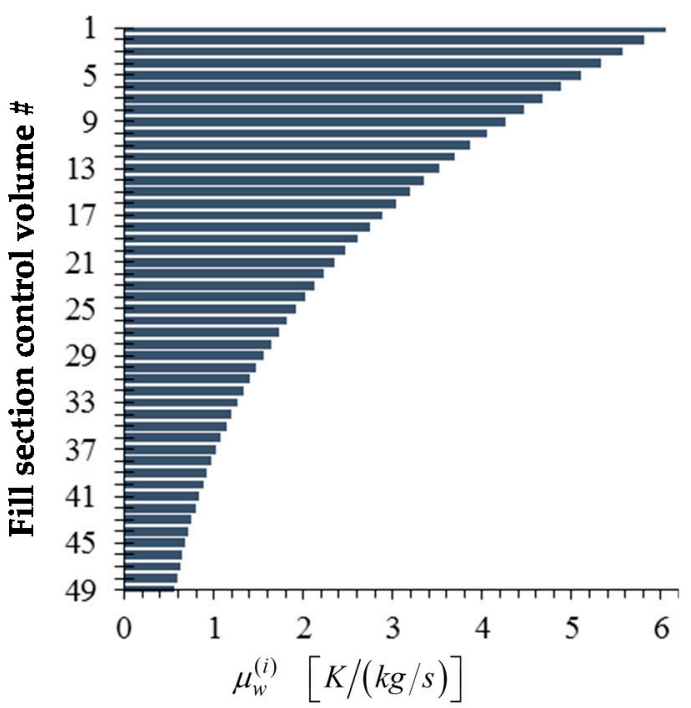

(a)

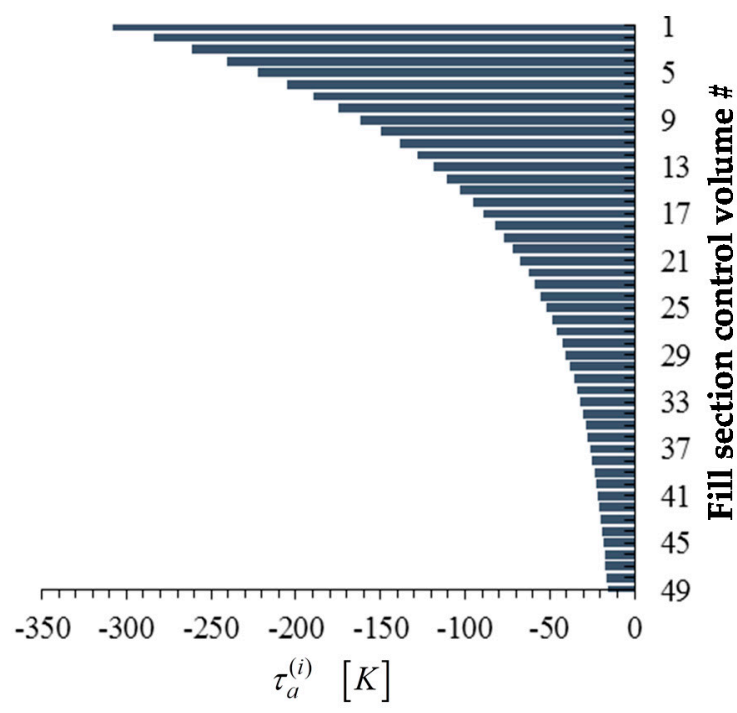

(c)

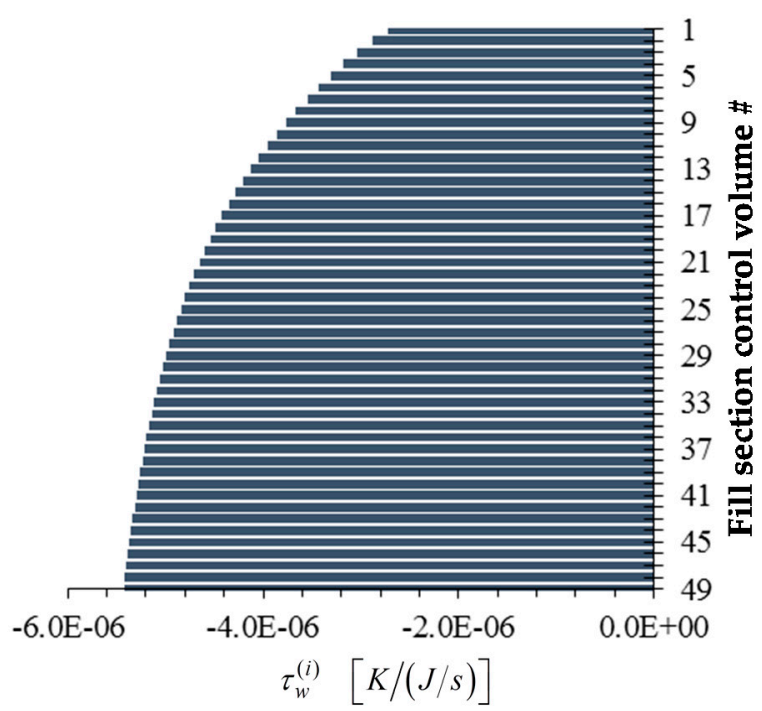

(b)

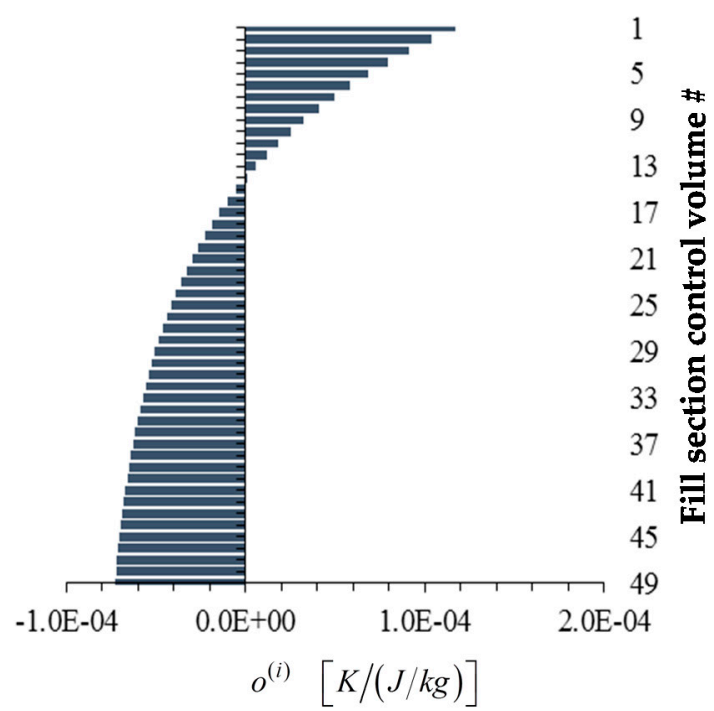

(d)

Figure 9. Bar plots of adjoint functions for the response $R \triangleq T_{w}^{(50)}$ as functions of the height of the cooling tower's fill section: (a) $\boldsymbol{\mu}_{w} \triangleq\left(\mu_{w}^{(1)}, \ldots, \mu_{w}^{(49)}\right) ;(\mathbf{b}) \boldsymbol{\tau}_{w} \triangleq\left(\tau_{w}^{(1)}, \ldots, \tau_{w}^{(49)}\right) ;(\mathbf{c}) \boldsymbol{\tau}_{a} \triangleq\left(\tau_{a}^{(1)}, \ldots, \tau_{a}^{(49)}\right)$; (d) $\mathbf{o} \triangleq\left(o^{(1)}, \ldots, o^{(49)}\right)$. For the response $R \triangleq T_{w}^{(50)}$, the value of the adjoint function $\mu_{a}$ is -0.3771 . 


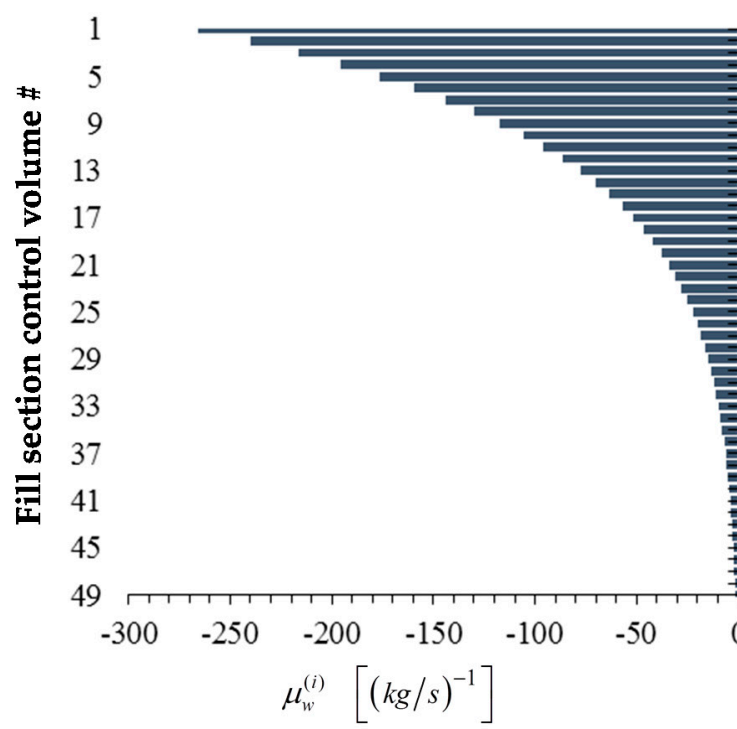

(a)

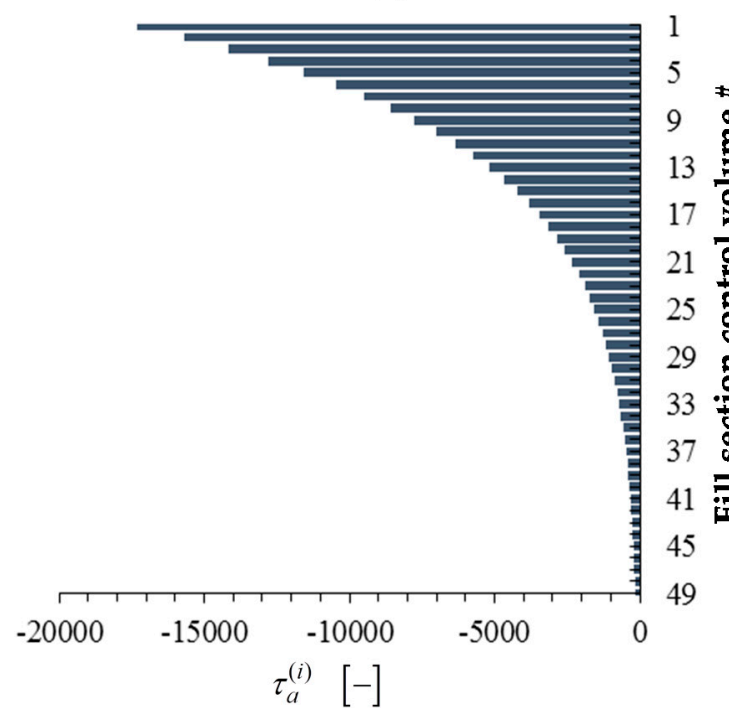

(c)

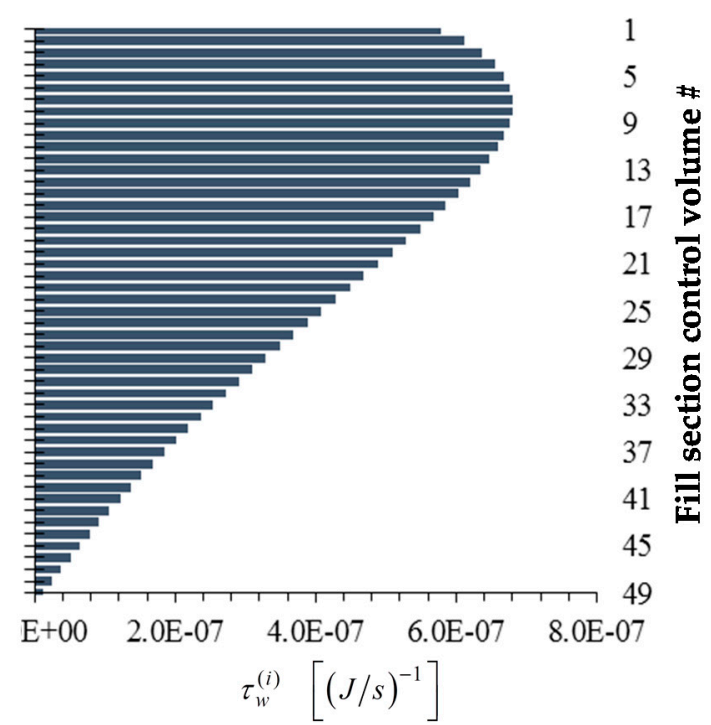

(b)

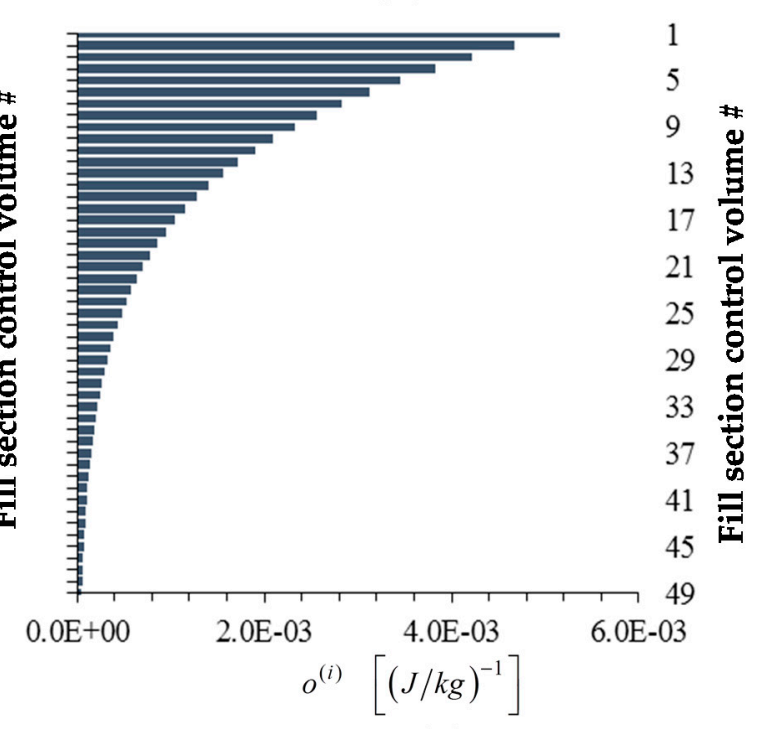

(d)

Figure 10. Bar plots of adjoint functions for the response $R \triangleq R H^{(1)}$ as functions of the height of the cooling tower's fill section: (a) $\boldsymbol{\mu}_{w} \triangleq\left(\mu_{w}^{(1)}, \ldots, \mu_{w}^{(49)}\right) ;(\mathbf{b}) \boldsymbol{\tau}_{w} \triangleq\left(\tau_{w}^{(1)}, \ldots, \tau_{w}^{(49)}\right) ;(\mathbf{c}) \boldsymbol{\tau}_{a} \triangleq\left(\tau_{a}^{(1)}, \ldots, \tau_{a}^{(49)}\right)$; (d) $\mathbf{o} \triangleq\left(o^{(1)}, \ldots, o^{(49)}\right)$. For the response $R \triangleq R H^{(1)}$, the value of the adjoint function $\mu_{a}$ is -0.00743 . 


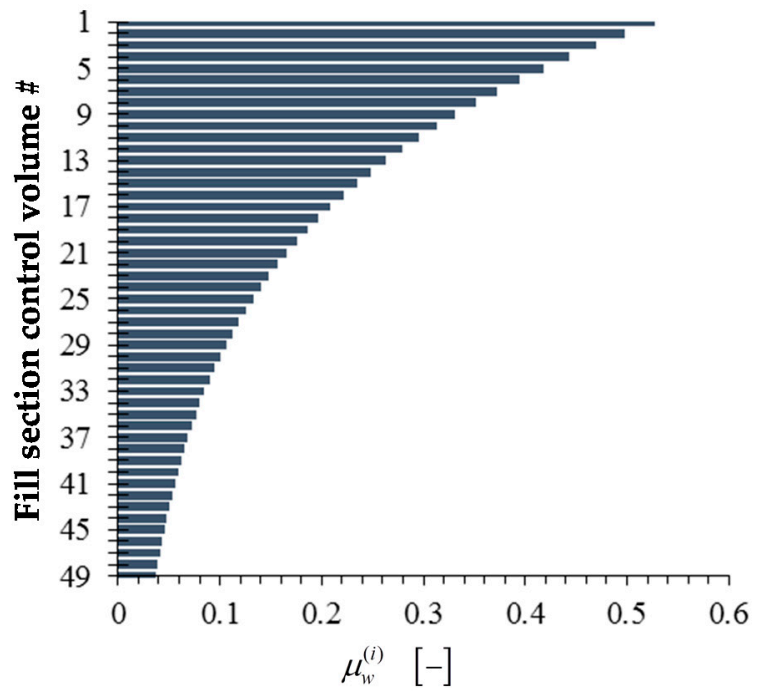

(a)

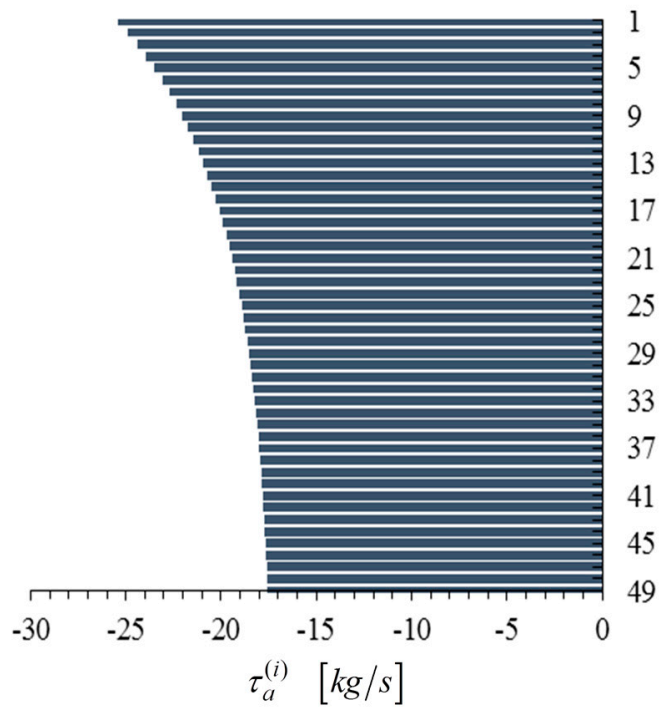

(c)

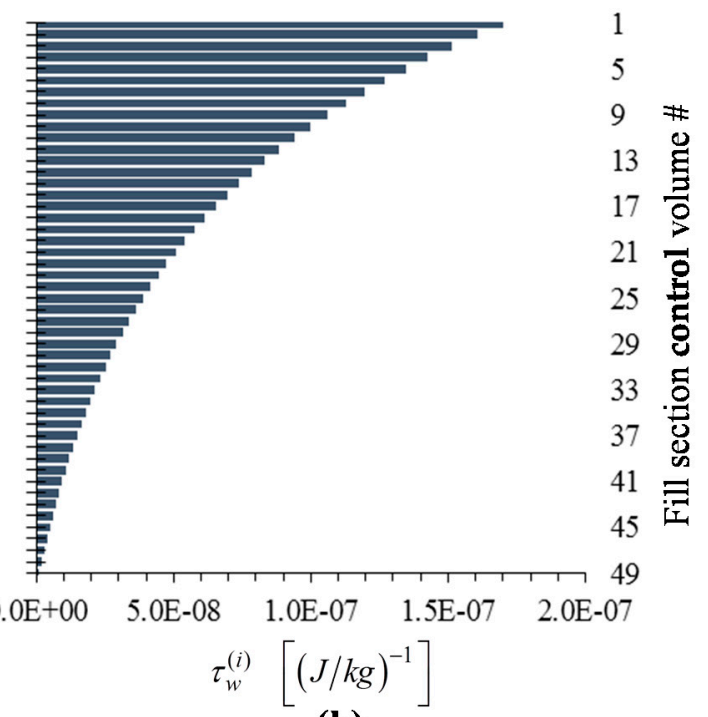

(b)

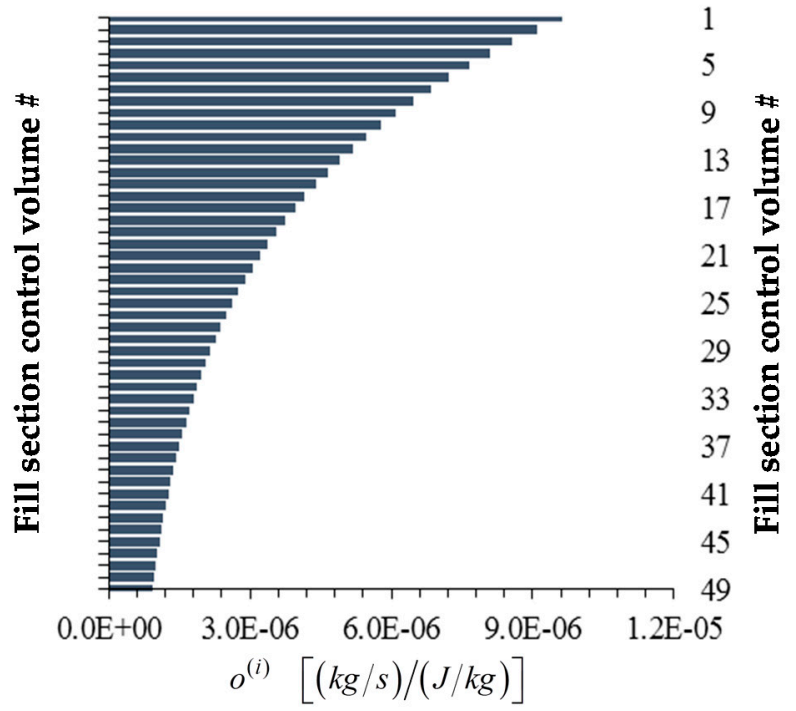

(d)

Figure 11. Bar plots of adjoint functions for the response $R \triangleq m_{w}^{(50)}$, as functions of the height of the cooling tower's fill section: $(\mathbf{a}) \mu_{w} \triangleq\left(\mu_{w}^{(1)}, \ldots, \mu_{w}^{(49)}\right) ;(\mathbf{b}) \boldsymbol{\tau}_{w} \triangleq\left(\tau_{w}^{(1)}, \ldots, \tau_{w}^{(49)}\right) ;(\mathbf{c}) \boldsymbol{\tau}_{a} \triangleq\left(\tau_{a}^{(1)}, \ldots, \tau_{a}^{(49)}\right)$; (d) $\mathbf{o} \triangleq\left(o^{(1)}, \ldots, o^{(49)}\right)$. For the response $R \triangleq m_{w}^{(50)}$, the value of the adjoint function $\mu_{a}$ is -0.0306 . 


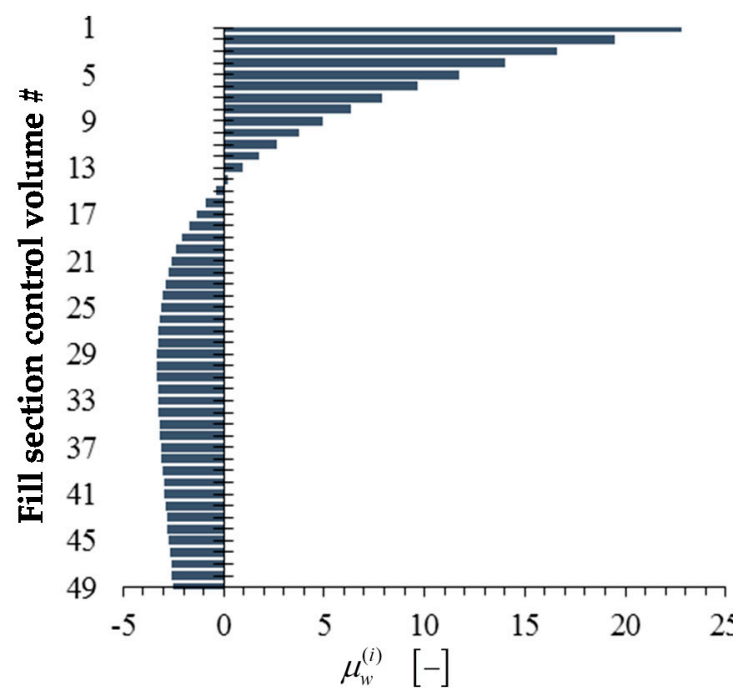

(a)

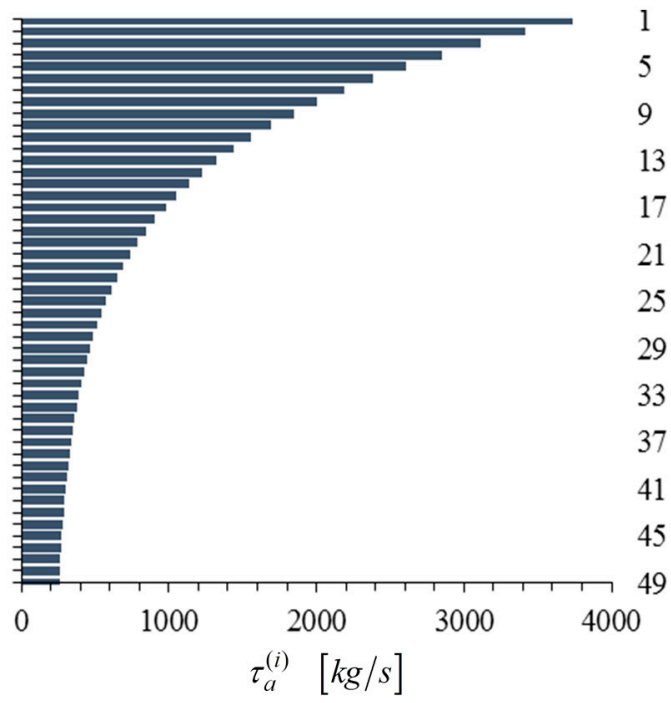

(c)

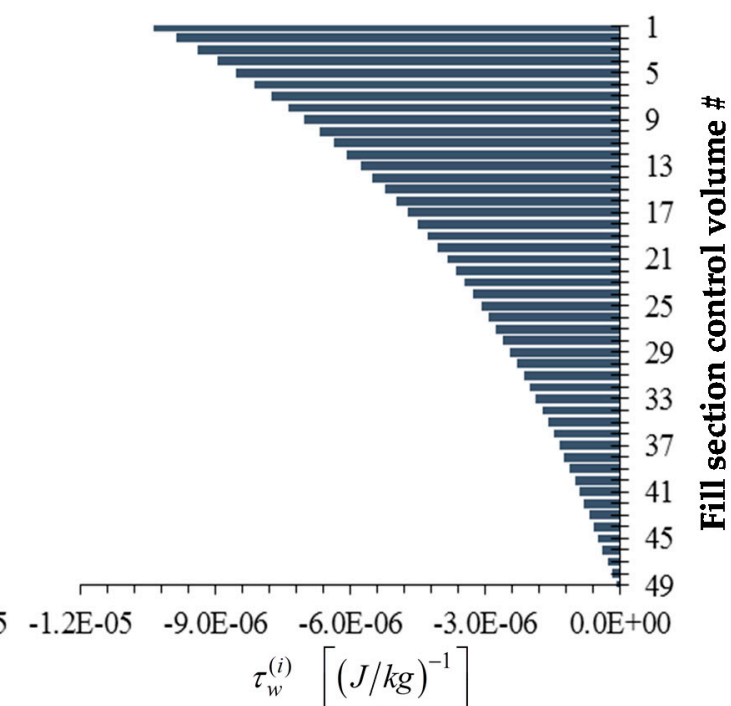

(b)

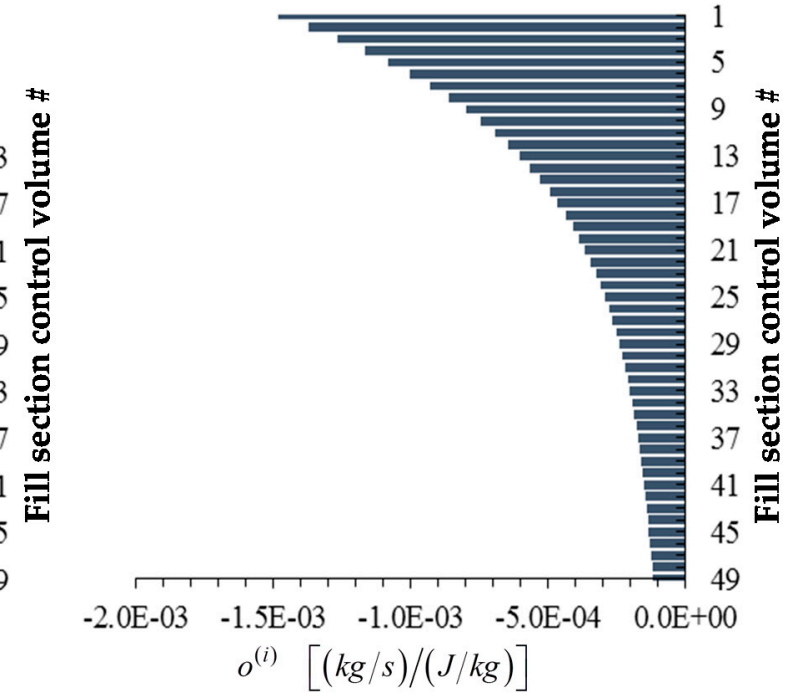

(d)

Figure 12. Bar plots of adjoint functions for the response $R \triangleq m_{a}$, as functions of the height of the cooling tower's fill section: $(\mathbf{a}) \boldsymbol{\mu}_{w} \triangleq\left(\mu_{w}^{(1)}, \ldots, \mu_{w}^{(49)}\right) ;(\mathbf{b}) \boldsymbol{\tau}_{w} \triangleq\left(\tau_{w}^{(1)}, \ldots, \tau_{w}^{(49)}\right) ;(\mathbf{c}) \boldsymbol{\tau}_{a} \triangleq\left(\tau_{a}^{(1)}, \ldots, \tau_{a}^{(49)}\right)$;

(d) $\mathbf{o} \triangleq\left(o^{(1)}, \ldots, o^{(49)}\right)$. For the response $R \triangleq m_{a}$, the value of the adjoint function $\mu_{a}$ is 5.805 .

\subsection{Sensitivity Analysis Results and Rankings}

As has been discussed above, there are a total of 8079 measured benchmark data sets for the cooling tower model operated in "fan-off" regime. As it has also been mentioned, 6717 benchmark data sets (out of the total of 8079 data sets) are considered to correspond to the "unsaturated conditions" which are analyzed in this work. The nominal values for boundary and atmospheric conditions used in this work were obtained from the statistics of these 6717 benchmark data sets corresponding to "unsaturated conditions". In turn, these "unsaturated" boundary and atmospheric conditions were used to obtain the sensitivity results reported in this Subsection. Sections 3.1.1-3.1.5, below, provide the numerical values and rankings, in descending order, of the relative sensitivities computed using the adjoint sensitivity analysis methodology for the five model responses $T_{a}^{(1)}, T_{w}^{(50)}, m_{w}^{(50)}, R H^{(1)}$, and $m_{a}$.

Note that the relative sensitivity $R S\left(\alpha_{i}\right)$ of a response $R\left(\alpha_{i}\right)$ to a parameter $\alpha_{i}$ is defined as $R S\left(\alpha_{i}\right) \triangleq\left[d R\left(\alpha_{i}\right) / d \alpha_{i}\right]\left[\alpha_{i} / R\left(\alpha_{i}\right)\right]$. Thus, the relative sensitivities are unit-less and are very useful in ranking the parameters to highlight their relative importance for the respective response. 
Thus, a relative sensitivity of 1.00 indicates that a change of $1 \%$ in the respective parameter will induce a $1 \%$ change in a response that is linear in the respective sensitivity. The higher the relative sensitivity, the more important the respective parameter to the respective response.

\subsubsection{Sensitivity Analysis Results and Rankings for the Outlet Air Temperature, $T_{a}^{(1)}$}

Table 2 lists the sensitivities, computed using Equations (18) and (19), of the air outlet temperature with respect to all of the model's parameters. The parameters have been ranked according to the descending order of their relative sensitivities.

Table 2. Ranked relative sensitivities of the outlet air temperature, $T_{a}^{(1)}$.

\begin{tabular}{|c|c|c|c|c|}
\hline Rank \# & Parameter $\left(\alpha_{i}\right)$ & Nominal Value & Rel. Sens. $R S\left(\alpha_{i}\right)$ & Rel. Std. Dev. (\%) \\
\hline 1 & Inlet water temperature, $T_{w, i n}$ & $298.893 \mathrm{~K}$ & 0.91878 & 0.56 \\
\hline 2 & Air temperature (dry bulb), $T_{d b}$ & $298.882 \mathrm{~K}$ & 0.06522 & 1.35 \\
\hline 3 & Inlet air temperature, $T_{a, i n}$ & $298.882 \mathrm{~K}$ & 0.06478 & 1.35 \\
\hline 4 & $\mathrm{P}_{\mathrm{vs}}(\mathrm{T})$ parameter, $a_{0}$ & 25.5943 & -0.01266 & 0.04 \\
\hline 5 & Dew point temperature, $T_{d p}$ & $292.077 \mathrm{~K}$ & 0.01005 & 0.78 \\
\hline 6 & $\mathrm{P}_{\mathrm{vs}}(\mathrm{T})$ parameter, $a_{1}$ & -5229.89 & 0.00828 & 0.08 \\
\hline 9 & Fan shroud inner diameter, $D_{f a n}$ & $4.1 \mathrm{~m}$ & -0.00104 & 1.0 \\
\hline 10 & Atmospheric pressure, $P_{a t m}$ & $100,588 \mathrm{~Pa}$ & -0.00084 & 0.41 \\
\hline 11 & Water enthalpy $\mathrm{h}_{\mathrm{f}}(\mathrm{T})$ parameter, $a_{1 f}$ & 4186.51 & 0.00070 & 0.04 \\
\hline 12 & $\mathrm{Nu}$ parameter, $a_{0, N u}$ & 8.235 & 0.00070 & 25.0 \\
\hline 13 & Fill section surface area, $A_{\text {surf }}$ & $14221 \mathrm{~m}^{2}$ & 0.00070 & 25.0 \\
\hline 14 & Wetted fraction of fill surface area, $w_{t s a}$ & 1.0 & 0.00070 & 0.00 \\
\hline 19 & Fill section frictional loss multiplier, $f$ & 4.0 & 0.00048 & 50.0 \\
\hline 20 & Fill section height, $\Delta z_{\text {fill }}$ & $2.013 \mathrm{~m}$ & 0.00046 & 1.0 \\
\hline 21 & $\mathrm{D}_{\mathrm{av}}(\mathrm{T})$ parameter, $a_{1, d a v}$ & 2.65322 & -0.00043 & 0.11 \\
\hline 22 & $\mathrm{C}_{\mathrm{pa}}(\mathrm{T})$ parameter, $a_{0, c p a}$ & 1030.5 & -0.00041 & 0.03 \\
\hline 23 & Thermal conductivity of air at $\mathrm{T}=300 \mathrm{~K}, k_{\text {air }}$ & $0.02624 \mathrm{~W} /(\mathrm{m} \cdot \mathrm{K})$ & 0.00037 & 6.04 \\
\hline 24 & Heat transfer coefficient multiplier, $f_{h t}$ & 1.0 & 0.00037 & 50.0 \\
\hline 25 & $\mathrm{~h}_{\mathrm{g}}(\mathrm{T})$ parameter, $a_{0 g}$ & $2,005,744$ & -0.00036 & 0.05 \\
\hline 26 & Mass transfer coefficient multiplier, $f_{m t}$ & 1.0 & 0.00034 & 50.0 \\
\hline 27 & $\mathrm{D}_{\mathrm{av}}(\mathrm{T})$ parameter, $a_{2, d a v}$ & $-6.1681 \times 10^{-3}$ & 0.00030 & 0.37 \\
\hline 28 & $\mathrm{D}_{\mathrm{av}}(\mathrm{T})$ parameter, $a_{0, d a v}$ & $7.06085 \times 10^{-9}$ & 0.00022 & 0 \\
\hline 29 & $\mathrm{~h}_{\mathrm{f}}(\mathrm{T})$ parameter, $a_{0 f}$ & $-1,143,423$ & -0.00020 & 0.05 \\
\hline 38 & Cooling tower deck width in x-dir, $W_{d k x}$ & $8.5 \mathrm{~m}$ & 0.000017 & 1.0 \\
\hline 39 & Cooling tower deck width in $y$-dir, $W_{d k y}$ & $8.5 \mathrm{~m}$ & 0.000017 & 1.0 \\
\hline 40 & Cooling tower deck height above ground, $\Delta z_{d k}$ & $10.0 \mathrm{~m}$ & 0.000014 & 1.0 \\
\hline 41 & $\mathrm{C}_{\mathrm{pa}}(\mathrm{T})$ parameter, $a_{2, c p a}$ & $3.9734 \times 10^{-4}$ & -0.000013 & 0.84 \\
\hline 42 & Fan shroud height, $\Delta z_{f a n}$ & $3.0 \mathrm{~m}$ & 0.000004 & 1.0 \\
\hline 43 & Rain section height, $\Delta z_{\text {rain }}$ & $1.633 \mathrm{~m}$ & -0.000002 & 1.0 \\
\hline 44 & Basin section height, $\Delta z_{b s}$ & $1.168 \mathrm{~m}$ & -0.000001 & 1.0 \\
\hline 45 & Nu parameter, $a_{1, N u}$ & 0.0031498 & 0.000 & 31.75 \\
\hline 46 & $\mathrm{Nu}$ parameter, $a_{2, N u}$ & 0.9902987 & 0.000 & 33.02 \\
\hline 47 & $\mathrm{Nu}$ parameter, $a_{3, N u}$ & 0.023 & 0.000 & 38.26 \\
\hline
\end{tabular}

As the results in Table 2 indicate, the first parameter (i.e., $T_{w, i n}$ ) has a relative sensitivity around $90 \%$, and is therefore the most important for the air outlet temperature response, $T_{a}^{(1)}$, since that means that a $1 \%$ change in $T_{w, i n}$ would induce a $0.91 \%$ change in $T_{a}^{(1)}$. The next four parameters (i.e., $T_{d b}$, $\left.T_{a, i n}, a_{0}, T_{d p}\right)$ have relative sensitivities between $1 \%$ and $6 \%$, and are therefore somewhat important. Parameters \#6 through \#9 (i.e., $a_{1}, V_{w}, D_{h}, D_{f a n}$ ) have relative sensitivities between $0.1 \%$ and $0.8 \%$. 
The remaining 38 parameters are relatively unimportant for this response, having relative sensitivities smaller than $1 \%$ of the largest relative sensitivity (with respect to $T_{a, i n}$ ) for this response. Positive sensitivities imply that a positive change in the respective parameter would cause an increase in the response, while negative sensitivities imply that a positive change in the respective parameter would cause a decrease in the response.

3.1.2. Sensitivity Analysis Results and Rankings for the Outlet Water Temperature, $T_{w}^{(50)}$

The results and ranking of the relative sensitivities of the outlet water temperature with respect to the most important nine parameters for this response are listed in Table 3. The largest sensitivity of $T_{w}^{(50)}$ is to the parameter $T_{w, i n}$, and has the value of 0.5055 ; this means that a $1 \%$ increase in $T_{w, i n}$ would induce a $0.5055 \%$ increase in $T_{w}^{(50)}$. The sensitivities to the remaining 38 model parameters have not been listed since they are smaller than $1 \%$ of the largest sensitivity (with respect to $T_{w, \text { in }}$ ) for this response.

Table 3. Most important relative sensitivities of the outlet water temperature, $T_{w}^{(50)}$.

\begin{tabular}{ccccc}
\hline Rank \# & Parameter $\left(\boldsymbol{\alpha}_{\boldsymbol{i}}\right)$ & Nominal Value & Rel. Sens. $\boldsymbol{R S}\left(\boldsymbol{\alpha}_{\boldsymbol{i}}\right)$ & Rel. Std. Dev. (\%) \\
\hline 1 & Inlet water temperature, $T_{w, i n}$ & $298.893 \mathrm{~K}$ & 0.50556 & 0.56 \\
2 & Inlet air temperature, $T_{a, i n}$ & $298.882 \mathrm{~K}$ & 0.25323 & 1.35 \\
3 & Air temperature (dry bulb), $T_{d b}$ & $298.882 \mathrm{~K}$ & 0.25263 & 1.35 \\
4 & Dew point temperature, $T_{d p}$ & $292.077 \mathrm{~K}$ & 0.17100 & 0.78 \\
5 & $\mathrm{P}_{\mathrm{vs}}(\mathrm{T})$ parameters, $a_{0}$ & 25.5943 & -0.12617 & 0.04 \\
6 & $\mathrm{P}_{\mathrm{vs}}(\mathrm{T})$ parameters, $a_{1}$ & -5229.89 & 0.08251 & 0.08 \\
7 & Inlet air humidity ratio, $\omega_{i n}$ & 0.0139 & 0.00934 & 13.8 \\
8 & Water enthalpy hf(T) parameter, $a_{1 f}$ & 4186.50768 & 0.00704 & 0.04 \\
9 & Wind speed, $V_{w}$ & $1.859 \mathrm{~m} / \mathrm{s}$ & -0.00595 & 50.7 \\
\hline
\end{tabular}

3.1.3. Sensitivity Analysis Results and Rankings for the Outlet Water Mass Flow Rate, $m_{w}^{(50)}$

The results and ranking of the relative sensitivities of the outlet water mass flow rate with respect to the most important 12 parameters for this response are listed in Table 4 . This response is most sensitive to $m_{w, \text { in }}$ (a 1\% increase in this parameter would cause a 1.01\% increase in the response) and the second largest sensitivity is to the parameter $T_{w, \text { in }}$ (a 1\% increase in this parameter would cause a $0.214 \%$ decrease in the response). The sensitivities to the remaining 35 model parameters have not been listed since they are smaller than $1 \%$ of the largest sensitivity (with respect to $m_{w, i n}$ ) for this response.

Table 4. Most important relative sensitivities of the outlet water mass flow rate, $m_{w}^{(50)}$.

\begin{tabular}{ccccc}
\hline Rank \# & Parameter $\left(\boldsymbol{\alpha}_{\boldsymbol{i}}\right)$ & Nominal Value & Rel. Sens. $\boldsymbol{R S}\left(\boldsymbol{\alpha}_{\boldsymbol{i}}\right)$ & Rel. Std. Dev. (\%) \\
\hline 1 & Inlet water mass flow rate, $m_{w, i n}$ & $44.0193 \mathrm{~kg} / \mathrm{s}$ & 1.00240 & 5 \\
2 & Inlet water temperature, $T_{w, i n}$ & $298.893 \mathrm{~K}$ & -0.21368 & 0.56 \\
3 & Dew point temperature, $T_{d p}$ & $292.077 \mathrm{~K}$ & 0.08748 & 0.78 \\
4 & Inlet air temperature, $T_{a, i n}$ & $298.882 \mathrm{~K}$ & 0.08692 & 1.35 \\
5 & Air temperature (dry bulb), $T_{d b}$ & $298.882 \mathrm{~K}$ & 0.08663 & 1.35 \\
6 & $\mathrm{P}_{\mathrm{vs}}(\mathrm{T})$ parameters, $a_{0}$ & 25.5943 & -0.06479 & 0.04 \\
7 & $\mathrm{P}_{\mathrm{vs}}(\mathrm{T})$ parameters, $a_{1}$ & -5229.89 & 0.04238 & 0.08 \\
8 & Inlet air humidity ratio, $\omega_{i n}$ & 0.0139 & 0.00478 & 13.8 \\
9 & Wind speed, $V_{w}$ & $1.859 \mathrm{~m} / \mathrm{s}$ & -0.00313 & 50.7 \\
10 & Fan shroud inner diameter, $D_{f a n}$ & $4.1 \mathrm{~m}$ & -0.00189 & 1 \\
11 & Fill section equivalent diameter, $D_{h}$ & $0.0381 \mathrm{~m}$ & -0.00152 & 1 \\
12 & Fill section flow area, $A_{f i l l}$ & $67.29 \mathrm{~m}^{2}$ & 0.00124 & 10 \\
\hline
\end{tabular}




\subsubsection{Sensitivity Analysis Results and Rankings for the Outlet Air Relative Humidity, $R H^{(1)}$}

The results and ranking of the relative sensitivities of the outlet air relative humidity with respect to the most important 29 parameters for this response are listed in Table 5. The first three sensitivities of this response are the most relevant; in particular, an increase of $1 \%$ in $T_{d b}$ or $T_{a, i n}$ would cause an increase in the response of $0.27 \%$ or $0.25 \%$, respectively. On the other hand, an increase of $1 \%$ in $T_{w, \text { in }}$ would cause a decrease of $0.32 \%$ in the response. The sensitivities to the remaining 18 model parameters have not been listed since they are smaller than $1 \%$ of the largest sensitivity (with respect to $T_{w, i n}$ ) for this response.

Table 5. Most important relative sensitivities of the outlet air relative humidity, $R H^{(1)}$.

\begin{tabular}{|c|c|c|c|c|}
\hline Rank \# & Parameter $\left(\alpha_{i}\right)$ & Nominal Value & Rel. Sens. $R S\left(\alpha_{i}\right)$ & Rel. Std. Dev. (\%) \\
\hline 1 & Inlet water temperature, $T_{w \text {,in }}$ & $298.893 \mathrm{~K}$ & -0.31903 & 0.56 \\
\hline 2 & Air temperature (dry bulb), $T_{d b}$ & $298.882 \mathrm{~K}$ & 0.27111 & 1.35 \\
\hline 3 & Inlet air temperature, $T_{a, i n}$ & $298.882 \mathrm{~K}$ & 0.24914 & 1.35 \\
\hline 4 & Dew point temperature, $T_{d p}$ & $292.077 \mathrm{~K}$ & 0.06200 & 0.78 \\
\hline 5 & $\mathrm{D}_{\mathrm{av}}\left(T_{d b}\right)$ parameter, $a_{1, d a v}$ & 2.65322 & -0.21076 & 0.11 \\
\hline 6 & Fill section equivalent diameter, $D_{h}$ & $0.0381 \mathrm{~m}$ & -0.01753 & 1 \\
\hline 7 & Mass transfer coefficient multiplier, $f_{m t}$ & 1.0 & 0.01662 & 50 \\
\hline 8 & $\mathrm{D}_{\mathrm{av}}\left(T_{d b}\right)$ parameter, $a_{2, d a v}$ & -0.006168 & 0.01464 & 0.37 \\
\hline 9 & Wind speed, $V_{w}$ & $1.859 \mathrm{~m} / \mathrm{s}$ & -0.01353 & 50.7 \\
\hline 10 & $\mathrm{D}_{\mathrm{av}}\left(T_{d b}\right)$ parameter, $a_{0, d a v}$ & $7.0608 \times 10^{-9}$ & 0.01108 & 0 \\
\hline 11 & Fill section surface area, $A_{\text {surf }}$ & $14221 \mathrm{~m}^{2}$ & 0.00991 & 25 \\
\hline 12 & Wetted fraction of fill surface area, $w_{t s a}$ & 1 & 0.00991 & 0 \\
\hline 13 & $\mathrm{Nu}$ parameter, $a_{0, N u}$ & 8.235 & 0.00991 & 25 \\
\hline 14 & Fan shroud inner diameter, $D_{f a n}$ & $4.1 \mathrm{~m}$ & -0.00820 & 1 \\
\hline 15 & Thermal conductivity of air at $\mathrm{T}=300 \mathrm{~K}, k_{\text {air }}$ & $0.02624 \mathrm{~W} /(\mathrm{mK})$ & -0.00671 & 6.04 \\
\hline 16 & Heat transfer coefficient multiplier, $f_{h t}$ & 1 & -0.00671 & 50 \\
\hline 17 & $\mathrm{C}_{\mathrm{pa}}(\mathrm{T})$ parameter, $a_{0, c p a}$ & 1030.5 & 0.00670 & 0.03 \\
\hline 18 & $\mathrm{P}_{\mathrm{vs}}(\mathrm{T})$ parameters, $a_{0}$ & 25.5943 & -0.00656 & 0.04 \\
\hline 19 & Kinematic viscosity of air at $300 \mathrm{~K}, \mathrm{v}$ & $1.568 \times 10^{-5}\left(\mathrm{~m}^{2} / \mathrm{s}\right)$ & 0.00554 & 12.09 \\
\hline 20 & Prandlt number of air at $\mathrm{T}=80^{\circ} \mathrm{C}, \mathrm{Pr}$ & 0.708 & -0.00554 & 0.71 \\
\hline 21 & Schmidt number, $S c$ & 0.5998 & 0.00554 & 2.66 \\
\hline 22 & Fill section flow area, $A_{\text {fill }}$ & $67.29 \mathrm{~m}^{2}$ & -0.00539 & 10 \\
\hline 23 & $\mathrm{D}_{\mathrm{av}}(\mathrm{T})$ parameter, $a_{3, d a v}$ & $6.55266 \times 10^{-6}$ & -0.00465 & 0.58 \\
\hline 24 & Dynamic viscosity of air at $\mathrm{T}=300 \mathrm{~K}, \mu$ & $1.983 \times 10^{-5} \mathrm{~kg} /(\mathrm{m} \cdot \mathrm{s})$ & 0.00381 & 4.88 \\
\hline 25 & Fill section frictional loss multiplier, $f$ & 4 & 0.00381 & 50 \\
\hline 26 & $\mathrm{P}_{\mathrm{vs}}(\mathrm{T})$ parameters, $a_{1}$ & -5229.89 & 0.00379 & 0.08 \\
\hline 27 & Atmosphere pressure, $P_{a t m}$ & $100,588 \mathrm{~Pa}$ & 0.00372 & 0.41 \\
\hline 28 & Fill section height, $\Delta z_{\text {fill }}$ & $2.013 \mathrm{~m}$ & 0.00362 & 1 \\
\hline 29 & Inlet air humidity ratio, $\omega_{i n}$ & 0.0139 & 0.00339 & 13.8 \\
\hline
\end{tabular}

\subsubsection{Relative Sensitivities of the Air Mass Flow Rate, $m_{a}$}

The results and ranking of the relative sensitivities of the air mass flow rate with respect to the most important 14 parameters for this response are listed in Table 6 . The first three sensitivities of this response are very large (relative sensitivities larger than unity are customarily considered to be very significant). In particular, an increase of $1 \%$ in $T_{a, i n}$ or $T_{d b}$ would cause a decrease in the response of $38.51 \%$ or $38.49 \%$, respectively. On the other hand, an increase of $1 \%$ in $T_{w}$,in would cause an increase of $36 \%$ in the response. The sensitivities to the remaining 33 model parameters have not been listed since they are smaller than $1 \%$ of the largest sensitivity (with respect to $T_{a, i n}$ ) for this response.

Overall, the air mass flow rate, $m_{a}$, displays the largest sensitivities, so this response is the most sensitive to parameter variations. The other responses, namely the outlet air temperature, the outlet water temperature, the outlet water mass flow rate and the outlet air relative humidity display sensitivities of comparable magnitude. 
Table 6. Most important relative sensitivities of the air mass flow rate, $m_{a}$.

\begin{tabular}{|c|c|c|c|c|}
\hline Rank\# & Parameter $\left(\alpha_{i}\right)$ & Nominal Value & Rel. Sens. $R S\left(\alpha_{i}\right)$ & Rel. Std. Dev. (\%) \\
\hline 1 & Inlet air temperature, $T_{a, i n}$ & $298.882 \mathrm{~K}$ & -38.51406 & 1.35 \\
\hline 2 & Air temperature (dry bulb), $T_{d b}$ & $298.882 \mathrm{~K}$ & -38.49249 & 1.35 \\
\hline 3 & Inlet water temperature, $T_{w, i n}$ & $298.893 \mathrm{~K}$ & 36.00130 & 0.56 \\
\hline 4 & Atmosphere pressure, $P_{a t m}$ & $100,588 \mathrm{~Pa}$ & 1.37474 & 0.41 \\
\hline 5 & Wind speed, $V_{w}$ & $1.859 \mathrm{~m} / \mathrm{s}$ & 1.36609 & 50.7 \\
\hline 6 & Fan shroud inner diameter, $D_{f a n}$ & $4.1 \mathrm{~m}$ & 0.82790 & 1 \\
\hline 7 & $\mathrm{P}_{\mathrm{vs}}(\mathrm{T})$ parameters, $a_{0}$ & 25.5943 & -0.76700 & 0.04 \\
\hline 8 & Fill section equivalent diameter, $D_{h}$ & $0.0381 \mathrm{~m}$ & 0.74221 & 1 \\
\hline 9 & Dew point temperature, $T_{d p}$ & $292.077 \mathrm{~K}$ & 0.70105 & 0.78 \\
\hline 10 & Fill section flow area, $A_{\text {fill }}$ & $67.29 \mathrm{~m}^{2}$ & 0.54384 & 10 \\
\hline 11 & $\mathrm{P}_{\mathrm{vs}}(\mathrm{T})$ parameters, $a_{1}$ & -5229.89 & 0.50156 & 0.08 \\
\hline 12 & Dynamic viscosity of air at $\mathrm{T}=300 \mathrm{~K}, \mu$ & $1.983 \times 10^{-5} \mathrm{~kg} /(\mathrm{m} \cdot \mathrm{s})$ & -0.38448 & 4.88 \\
\hline 13 & Fill section frictional loss multiplier, $f$ & 4 & -0.38448 & 50 \\
\hline 14 & Fill section height, $\Delta z_{\text {fill }}$ & $2.013 \mathrm{~m}$ & -0.36512 & 1 \\
\hline
\end{tabular}

\subsection{Cross-Comparison of Sensitivity Results}

In Tables 7-11, the ranked relative sensitivities for each response are compared side-by-side between three operating conditions, i.e., the two subcases discussed in [2] (partially saturated subcase I, completely saturated subcase II) and the unsaturated case analyzed in this paper. Among the three operating conditions, the "unsaturated case" is defined as a working condition in which air is unsaturated from the inlet to outlet of the cooling tower; while in the saturated subcase II, on the contrary, air is saturated from inlet to outlet of the cooling tower; the saturated subcase I is the combination of the these two cases, i.e., air in the lower portion of the fill section of the cooling tower is in unsaturated conditions, reaching saturation at some point along the height of the tower and remaining saturated in the upper part of the cooling tower. Cross-comparison of sensitivity results reveals the sensitivity variations between the three operating conditions.

The relative sensitivities and corresponding parameters listed in Table 7 are extracted from Tables 1 and 6 in [3], and Table 2 in this paper. As shown in Table 7, for all three operating conditions, the first most sensitive parameters of the response of air outlet temperature, $T_{a}^{(1)}$, is the same (i.e., $T_{w, \text { in }}$ ). The 2nd and 3rd most sensitive parameter are inverted in the unsaturated case with respect to the two subcases of the saturated case, but with values very close between the two parameters. The parameters that ranks in 4 th place for this response is the same for all cases (i.e., $a_{0}$ ). The 5 th parameter is $a_{0}$ for Subcases I and II and $T_{d p}$ for the unsaturated case.

For the first parameter (i.e., $T_{w, i n}$ ), the unsaturated case displays the largest sensitivity for this response; subcase II has the smallest sensitivity; while subcase I has an intermediate value of sensitivity between the two. This is expected since subcase I is a mixed case between the unsaturated case and the saturated subcase II, as explained above. For all the remaining parameters in the table the situation is reversed, with Subcase II showing the largest sensitivity values and the unsaturated case presenting the smallest ones, with Subcase I still in the middle. Generally, the sensitivity magnitude of subcase I is slightly closer to that of subcase II. This can be explained by the fact that air remains unsaturated less than half of the height of the fill section, and flows in saturated conditions for more than half of the height of the fill section, as analyzed in [2].

The relative sensitivities and corresponding parameters listed in Table 8 are extracted from Tables 2 and 7 in [3], and Table 3 in this paper. As shown in Table 8, for the response of water outlet temperature, $T_{w}^{(50)}$, both the unsaturated case and subcase I are most sensitive to the parameter $T_{w, i n}$, whereas subcase II is most sensitive to the parameter $T_{a, i n}$. As a comparison, the response of water outlet temperature to the parameter $T_{w, \text { in }}$ ranks in 3 rd place, with a value comparable to the other two cases. The next two most sensitive parameters that rank from 2 nd to 3 rd places of this response are also different between the operating conditions: for both the unsaturated case and subcase I, parameters $T_{a, \text { in }}$ and $T_{d b}$ rank in 2nd and 3rd places, respectively; however, for subcase II, parameters that take the 2 nd and 3rd places are $T_{d b}$ and $T_{w, i n}$, respectively. The parameters that take the 4th and 5 th places are also different between the operating conditions, as shown in the table. Overall, for the response 
of water outlet temperature, $T_{w}^{(50)}$, the sensitivity behavior of subcase I is more similar to that of the unsaturated case.

The relative sensitivities and corresponding parameters listed in Table 9 are extracted from Tables 3 and 8 in [3], and Table 4 in this paper. As shown in Table 9, for all three operating conditions, the first two most sensitive parameters of the response of water outlet mass flow rate, $m_{w}^{(50)}$, are the same (i.e., $m_{w, i n}$ and $T_{w, i n}$, respectively). In addition, for each of the first two parameters, all three operating conditions have comparable sensitivity magnitudes. This indicates that the sensitivities of the first two parameters are insensitive to the operating condition change. The third most sensitive parameter of this response is different between the operating conditions: for both the unsaturated case and subcase $\mathrm{I}$, this parameter is $T_{d p}$; whereas for subcase 2 , this parameter is $T_{a, i n}$. Similarly, the parameters that take the 4 th and 5 th places are also different between the operating conditions, as shown in the table.

The relative sensitivities and corresponding parameters listed in Table 10 are extracted from Tables 4 and 9 in [3], and Table 5 in this paper. As shown in Table 10, for Subcases I and II, the first three most sensitive parameters of the response of air outlet relative humidity, $R H^{(1)}$, are the same (i.e., $T_{a, i n}, T_{d b}$ and $T_{d p}$, respectively); the order is different for the unsaturated case. The next two most sensitive parameters that rank the 4 th and 5 th places of this response are different between the operating conditions.

For each of the first three parameters, all three operating conditions are sensitive to the parameter changes. In which, subcase II is the most sensitive case; and the unsaturated case is the least sensitive case comparatively. For instance, $1 \%$ change in $T_{a, i n}, T_{d b}$ or $T_{d p}$ will cause around $0.2 \%$ change in $R H^{(1)}$ for the unsaturated case, around $2 \%$ change in $R H^{(1)}$ for subcase I; and nearly $15 \%$ change in $R H^{(1)}$ for subcase II, respectively. Overall, for the response of air outlet relative humidity, $R H^{(1)}$, the sensitivity behavior of subcase I is also more similar to that of subcase II, as also the signs of most of the sensitivity values, inverted in the unsaturated case with respect to Subcase I and II, show in Table 10.

The relative sensitivities and corresponding parameters listed in Table 11 are extracted from Tables 5 and 10 in [3], and Table 6 in this paper. As shown in Table 11, for all the operating conditions, the first three most sensitive parameters of the response of air mass flow rate, $m_{a}$, are the same (i.e., $T_{d b}$, $T_{a, i n}$ and $T_{w, i n}$, respectively) with the order of the first two being swapped for the unsaturated case. $P_{a t m}$ is the 4th more sensitive parameter in all operating conditions, and with values comparable between the three cases; the parameters ranking in 5th place are different for the three operating conditions.

For each of the first three parameters, all three operating conditions are sensitive to the parameter changes. Differently from the response $R H^{(1)}$, subcase II is this time the least sensitive case, while the unsaturated case is the most sensitive case comparatively. For instance, $1 \%$ change in $T_{a, i n}, T_{d b}$ or $T_{w, i n}$ will cause around $38 \%$ change in $m_{a}$ for the unsaturated case, around $24 \%$ change in $m_{a}$ for subcase I; and nearly $22 \%$ change in $m_{a}$ for subcase II, respectively. Overall, for the response of air mass flow rate, $m_{a}$, the sensitivity behavior of subcase I is also more similar to that of subcase II.

Table 7. Cross-comparison of the top five relative sensitivities for the response of air outlet temperature, $T_{a}^{(1)}$.

\begin{tabular}{|c|c|c|c|}
\hline \multirow[b]{2}{*}{ Rank \# } & \multirow{2}{*}{$\begin{array}{l}\text { Rel. Sens. for Unsaturated } \\
\text { Conditions (Based on } 6717 \\
\text { Unsaturated Data Sets) }\end{array}$} & \multicolumn{2}{|c|}{ Rel. Sens. for Saturated Conditions } \\
\hline & & $\begin{array}{l}\text { Subcase I (Based on } 377 \text { Data } \\
\text { Sets with Inlet Air Unsaturated) }\end{array}$ & $\begin{array}{l}\text { Subcase II (Based on } 290 \text { Data } \\
\text { Sets with Inlet Air Saturated) }\end{array}$ \\
\hline \multirow{2}{*}{1} & 0.9179 & 0.8346 & 0.8161 \\
\hline & $T_{w, \text { in }}$ & $T_{w, \text { in }}$ & $T_{w, \text { in }}$ \\
\hline \multirow{2}{*}{2} & 0.0652 & 0.1436 & 0.1754 \\
\hline & $T_{d b}$ & $T_{a, i n}$ & $T_{a, i n}$ \\
\hline \multirow{2}{*}{3} & 0.0648 & 0.1429 & 0.1741 \\
\hline & $T_{a, i n}$ & $T_{d b}$ & $T_{d b}$ \\
\hline \multirow{2}{*}{4} & -0.0127 & -0.0231 & -0.0272 \\
\hline & $a_{0}$ & $a_{0}$ & $a_{0}$ \\
\hline & 0.0101 & 0.0151 & 0.0176 \\
\hline 5 & $T_{d p}$ & $a_{1}$ & $a_{1}$ \\
\hline
\end{tabular}


Table 8. Cross-comparison of the top five relative sensitivities for the response of water outlet temperature, $T_{w}^{(50)}$.

\begin{tabular}{|c|c|c|c|}
\hline \multirow[b]{2}{*}{ Rank \# } & \multirow{2}{*}{$\begin{array}{l}\text { Rel. Sens. for Unsaturated } \\
\text { Conditions (Based on } 6717 \\
\text { Unsaturated Data Sets) }\end{array}$} & \multicolumn{2}{|c|}{ Rel. Sens. for Saturated Conditions } \\
\hline & & $\begin{array}{l}\text { Subcase I (Based on } 377 \text { Data } \\
\text { Sets with Inlet Air Unsaturated) }\end{array}$ & $\begin{array}{l}\text { Subcase II (Based on } 290 \text { Data } \\
\text { Sets with Inlet Air Saturated) }\end{array}$ \\
\hline \multirow{2}{*}{1} & 0.5056 & 0.4856 & 0.4858 \\
\hline & $T_{w, \text { in }}$ & $T_{w, \text { in }}$ & $T_{a, i n}$ \\
\hline \multirow{2}{*}{2} & 0.2532 & 0.2461 & 0.4800 \\
\hline & $T_{a, i n}$ & $T_{a, i n}$ & $T_{d b}$ \\
\hline \multirow{2}{*}{3} & 0.2526 & 0.2434 & 0.4568 \\
\hline & $T_{d b}$ & $T_{d b}$ & $T_{w, i n}$ \\
\hline \multirow{2}{*}{4} & 0.1710 & 0.2074 & -0.1170 \\
\hline & $T_{d p}$ & $T_{d p}$ & $a_{0}$ \\
\hline \multirow{2}{*}{5} & -0.1262 & -0.1140 & 0.0756 \\
\hline & $a_{0}$ & $a_{0}$ & $a_{1}$ \\
\hline
\end{tabular}

Table 9. Cross-comparison of the top five relative sensitivities for the response of water outlet mass flow rate, $m_{w}^{(50)}$.

\begin{tabular}{|c|c|c|c|}
\hline \multirow[b]{2}{*}{ Rank \# } & \multirow{2}{*}{$\begin{array}{l}\text { Rel. Sens. for Unsaturated } \\
\text { Conditions (Based on } 6717 \\
\text { Unsaturated Data Sets) }\end{array}$} & \multicolumn{2}{|c|}{ Rel. Sens. for Saturated Conditions } \\
\hline & & $\begin{array}{l}\text { Subcase I (Based on } 377 \text { Data } \\
\text { Sets with Inlet Air Unsaturated) }\end{array}$ & $\begin{array}{l}\text { Subcase II (Based on } 290 \text { Data } \\
\text { Sets with Inlet Air Saturated) }\end{array}$ \\
\hline \multirow{2}{*}{1} & 1.002 & 1.002 & 1.002 \\
\hline & $m_{w, i n}$ & $m_{w, \text { in }}$ & $m_{w, \text { in }}$ \\
\hline \multirow{2}{*}{2} & -0.2137 & -0.1983 & -0.2129 \\
\hline & $T_{w, i n}$ & $T_{w, \text { in }}$ & $T_{w, i n}$ \\
\hline \multirow{2}{*}{3} & 0.0875 & 0.1069 & 0.1783 \\
\hline & $T_{d p}$ & $T_{d p}$ & $T_{a, i n}$ \\
\hline \multirow{2}{*}{4} & 0.0869 & -0.0593 & 0.1751 \\
\hline & $T_{a, i n}$ & $a_{0}$ & $T_{d b}$ \\
\hline \multirow{2}{*}{5} & 0.0867 & 0.0557 & -0.0613 \\
\hline & $T_{d b}$ & $T_{a, i n}$ & $a_{0}$ \\
\hline
\end{tabular}

Table 10. Cross-comparison of the top five relative sensitivities for the response of air outlet rel. humidity, $R H^{(1)}$.

\begin{tabular}{|c|c|c|c|}
\hline \multirow[b]{2}{*}{ Rank \# } & \multirow{2}{*}{$\begin{array}{l}\text { Rel. Sens. for Unsaturated } \\
\text { Conditions (Based on } 6717 \\
\text { Unsaturated Data Sets) }\end{array}$} & \multicolumn{2}{|c|}{ Rel. Sens. for Saturated Conditions } \\
\hline & & $\begin{array}{l}\text { Subcase I (Based on } 377 \text { Data } \\
\text { Sets with Inlet Air Unsaturated) }\end{array}$ & $\begin{array}{l}\text { Subcase II (Based on } 290 \text { Data } \\
\text { Sets with Inlet Air Saturated) }\end{array}$ \\
\hline \multirow[b]{2}{*}{1} & -0.3190 & -2.1108 & -14.347 \\
\hline & $T_{w, i n}$ & $T_{a, i n}$ & $T_{a, i n}$ \\
\hline \multirow{2}{*}{2} & 0.2711 & -1.9469 & -14.024 \\
\hline & $T_{d b}$ & $T_{d b}$ & $T_{d b}$ \\
\hline \multirow{2}{*}{3} & 0.2491 & 1.5759 & 13.216 \\
\hline & $T_{a, i n}$ & $T_{d p}$ & $T_{d p}$ \\
\hline \multirow{2}{*}{4} & 0.0620 & 0.3398 & 0.7257 \\
\hline & $T_{d p}$ & $T_{w, \text { in }}$ & $\omega_{\text {in }}$ \\
\hline \multirow{2}{*}{5} & -0.2108 & -0.1559 & 0.6619 \\
\hline & $a_{1, \text { dav }}$ & $a_{1, \text { dav }}$ & $T_{w, \text { in }}$ \\
\hline
\end{tabular}


Table 11. Cross-comparison of the top five relative sensitivities for the response of air mass flow rate, $m_{a}$.

\begin{tabular}{|c|c|c|c|}
\hline \multirow[b]{2}{*}{ Rank \# } & \multirow{2}{*}{$\begin{array}{l}\text { Rel. Sens. for Unsaturated } \\
\text { Conditions (Based on } 6717 \\
\text { Unsaturated Data Sets) }\end{array}$} & \multicolumn{2}{|c|}{ Rel. Sens. for Saturated Conditions } \\
\hline & & $\begin{array}{l}\text { Subcase I (Based on } 377 \text { Data } \\
\text { Sets with Inlet Air Unsaturated) }\end{array}$ & $\begin{array}{l}\text { Subcase II (Based on } 290 \text { Data } \\
\text { Sets with Inlet Air Saturated) }\end{array}$ \\
\hline \multirow{2}{*}{1} & -38.514 & -24.478 & -22.043 \\
\hline & $T_{a, i n}$ & $T_{d b}$ & $T_{d b}$ \\
\hline \multirow{2}{*}{2} & -38.492 & -24.456 & -22.002 \\
\hline & $T_{d b}$ & $T_{a, i n}$ & $T_{a, i n}$ \\
\hline \multirow[b]{2}{*}{3} & 36.001 & 22.209 & 20.375 \\
\hline & $T_{w, \text { in }}$ & $T_{w, \text { in }}$ & $T_{w, \text { in }}$ \\
\hline \multirow[b]{2}{*}{4} & 1.3747 & 1.2204 & 1.1942 \\
\hline & $P_{a t m}$ & $P_{a t m}$ & $P_{a t m}$ \\
\hline \multirow[b]{2}{*}{5} & 1.3661 & 0.8567 & -0.8716 \\
\hline & $V_{w}$ & $D_{f a n}$ & $a_{0}$ \\
\hline
\end{tabular}

3.3. Experimental Data Assimilation, Model Calibration and Best-Estimate Predicted Results with Reduced Predicted Uncertainties

This subsection presents the results of applying the Predictive Modeling of Coupled Multi-Physics Systems (PM_CMPS) methodology [4] to the counter-flow cooling tower model.

The a priori covariance matrix, $\operatorname{Cov}\left(T_{a, \text { out }}^{\text {meas }}, T_{w, \text { out }}^{\text {meas }}, R H_{\text {out }}^{\text {meas }}\right) \triangleq \mathbf{C}_{r r}$, of the measured responses (namely: the outlet air temperature, $T_{a, \text { out }}^{\text {meas }} \equiv\left[T_{a}^{(1)}\right]^{\text {measured }}$; the outlet water temperature, $T_{w, o u t}^{\text {meas }} \equiv\left[T_{w}^{(50)}\right]^{\text {measured }}$, and the outlet air relative humidity, $R H_{\text {out }}^{\text {meas }} \equiv\left[R H^{(1)}\right]^{\text {measured }}$ ), cf. Equation (A4), is reproduced below:

$$
\operatorname{Cov}\left(T_{a, \text { out }}^{\text {meas }}, T_{w, \text { out }}^{\text {meas }}, R H_{\text {out }}^{\text {meas }}\right) \triangleq \mathbf{C}_{r r}=\left(\begin{array}{ccc}
8.09 & 1.92 & -27.74 \\
1.92 & 1.94 & -1.96 \\
-27.74 & -1.96 & 195.81
\end{array}\right) .
$$

The a priori response-parameter covariance matrix, $\mathbf{C}_{r \alpha}$, cf. Equation (A5), is reproduced below:

$$
\operatorname{Cov}\left(T_{a, 0 u t}^{\text {meas }}, T_{w, \text { out }}^{\text {meas }}, R H^{\text {meas }}, \alpha_{1}, \ldots, \alpha_{47}\right) \triangleq \mathbf{C}_{r \alpha}=\left(\begin{array}{cccccccc}
10.36 & 2.81 & 2.22 & -232.64 & 1.30 & 0 & \cdots & 0 \\
1.58 & 1.96 & 2.01 & -23.76 & -0.10 & 0 & \cdots & 0 \\
-35.89 & 2.43 & -0.79 & 720.11 & -5.48 & 0 & \cdots & 0
\end{array}\right) .
$$

where the measured correlated parameters are: $\alpha_{1} \triangleq T_{d b}, \alpha_{2} \triangleq T_{d p}, \alpha_{3} \triangleq T_{w, i n}, \alpha_{4} \triangleq P_{a t m}$, and $\alpha_{5} \triangleq V_{w}$.

The a priori parameter covariance matrix, $\mathbf{C}_{\alpha \alpha}$, is:

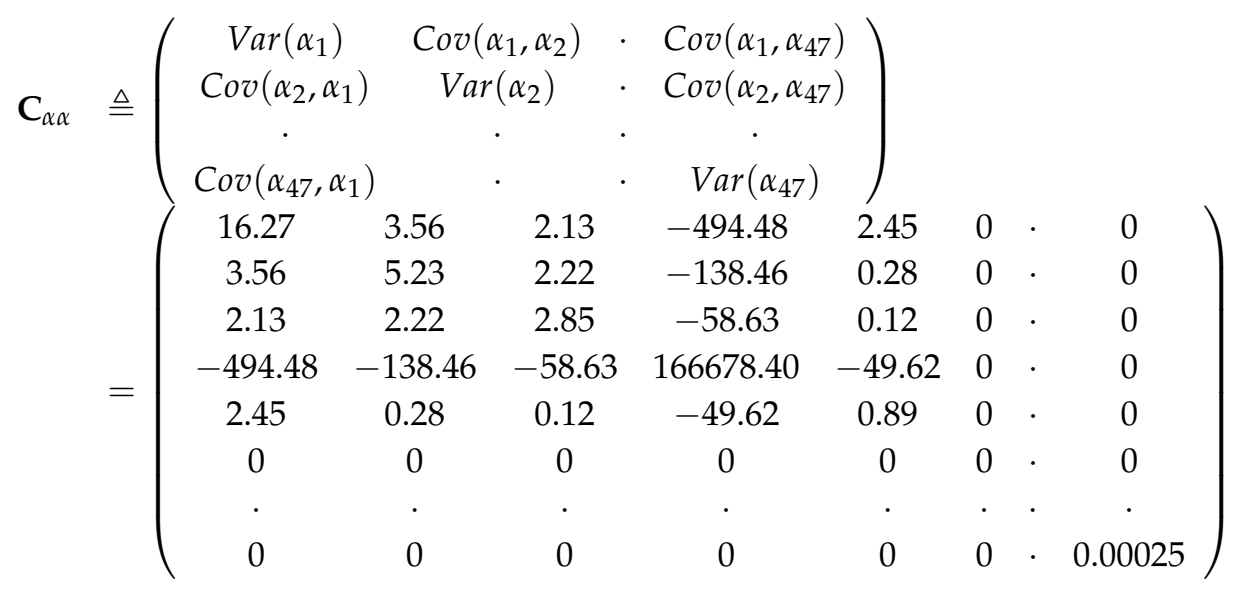


The a priori covariance matrix of the computed responses, $\mathbf{C}_{r r}^{\text {comp }}$, is given below:

$$
\begin{aligned}
& \mathbf{C}_{r r}^{c o m p} \equiv \operatorname{Cov}\left(T_{a}^{(1)}, T_{w}^{(50)}, R H^{(1)}\right)=\mathbf{S}_{r \alpha} \mathbf{C}_{\alpha \alpha} \mathbf{S}_{r \alpha}^{\dagger} \\
& =\left(\begin{array}{c}
\frac{\partial T_{a}^{(1)}}{\partial \alpha_{1}}, \ldots, \frac{\partial T_{a}^{(1)}}{\partial \alpha_{N \alpha}} \\
\frac{\partial T_{w}^{(50)}}{\partial \alpha_{1}}, \ldots, \frac{\partial T_{w}^{(50)}}{\partial \alpha_{N \alpha}} \\
\frac{\partial R H^{(1)}}{\partial \alpha_{1}}, \ldots, \frac{\partial R H^{(1)}}{\partial \alpha_{N \alpha}}
\end{array}\right)\left(\begin{array}{cccc}
\operatorname{Var}\left(\alpha_{1}\right) & \operatorname{Cov}\left(\alpha_{1}, \alpha_{2}\right) & \cdot & \operatorname{Cov}\left(\alpha_{1}, \alpha_{47}\right) \\
\operatorname{Cov}\left(\alpha_{2}, \alpha_{1}\right) & \operatorname{Var}\left(\alpha_{2}\right) & \cdot & \operatorname{Cov}\left(\alpha_{2}, \alpha_{47}\right) \\
\cdot & \cdot & \cdot & \cdot \\
\operatorname{Cov}\left(\alpha_{47}, \alpha_{1}\right) & \cdot & \cdot & \operatorname{Var}\left(\alpha_{47}\right)
\end{array}\right)\left(\begin{array}{c}
\frac{\partial T_{a}^{(1)}}{\partial \alpha_{1}}, \ldots, \frac{\partial T_{a}^{(1)}}{\partial \alpha_{N \alpha}} \\
\frac{\partial T_{w}^{(50)}}{\partial \alpha_{1}}, \ldots, \frac{\partial T_{w}^{(50)}}{\partial \alpha_{N \alpha}} \\
\frac{\partial R H^{(1)}}{\partial \alpha_{1}}, \ldots, \frac{\partial R H^{(1)}}{\partial \alpha_{N \alpha}}
\end{array}\right)^{+} \\
& =\left(\begin{array}{lll}
2.78 & 2.64 & 0.11 \\
2.64 & 3.85 & 0.56 \\
0.11 & 0.56 & 1.37
\end{array}\right) \text {. }
\end{aligned}
$$

3.3.1. Model Calibration: Predicted Best-Estimated Parameter Values with Reduced Predicted Standard Deviations

The best-estimate nominal parameter values have been computed as follows:

$$
\boldsymbol{\alpha}^{\text {pred }}=\boldsymbol{\alpha}^{0}-\left(\mathbf{C}_{\alpha \alpha} \mathbf{S}_{r \alpha}^{+}-\mathbf{C}_{\alpha r}\right)\left[\mathbf{D}_{r r}\right]^{-1}\left[\mathbf{r}^{c}\left(\boldsymbol{\alpha}^{0}, \boldsymbol{\beta}^{0}\right)-\mathbf{r}^{m}\right],
$$

in conjunction with the a priori matrices given in Equations (29)-(32) and the sensitivities presented in Tables 1-5. The resulting best-estimate nominal values are listed in Table 12, below. The corresponding best-estimate absolute standard deviations for these parameters are also presented in this table. These values are the square-roots of the diagonal elements of the matrix $\mathbf{C}_{\alpha \alpha}^{\text {pred }}$. For comparison, the original nominal parameter values and original absolute standard deviations are also listed. As the results in Table 12 indicate, the predicted best-estimate standard deviations are all smaller or at most equal to (i.e., left unaffected) the original standard deviations. The parameters are affected proportionally to the

\begin{tabular}{|c|c|c|c|c|c|c|}
\hline$i$ & Independent Scalar Parameters $\left(\alpha_{i}\right)$ & $\begin{array}{c}\text { Math. } \\
\text { Notation }\end{array}$ & $\begin{array}{c}\text { Original } \\
\text { Nominal Value }\end{array}$ & $\begin{array}{l}\text { Original Absolute } \\
\text { Std. Dev. }\end{array}$ & $\begin{array}{l}\text { Best-Estimated } \\
\text { Nominal Value }\end{array}$ & $\begin{array}{c}\text { Best-Estimated } \\
\text { Absolute Std. Dev. }\end{array}$ \\
\hline 1 & Air temperature (dry bulb), (K) & $T_{d b}$ & 298.882 & 4.034 & 298.799 & 2.23 \\
\hline 2 & Dew point temperature $(\mathrm{K})$ & $T_{d p}$ & 292.077 & 2.287 & 292.803 & 2.16 \\
\hline 3 & Inlet water temperature $(\mathrm{K})$ & $T_{w, i n}$ & 298.893 & 1.687 & 298.712 & 1.63 \\
\hline 4 & Atmospheric pressure $(\mathrm{Pa})$ & $P_{a t m}$ & 100,588 & 408.26 & 100566 & 397.57 \\
\hline 5 & Wind speed $(\mathrm{m} / \mathrm{s})$ & $V_{w}$ & 1.859 & 0.941 & 1.794 & 0.783 \\
\hline 6 & Sum of loss coefficients above fill & $k_{\text {sum }}$ & 10 & 5 & 10.045 & 4.996 \\
\hline 7 & $\begin{array}{l}\text { Dynamic viscosity of air at } \\
\mathrm{T}=300 \mathrm{~K}(\mathrm{~kg} / \mathrm{m} \cdot \mathrm{s})\end{array}$ & $\mu$ & $1.983 \times 10^{-5}$ & $9.676 \times 10^{-7}$ & $1.983 \times 10^{-5}$ & $9.674 \times 10^{-7}$ \\
\hline 8 & $\begin{array}{l}\text { Kinematic viscosity of air at } \\
\mathrm{T}=300 \mathrm{~K}\left(\mathrm{~m}^{2} / \mathrm{s}\right)\end{array}$ & $v$ & $1.568 \times 10^{-5}$ & $1.895 \times 10^{-6}$ & $1.566 \times 10^{-5}$ & $1.895 \times 10^{-6}$ \\
\hline 9 & $\begin{array}{l}\text { Thermal conductivity of air at } \\
\qquad \mathrm{T}=300 \mathrm{~K}(\mathrm{~W} / \mathrm{m} \cdot \mathrm{K})\end{array}$ & $k_{\text {air }}$ & 0.02624 & $1.584 \times 10^{-3}$ & 0.02624 & $1.583 \times 10^{-3}$ \\
\hline 10 & Heat transfer coefficient multiplier & $f_{h t}$ & 1 & 0.5 & 1.00532 & 0.5 \\
\hline 11 & Mass transfer coefficient multiplier & $f_{m t}$ & 1 & 0.5 & 0.9342 & 0.496 \\
\hline 12 & Fill section frictional loss multiplier & $f$ & 4 & 2 & 4.088 & 1.96 \\
\hline 13 & \multirow{2}{*}{$\mathrm{P}_{\mathrm{vs}}(\mathrm{T})$ parameters } & $a_{0}$ & 25.5943 & 0.01 & 25.5943 & 0.01 \\
\hline 14 & & $a_{1}$ & -5229.89 & 4.4 & -5229.92 & 4.40 \\
\hline 15 & \multirow{3}{*}{$\mathrm{C}_{\mathrm{pa}}(\mathrm{T})$ parameters } & $a_{0, c p a}$ & 1030.5 & 0.2940 & 1030.5 & 0.294 \\
\hline 16 & & $a_{1, c p a}$ & -0.19975 & 0.0020 & -0.19975 & 0.0020 \\
\hline 17 & & $a_{2, \mathrm{cpa} a}$ & $3.9734 \times 10^{-4}$ & $3.345 \times 10^{-6}$ & $3.9734 \times 10^{-4}$ & $3.345 \times 10^{-6}$ \\
\hline
\end{tabular}
magnitudes of their corresponding sensitivities: the parameters experiencing the largest reductions in their predicted standard deviations are those having the largest sensitivities.

Table 12. Best-estimated nominal parameter values and their standard deviations. 
Table 12. Cont.

\begin{tabular}{|c|c|c|c|c|c|c|}
\hline$i$ & Independent Scalar Parameters $\left(\alpha_{i}\right)$ & $\begin{array}{l}\text { Math. } \\
\text { Notation }\end{array}$ & $\begin{array}{c}\text { Original } \\
\text { Nominal Value }\end{array}$ & $\begin{array}{l}\text { Original Absolute } \\
\text { Std. Dev. }\end{array}$ & $\begin{array}{l}\text { Best-Estimated } \\
\text { Nominal Value }\end{array}$ & $\begin{array}{l}\text { Best-Estimated } \\
\text { Absolute Std. Dev. }\end{array}$ \\
\hline 18 & \multirow{4}{*}{$\mathrm{D}_{\mathrm{av}}(\mathrm{T})$ parameters } & $a_{0, d a v}$ & $7.06085 \times 10^{-9}$ & 0 & $7.0608 \times 10^{-9}$ & 0 \\
\hline 19 & & $a_{1, \text { dav }}$ & 2.65322 & 0.003 & 2.65322 & 0.003 \\
\hline 20 & & $a_{2, d a v}$ & $-6.1681 \times 10^{-3}$ & $2.3 \times 10^{-5}$ & $-6.168 \times 10^{-3}$ & $2.3 \times 10^{-5}$ \\
\hline 21 & & $a_{3, d a v}$ & $6.55266 \times 10^{-6}$ & $3.8 \times 10^{-8}$ & $6.5526 \times 10^{-6}$ & $3.8 \times 10^{-8}$ \\
\hline 22 & $\mathrm{~h}_{\mathrm{f}}(\mathrm{T})$ parameters & $a_{0 f}$ & $-1,143,423.78$ & 543. & $-1,143,423.7$ & 543 \\
\hline 24 & \multirow{2}{*}{$h_{g}(T)$ parameters } & $a_{0 g}$ & $2,005,743.99$ & 1046 & $2,005,743.78$ & 1046 \\
\hline 25 & & $a_{1 g}$ & 1815.437 & 3.5 & 1815.43630 & 3.5 \\
\hline 26 & \multirow{2}{*}{ Nu parameters } & $a_{0, N u}$ & 8.235 & 2.059 & 8.11039 & 2.055 \\
\hline 27 & & $a_{1, N u}$ & 0.00314987 & 0.001 & 0.00314987 & 0.001 \\
\hline 31 & Cooling tower deck width in y-dir (m) & $W_{d k y}$ & 8.5 & 0.085 & 8.5 & 0.085 \\
\hline 32 & $\begin{array}{l}\text { Cooling tower deck height above } \\
\text { ground (m) }\end{array}$ & $\Delta z_{d k}$ & 10 & 0.1 & 10 & 0.1 \\
\hline 33 & Fan shroud height $(\mathrm{m})$ & $\Delta z_{f a n}$ & 3.0 & 0.03 & 3.0 & 0.03 \\
\hline 34 & Fan shroud inner diameter $(\mathrm{m})$ & $D_{\text {fan }}$ & 4.1 & 0.041 & 4.1 & 0.041 \\
\hline 35 & Fill section height $(\mathrm{m})$ & $\Delta z_{\text {fill }}$ & 2.013 & 0.02013 & 2.013 & 0.02013 \\
\hline 36 & Rain section height $(\mathrm{m})$ & $\Delta z_{\text {rain }}$ & 1.633 & 0.01633 & 1.633 & 0.01633 \\
\hline 37 & Basin section height $(\mathrm{m})$ & $\Delta z_{b s}$ & 1.168 & 0.01168 & 1.168 & 0.01168 \\
\hline 38 & Drift eliminator thickness $(\mathrm{m})$ & $\Delta z_{d e}$ & 0.1524 & 0.001524 & 0.1524 & 0.001524 \\
\hline 44 & Inlet water mass flowrate $(\mathrm{kg} / \mathrm{s})$ & $m_{w, \text { in }}$ & 44.0193 & 2.201 & 44.0696 & 2.199 \\
\hline 45 & Inlet air temperature $(\mathrm{K})$ & $T_{a, i n} ;$ & set to $T_{d b}$ & 4.034 & 299.841 & 2.73 \\
\hline 46 & Inlet air humidity ratio & $\omega_{\text {in }}$ & 0.01379 & 0.00192 & 0.01406 & 0.00191 \\
\hline$i$ & Special Dependent Parameters & $\begin{array}{c}\text { Math. } \\
\text { Notation }\end{array}$ & $\begin{array}{c}\text { Original } \\
\text { Nominal Value }\end{array}$ & Absolute Std. Dev. & $\begin{array}{c}\text { Best-estimated } \\
\text { Nominal Value }\end{array}$ & $\begin{array}{c}\text { Best-estimated } \\
\text { Absolute Std. Dev. }\end{array}$ \\
\hline 47 & Schmidt number & Sc & 0.5999 & 0.0159 & 0.5999 & 0.0159 \\
\hline
\end{tabular}

\subsubsection{Predicted Best-Estimated Response Values with Reduced Predicted Standard Deviations}

The predicted response covariance matrix, $\mathbf{C}_{r r}^{p r e d}$, is as follows:

$$
\mathbf{C}_{r r}^{\text {pred }} \equiv \operatorname{Cov}\left(\left[T_{a}^{(1)}\right]^{b e},\left[T_{w}^{(50)}\right]^{b e},\left[R H^{(1)}\right]^{b e}\right)=\left(\begin{array}{ccc}
1.40 & 0.92 & -0.13 \\
0.92 & 1.27 & 0.17 \\
-0.13 & 0.17 & 1.30
\end{array}\right) .
$$

The non-zero elements with the largest magnitudes of best-estimate response-parameter correlation matrix, $\mathbf{C}_{\alpha r}^{p r e d}$, are as follows:

$$
\begin{aligned}
& \text { rel.cor. }\left(R_{1}, \alpha_{4}\right)=-0.040 ; \text { rel.cor. }\left(R_{1}, \alpha_{41}\right)=-0.038 ; \\
& \text { rel.cor. }\left(R_{2}, \alpha_{4}\right)=-0.095 ; \text { rel.cor. }\left(R_{2}, \alpha_{41}\right)=-0.008 ; \\
& \text { rel.cor. }\left(R_{3}, \alpha_{4}\right)=0.019 ; \quad \text { rel.cor. }\left(R_{3}, \alpha_{41}\right)=0.222 .
\end{aligned}
$$

The notation used in Equation (35) is as follows: $R_{1} \triangleq T_{a}^{(1)}, R_{2} \triangleq T_{w}^{(50)}, R_{3} \triangleq R H^{(1)} ; \alpha_{4} \triangleq P_{a t m}$, $\alpha_{41} \triangleq A_{\text {surf }}$. 
The resulting best-estimate predicted nominal values are summarized in Table 13. To facilitate comparison, the corresponding measured and computed nominal values are also presented in this table. Note that there are no direct measurements for the outlet water flow rate, $m_{w}^{(50)}$. For this response, therefore, the predicted best-estimate nominal value has been obtained by a forward re-computation using the best-estimate nominal parameter values listed in Table 12, while the predicted best estimate standard deviation for this response has been obtained as follows:

$$
\left[\mathbf{C}_{r r}^{c o m p}\right]^{b e}=\left[\mathbf{S}_{r \alpha}\right]^{b e}\left[\mathbf{C}_{\alpha \alpha}\right]^{b e}\left[\mathbf{S}_{r \alpha}^{+}\right]^{b e}
$$

The results presented in Table 13 indicate that the predicted standard deviations are smaller than either the computed or the experimentally measured ones. This is indeed the consequence of using the PM_CMPS methodology in conjunction with consistent (as opposed to discrepant) computational and experimental information. Often, however, the information is inconsistent, usually due to the presence of unrecognized errors. Solutions for addressing such situations have been proposed in [10]. It is also important to note that the PM_CMPS methodology has improved (i.e., reduced, albeit not by a significant amount) the predicted standard deviation for the outlet water flow rate response, for which no measurements were available. This improvement stems from the global characteristics of the PM_CMPS methodology, which combines all of the available simultaneously on phase-space, as opposed to combining it sequentially, as is the case with the current state-of-the-art data assimilation procedures [11,12].

Table 13. Computed, measured, and optimal best-estimate nominal values and standard deviations for the outlet air temperature, outlet water temperature, outlet air relative humidity, outlet water mass flow rate and air mass flow rate responses.

\begin{tabular}{cccccc}
\hline $\begin{array}{c}\text { Norminal Values and } \\
\text { Standard Deviations }\end{array}$ & $\boldsymbol{T}_{a}^{(1)}[\mathrm{K}]$ & $\boldsymbol{T}_{w}^{(50)}[\mathrm{K}]$ & $\boldsymbol{R H}^{(\mathbf{1})}[\%]$ & $\boldsymbol{m}_{w}^{(50)}[\mathrm{kg} / \mathbf{s}]$ & $\boldsymbol{m}_{\boldsymbol{a}}[\mathrm{kg} / \mathbf{s}]$ \\
\hline Measured & & & & & \\
nominal value & 299.11 & 298.10 & 89.61 & - & - \\
standard deviation & \pm 2.84 & \pm 1.39 & \pm 13.62 & - & - \\
$\quad \begin{array}{c}\text { Computed } \\
\text { nominal value }\end{array}$ & 298.79 & 297.42 & 99.80 & 43.91 & 15.84 \\
standard deviation & \pm 1.67 & \pm 1.96 & \pm 1.17 & \pm 2.20 & \pm 12.20 \\
Best-estimate & & & & & \\
nominal value & 298.65 & 297.52 & 99.69 & 43.97 & 14.86 \\
standard deviation & \pm 1.57 & \pm 1.38 & \pm 1.09 & \pm 2.19 & \pm 8.34 \\
\hline
\end{tabular}

\section{Discussion}

The original numerical method presented in [1] for the model solution has been replaced in this work with a considerably more accurate and efficient one which guarantees convergence of the computations for all of the available data sets. The adjoint model of the cooling tower has been implemented to compute exactly and efficiently the sensitivities of the model responses to all the 47 model parameters. The adjoint sensitivity model yields the adjoint state functions which are used to compute the sensitivities of each model response to all of the 47 model parameters by means of just one adjoint model computation. These adjoint state functions have been computed and their numerical accuracy has been independently verified. The response sensitivities to all model parameters have been computed for the following responses: (i) the outlet air temperature; (ii) the outlet water temperature; (iii) the outlet water mass flow rate; (iv) the air outlet relative humidity; and (v) air mass flow rate. Thes sensitivities have been subsequently used within the "predictive modeling for coupled multi-physics systems" (PM_CMPS) methodology [4] to obtain: (a) optimal best-estimate prediction for the model parameter values; (b) optimal best-estimate nominal values of the model responses; 
(c) reduced predicted standard deviations for the best-estimate calibrated model parameter values; and (d) reduced predicted standard deviations for the best-estimate predicted response values.

The results presented in this work show that the PM_CMPS methodology reduces the predicted standard deviation to values that are smaller than both the standard deviations of the measured and the computed response, respectively, even for responses, such as for the air mass flow rate, for which no experimentally measured values are available. This reduction stems from the fact that the PM_CMPS methodology simultaneously combines all the available data in the phase-space; customary data assimilation methodologies [11,12] only allow a sequential combination of the available information. All in all, the application of the PM_CMPS methodology has produced and improved, calibrated and validated model for simulating the functioning of a buoyancy-operated cooling tower under unsaturated conditions. Ongoing work aims at using second-order sensitivities, to be computed by applying the $2 n d-A S A M$ presented in $[13,14]$. The availability of second-order response sensitivities will enable the computation of non-Gaussian features, such as skewness and kurtosis, of the response distributions of interest.

Acknowledgments: This work has been sponsored by the US Department of Energy under a contract with the University of South Carolina.

Author Contributions: Federico Di Rocco performed all of the numerical calculations in this paper. Dan Gabriel Cacuci conceived and directed the research reported herein, and wrote the paper.

Conflicts of Interest: The authors declare no conflict of interest. The founding sponsors had no role in the design of the study; in the collection, analyses, or interpretation of data; in the writing of the manuscript, and in the decision to publish the results.

\section{Appendix A. Statistical Analysis of Experimentally Measured Responses for SRNL F-Area Cooling Towers}

Histogram plots of the 6717 measurement sets considered in this work (each set containing measurements of $T_{\alpha, \text { out (Tidbit) }}, T_{\alpha, \text { out }(\text { Hobo })}, T_{w, \text { out }}^{\text {meas }}$, and $\left.R H^{\text {meas }}\right)$, together with statistical analyses thereof are presented in the remainder of this Appendix.

The measured outlet (exit) air relative humidity, $R H^{\text {meas }}$, was obtained using Hobo humidity sensors. The accuracy of these sensors is depicted in Figure A1, which indicates the following tolerances (standard deviations): $\pm 2.5 \%$ for relative humidity from $10 \%$ to $90 \%$; between $\pm 2.5 \%$ and $\pm 3.5 \%$ for relative humidity from $90 \%$ to $95 \%$; and $\pm 3.5 \%- \pm 4.0 \%$ from $95 \%$ to $100 \%$. However, when exposed to relative humidity above $95 \%$, the maximum sensor error may temporally increase by an additional $1 \%$, so that the error can reach values between $\pm 4.5 \%$ and $\pm 5.0 \%$ for relative humidity from $95 \%$ to $100 \%$.

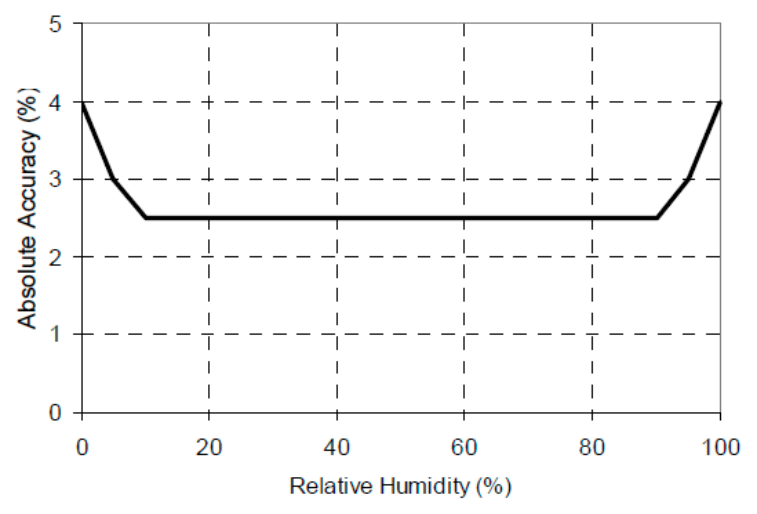

Figure A1. Humidity sensor accuracy plot (adopted from the specification of HOBO Pro v2).

As shown in this Figure A2, although the computed relative humidity for each of the 6717 data sets is less than $100 \%$, the measured relative humidity $R H^{\text {meas }}$ actually spans the range from $33.0 \%$ to $104.1 \%$; in this range, 4925 data sets have their respective $R H^{\text {meas }}$ less than $100 \%$ while the other 
1792 data sets have their respective $R H^{\text {meas }}$ over $100 \%$. This situation is nevertheless consistent with the range of the sensors when their tolerances (standard deviations) are taken into account, which would make it possible for a measurement with RH $^{\text {meas }}=105 \%$ to be nevertheless "unsaturated". Consequently, all the 6717 benchmark data sets plotted in Figure A1, were considered as "unsaturated", since their respective $R H^{\text {meas }}$ was less than $105 \%$.

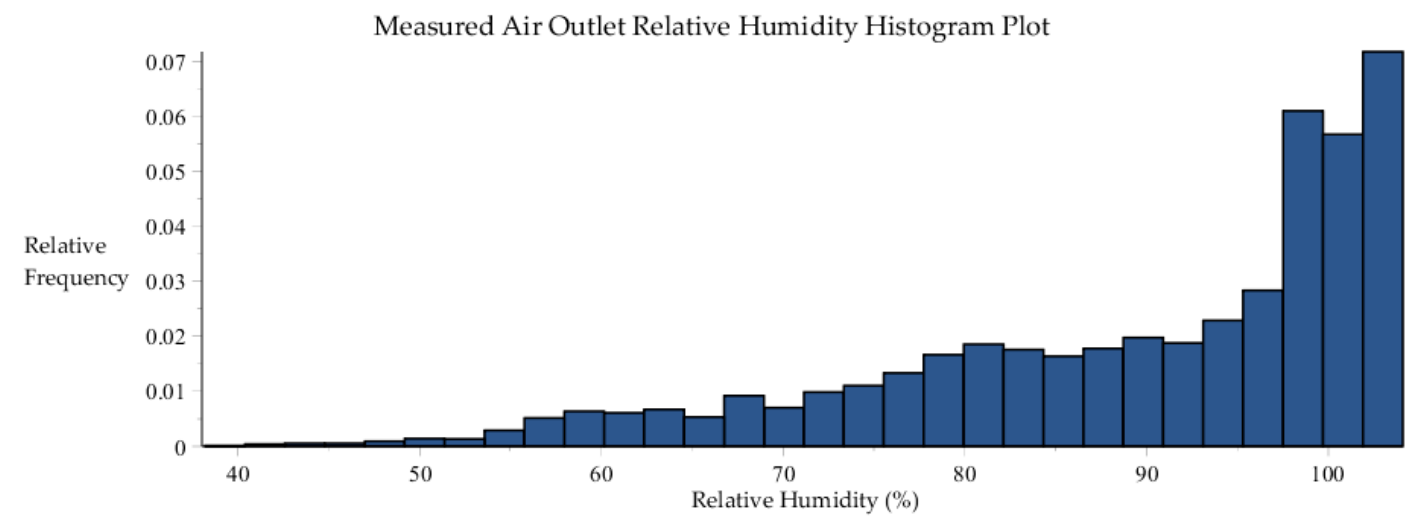

Figure A2. Histogram plot of the measured air outlet relative humidity, within the 6717 data sets collected by SRNL from F-Area cooling towers.

The statistical properties of the (measured air outlet relative humidity) distribution shown in Figure A2 have been computed using standard packages, and are presented in Table A1. These statistical properties will be needed for the uncertainty quantification and predictive modeling computations presented in the main body of this work.

Table A1. Statistics of the air outlet relative humidity distribution [\%].

\begin{tabular}{cccccccc}
\hline Minimum & Maximum & Range & Mean & Std. Dev. & Variance & Skewness & Kurtosis \\
\hline 38.2 & 104.1 & 65.9 & 89.61 & 13.63 & 185.72 & -1.01 & 3.22 \\
\hline
\end{tabular}

The histogram plots and their corresponding statistical characteristics of the 6717 data sets for the other measurements, namely for: the outlet air temperature $\left[T_{a, \text { out }}\right.$ (Tidbit) $]$ measured using the "Tidbit" sensors; the outlet air temperature $\left[T_{a, o u t(H o b o)}\right]$ measured using the "Hobo" sensors; and the outlet water temperature $\left[T_{w, o u t}^{\text {meas }}\right]$ are reported below in Figures A3-A6, and Tables A2-A5, respectively.

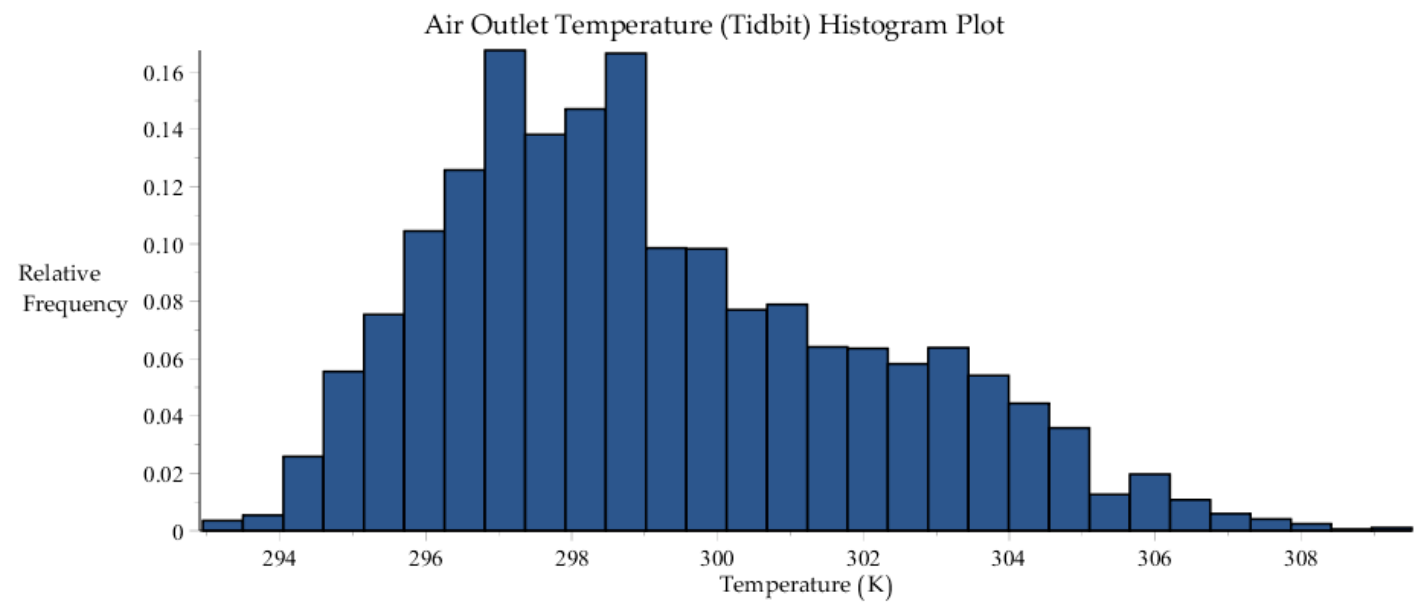

Figure A3. Histogram plot of the air outlet temperature measured using "Tidbit" sensors, within the 6717 data sets collected by SRNL from F-Area cooling towers. 


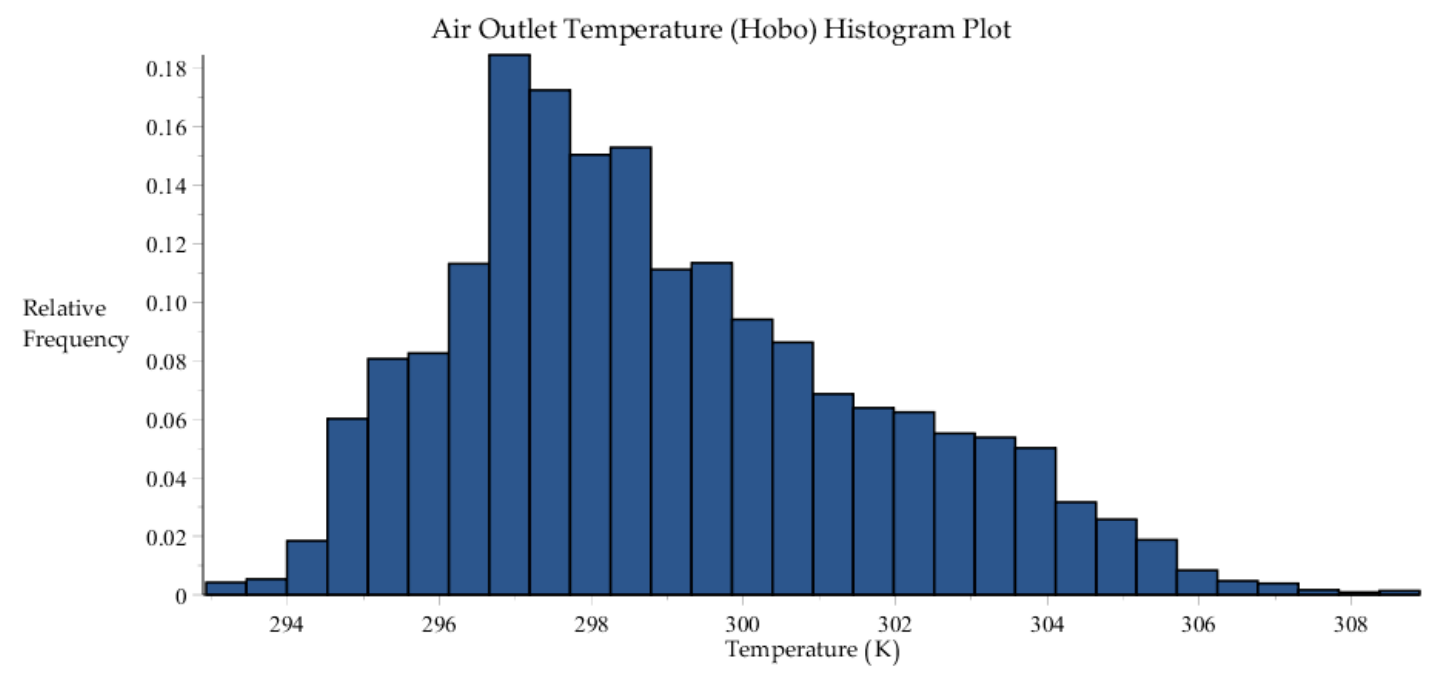

Figure A4. Histogram plot of the air outlet temperature measured using "Hobo" sensors, within the 6717 data sets collected by SRNL from F-Area cooling towers.

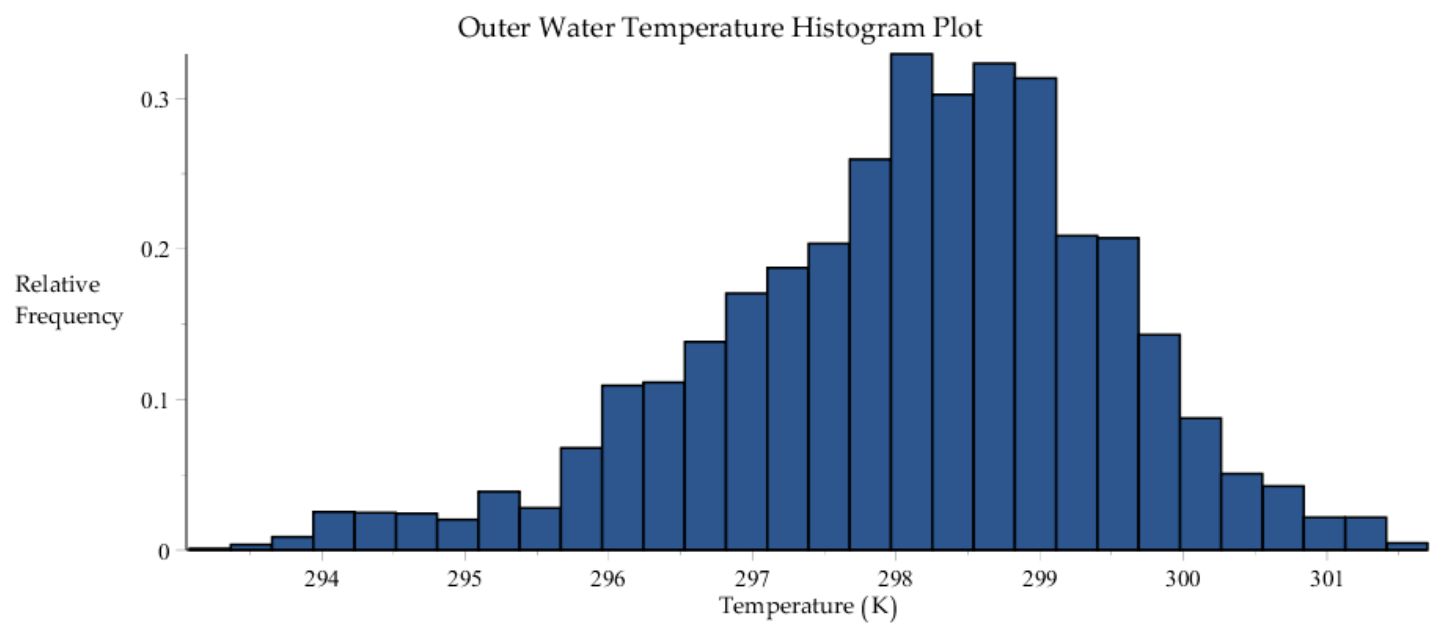

Figure A5. Histogram plot of water outlet temperature measurements, within the 7688 data sets collected by SRNL from F-Area cooling towers.

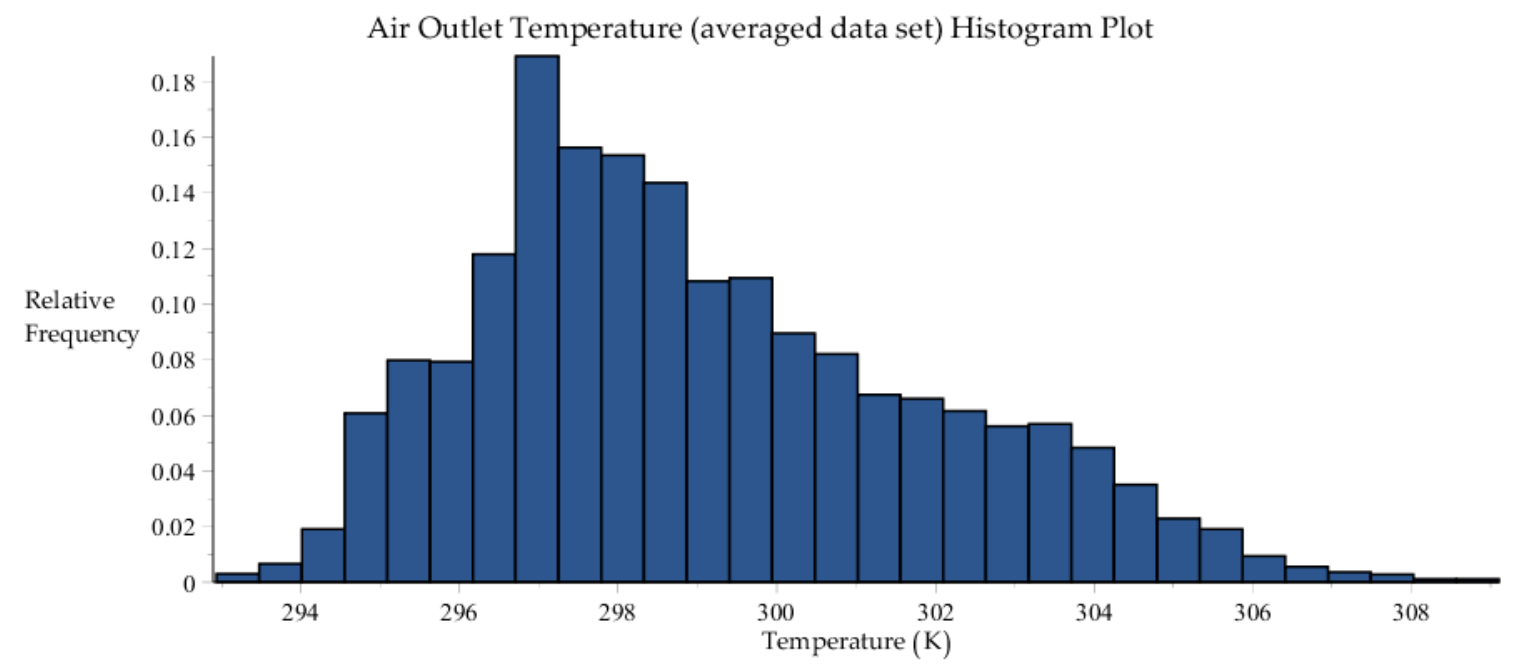

Figure A6. Histogram plot of air outlet temperatures averaged from Figures A3 and A4. 
Table A2. Statistics of the air outlet temperature distribution $[\mathrm{K}]$, measured using "Tidbit" sensors.

\begin{tabular}{cccccccc}
\hline Minimum & Maximum & Range & Mean & Std. Dev. & Variance & Skewness & Kurtosis \\
\hline 292.94 & 309.52 & 16.58 & 299.21 & 2.92 & 8.55 & 0.59 & 2.71 \\
\hline
\end{tabular}

Table A3. Air outlet temperature distribution statistics [K], measured using "Hobo" sensors.

\begin{tabular}{cccccccc}
\hline Minimum & Maximum & Range & Mean & Std. Dev. & Variance & Skewness & Kurtosis \\
\hline 292.93 & 308.90 & 15.97 & 299.00 & 2.77 & 7.68 & 0.58 & 2.75 \\
\hline
\end{tabular}

Table A4. Water outlet temperature distribution statistics [K].

\begin{tabular}{cccccccc}
\hline Minimum & Maximum & Range & Mean & Std. Dev. & Variance & Skewness & Kurtosis \\
\hline 293.08 & 301.70 & 8.62 & 298.10 & 1.39 & 1.94 & -0.51 & 3.31 \\
\hline
\end{tabular}

Table A5. Statistics of the averaged air outlet temperature distribution [K].

\begin{tabular}{cccccccc}
\hline Minimum & Maximum & Range & Mean & Std. Dev. & Variance & Skewness & Kurtosis \\
\hline 292.93 & 309.10 & 16.17 & 299.11 & 2.84 & 8.09 & 0.58 & 2.71 \\
\hline
\end{tabular}

Ordering the above-mentioned four measured responses as follows: (i) outlet air temperature $T_{a, \text { out(Tidbit) }}$; (ii) outlet air temperature $T_{a, \text { out (Hobo) }}$; (iii) outlet water temperature $T_{w, \text { out }}^{\text {meas }}$; and (iv) outlet air relative humidity $R H_{\text {out }}^{\text {meas }}$, yields the following "measured response covariance matrix", denoted as $\operatorname{Cov}\left(T_{a, \text { out (Tidbit) }}, T_{a, \text { out }(\text { Hobo })}, T_{w, \text { out }}^{\text {meas }}, R H_{\text {out }}^{\text {meas }}\right)$ :

$$
\operatorname{Cov}\left(T_{a, \text { out (Tidbit) })}, T_{a, \text { out (Hobo })}, T_{w, \text { out }}^{\text {meas }}, R H_{\text {out }}^{\text {meas }}\right)=\left(\begin{array}{cccc}
8.55 & 8.06 & 1.92 & -28.43 \\
8.06 & 7.68 & 1.91 & -27.04 \\
1.92 & 1.91 & 1.94 & -1.97 \\
-28.43 & -27.04 & -1.97 & 185.72
\end{array}\right) .
$$

For the purposes of uncertainty quantification, data assimilation, model calibration and predictive modeling, the temperatures measurements provided by the "Tidbit" and "Hobo" sensors can be combined into an "averaged" data set of measured air outlet temperatures, which will be denoted as $T_{a, \text { out }}^{\text {meas }}$. The histogram plot and corresponding statistical characteristics of this averaged air outlet temperature are presented in Figure A6 and Table A5, respectively.

Computing the covariance matrix, denoted as $\left[\operatorname{Cov}\left(T_{a, \text { out }}^{\text {meas }}, T_{w, o u t}^{\text {meas }}, R H_{\text {out }}^{\text {meas }}\right)\right]_{\text {data }}$, for all of the relevant experimental data for the averaged outlet air temperature $\left[T_{a, \text { out }}^{\text {meas }}\right]$, the outlet water temperature $\left[T_{w, o u t}^{\text {meas }}\right]$, and the outlet air relative humidity $\left[R H_{\text {out }}^{\text {meas }}\right]$, yields the following result:

$$
\left[\operatorname{Cov}\left(T_{a, \text { out }}^{\text {meas }}, T_{w, \text { out }}^{\text {meas }}, R H_{\text {out }}^{\text {meas }}\right)\right]_{\text {data }}=\left(\begin{array}{ccc}
8.09 & 1.91 & -27.74 \\
1.91 & 1.94 & -1.97 \\
-27.74 & -1.97 & 185.72
\end{array}\right) \text {. }
$$

A comparison between the results in Equations (A1) and (A2) makes clear that the elimination of the second column and row in Equation (A1) yields a 3-by-3 matrix which has entries basically equivalent to the covariance matrix shown in Equation (A2). Therefore, this means that the temperature distributions measured by the "Tidbit" and "Hobo" sensors do not need to be dealt with as separate data sets for the purposes of uncertainty quantification and predictive modeling.

The standard deviation of the humidity sensor utilized for the measurements $\left(\sigma_{\text {sensor }}=5.0 \%\right.$ for the response $R H^{(1)}$ ) have been already considered by including in the category of the "unsaturated" 
data sets those that have their respective measured relative humidity, $R H^{\text {meas }}$, up to $105.0 \%$. In addition to that, the respective uncertainties of the temperature sensors (standard deviations, $\sigma_{\text {sensor }}=0.2 \mathrm{~K}$ for both responses $T_{a}^{(1)}$ and $T_{w}^{(50)}$ ) must also be taken into consideration for the 6717 data sets. The measuring methods and devices are not dependent with respect to each other, therefore the data standard deviation $\sigma_{\text {statistic }}$, stemming from the statistical analysis of the 6717 benchmark data sets, and the sensor standard deviation, $\sigma_{\text {sensor }}$, stemming from the instrument's uncertainty, must stack according to the well-known formula of "addition of the variances of uncorrelated variates", i.e.,:

$$
\sigma=\sqrt{\sigma_{\text {statistic }^{2}+\sigma_{\text {sensor }}^{2}}}
$$

Coupling the above relation with the result presented in Equation (A2) will lead to incremented values of the variances on the diagonal of the respective "measured covariance matrix"; this new form of the covariance matrix which will be denoted as $\operatorname{Cov}\left(T_{a, \text { out }}^{\text {meas }}, T_{w, \text { out }}^{\text {meas }}, R H_{\text {out }}^{\text {meas }}\right)$. The obtained result is:

$$
\operatorname{Cov}\left(T_{a, \text { out }}^{\text {meas }}, T_{w, \text { out }}^{\text {meas }}, R H_{\text {out }}^{\text {meas }}\right)=\left(\begin{array}{ccc}
8.09 & 1.91 & -27.74 \\
1.91 & 1.94 & -1.97 \\
-27.74 & -1.97 & 195.81
\end{array}\right)
$$

In the predictive modeling formalism (which includes uncertainty quantification, data assimilation, and model calibration) the covariance matrix between the measured parameters and responses is required as an input. In the case of interest, all the parameters and responses can be considered as uncorrelated, except for the measured responses considered in this Appendix and the measured parameters listed in Appendix B. The "parameter-response" covariance matrix in Equation (A5), indicated as $\operatorname{Cov}\left(T_{a, \text { out }}^{\text {meas }}, T_{w, \text { out }}^{\text {meas }}, R H^{\text {meas }}, \alpha_{1}, \ldots, \alpha_{47}\right)$, refers to the above mentioned parameters (namely: dry-bulb air temperature, $T_{d b}$; dew-point air temperature, $T_{d p}$, inlet water temperature, $T_{w, i n}$, atmospheric pressure, $P_{a t m}$, and wind speed $V_{w}$ ) and responses (i.e., average outlet air temperature, outlet water temperature, and outlet air relative humidity):

$$
\operatorname{Cov}\left(T_{a, \text { out }}^{\text {meas }}, T_{w, \text { out }}^{\text {meas }}, R H^{\text {meas }}, \alpha_{1}, \ldots, \alpha_{52}\right)=\left(\begin{array}{cccccccc}
10.36 & 2.81 & 2.22 & -232.64 & 1.30 & 0 & \cdots & 0 \\
1.58 & 1.96 & 2.01 & -23.76 & -0.10 & 0 & \cdots & 0 \\
-35.89 & 2.43 & -0.79 & 720.11 & -5.48 & 0 & \cdots & 0
\end{array}\right) \text {. }
$$

\section{Appendix B. Model Parameters for the SRNL F-Area Cooling Towers}

The mean values and standard deviations for the independent model parameters $\alpha_{i},\left(i=1, \ldots, N_{\alpha}=47\right)$, presented in Table B1, below, have been derived in collaboration with

\begin{tabular}{|c|c|c|c|c|c|c|}
\hline $\begin{array}{l}\text { Index } i \\
\text { of } \alpha_{i}\end{array}$ & Independent Scalar Parameters & $\mathrm{C}++$ String & Math. Notation & Nominal Value(s) & $\begin{array}{l}\text { Absolute } \\
\text { Std. Dev. }\end{array}$ & $\begin{array}{l}\text { Rel. Std. } \\
\text { Dev. (\%) }\end{array}$ \\
\hline 1 & Air temperature (dry bulb) (K) & $\mathrm{tdb}$ & $T_{d b}$ & 298.882 & 4.034 & 1.35 \\
\hline 3 & Inlet water temperature $(\mathrm{K})$ & twin & $T_{w, i n}$ & 298.893 & 1.687 & 0.56 \\
\hline 4 & Atmospheric pressure $(\mathrm{Pa})$ & patm & $P_{a t m}$ & 100,588 & 408.26 & 0.41 \\
\hline 7 & $\begin{array}{l}\text { Dynamic viscosity of air at } \\
\mathrm{T}=300 \mathrm{~K}(\mathrm{~kg} / \mathrm{m} \cdot \mathrm{s})\end{array}$ & muair & $\mu$ & $1.983 \times 10^{-5}$ & $9.676 \times 10^{-7}$ & 4.88 \\
\hline 8 & $\begin{array}{l}\text { Kinematic viscosity of air at } \\
\mathrm{T}=300 \mathrm{~K}\left(\mathrm{~m}^{2} / \mathrm{s}\right)\end{array}$ & nuair & $v$ & $1.568 \times 10^{-5}$ & $1.895 \times 10^{-6}$ & 12.09 \\
\hline 9 & $\begin{array}{l}\text { Thermal conductivity of air at } \\
\mathrm{T}=300 \mathrm{~K}(\mathrm{~W} / \mathrm{m} \cdot \mathrm{K})\end{array}$ & tcair & $k_{\text {air }}$ & 0.02624 & $1.584 \times 10^{-3}$ & 6.04 \\
\hline
\end{tabular}
Dr. Sebastian Aleman of SRNL (private communications, 2016).

Table B1. Parameters for SRNL F-area cooling towers. 
Table B1. Cont.

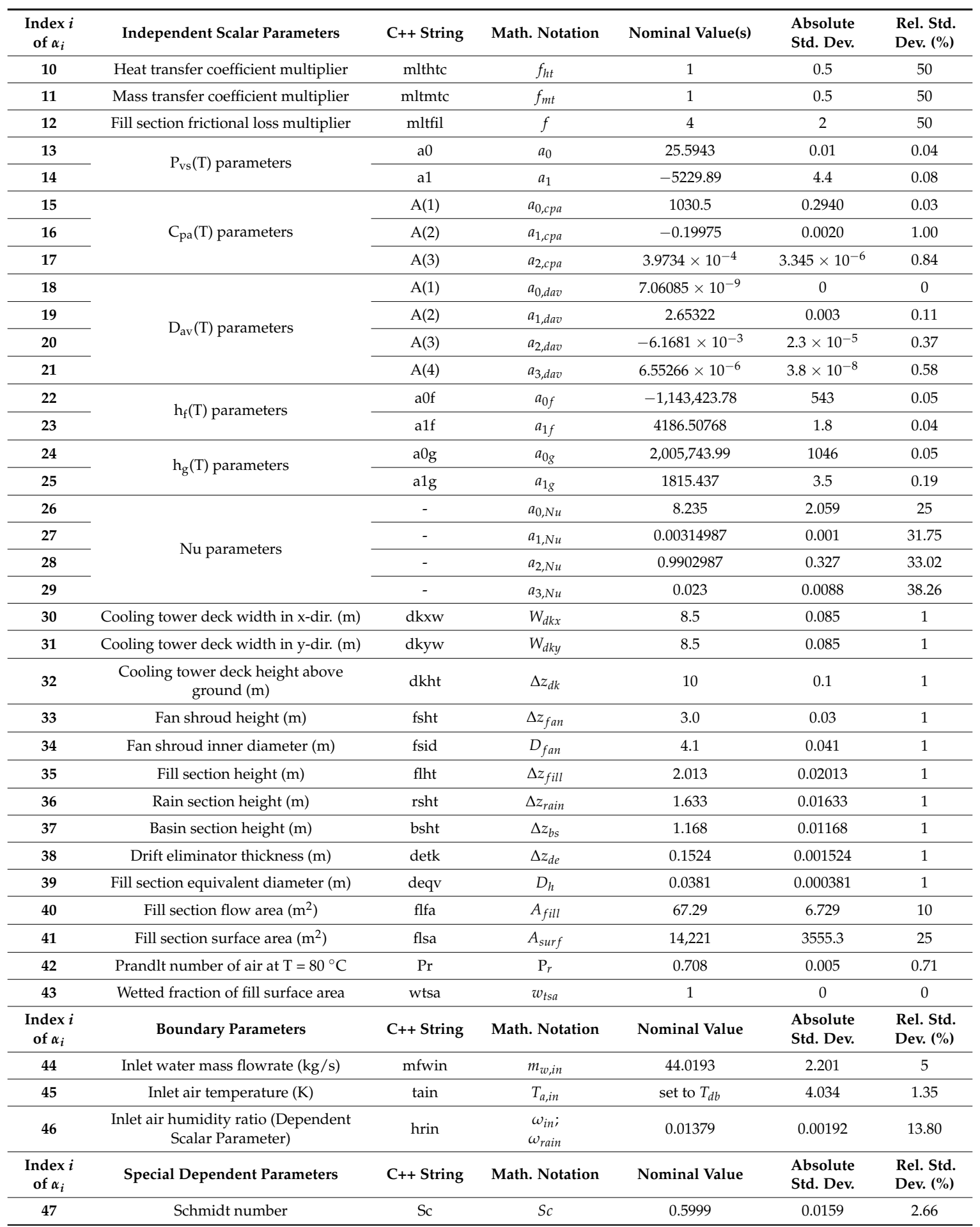

The above independent model parameters are used for computing various dependent model parameters and thermal material properties, as shown in Tables B2 and B3, below. 
Table B2. Dependent scalar model parameters.

\begin{tabular}{|c|c|c|}
\hline Dependent Scalar Parameters & Math. Notation & Defining Equation or Correlation \\
\hline Mass diffusivity of water vapor in air $\left(\mathrm{m}^{2} / \mathrm{s}\right)$ & $D_{a v}\left(T_{a}, \boldsymbol{\alpha}\right)$ & $\frac{a_{0, d a v} T^{1.5}}{a_{1 d a v}+\left(a_{2} d a v+a_{3 d a v} T\right) T}$ \\
\hline Heat transfer coefficient $\left(\mathrm{W} / \mathrm{m}^{2} \cdot \mathrm{K}\right)$ & $h(\boldsymbol{\alpha})$ & $\frac{f_{h t} N_{u} k_{a i r}}{D_{h}}$ \\
\hline Mass transfer coefficient $(\mathrm{m} / \mathrm{s})$ & $k_{m}(\boldsymbol{\alpha})$ & $\frac{f_{m t} S_{h} D_{a v}\left(T_{d b}, \boldsymbol{\alpha}\right)}{D_{h}}$ \\
\hline Heat transfer term $(\mathrm{W} / \mathrm{K})$ & $H\left(m_{a}, \boldsymbol{\alpha}\right)$ & $h(\boldsymbol{\alpha}) w_{t s a} A_{f f}$ \\
\hline Mass transfer term $\left(\mathrm{m}^{3} / \mathrm{s}\right)$ & $M\left(m_{a}, \boldsymbol{\alpha}\right)$ & $M_{\mathrm{H}_{2} \mathrm{O}} k_{m}(\boldsymbol{\alpha}) w_{t s a} A_{f f}$ \\
\hline Density of dry air $\left(\mathrm{kg} / \mathrm{m}^{3}\right)$ & $\rho(\boldsymbol{\alpha})$ & $\frac{P_{a t m}}{R_{a i r} T_{d h}}$ \\
\hline Air velocity in the fill section $(\mathrm{m} / \mathrm{s})$ & $v_{a}\left(m_{a}, \boldsymbol{\alpha}\right)$ & $\frac{\left|m_{a}\right|}{\rho(\boldsymbol{\alpha}) A_{\text {fill }}}$ \\
\hline Fill falling-film surface area per vertical section $\left(\mathrm{m}^{2}\right)$ & $A_{f f}$ & $\frac{A_{\text {surf }}}{I}$ \\
\hline Rain section inlet flow area $\left(\mathrm{m}^{2}\right)$ & $A_{\text {in }}$ & $W_{d k x} W_{d k y}$ \\
\hline Height for natural convection (m) & $Z$ & $\Delta z_{d k}+\Delta z_{f a n}-\Delta z_{b s}$ \\
\hline Height above fill section $(\mathrm{m})$ & $\Delta z_{4-2}$ & $Z-\Delta z_{\text {fill }}-\Delta z_{\text {rain }}$ \\
\hline Fill section control volume height (m) & $\Delta z$ & $\frac{\Delta z_{\text {fill }}}{I}$ \\
\hline Fill section length, including drift eliminator $(\mathrm{m})$ & $L_{\text {fill }}$ & $\Delta z_{f i l l}+\Delta z_{d e}$ \\
\hline Fan shroud inner radius (m) & $r_{f a n}$ & $0.5 D_{f a n}$ \\
\hline Fan shroud flow area $\left(\mathrm{m}^{2}\right)$ & $A_{\text {out }}$ & $\pi r_{f a n}^{2}$ \\
\hline
\end{tabular}

Table B3. Thermal Properties (Dependent Scalar Model Parameters).

\begin{tabular}{|c|c|c|}
\hline Thermal Properties (Functions of State Variables) & Math. Notation & Defining Equation or Correlation \\
\hline $\mathrm{h}_{\mathrm{f}}\left(\mathrm{T}_{\mathrm{W}}\right)=$ saturated liquid enthalpy $(\mathrm{J} / \mathrm{kg})$ & $h_{f}\left(T_{w}, \boldsymbol{\alpha}\right)$ & $a_{0 f}+a_{1 f} T_{w}$ \\
\hline $\mathrm{H}_{\mathrm{g}}\left(\mathrm{T}_{\mathrm{w}}\right)=$ saturated vapor enthalpy $(\mathrm{J} / \mathrm{kg})$ & $h_{g, w}\left(T_{w}, \boldsymbol{\alpha}\right)$ & $a_{0 g}+a_{1 g} T_{w}$ \\
\hline $\mathrm{H}_{\mathrm{g}}\left(\mathrm{T}_{\mathrm{a}}\right)=$ saturated vapor enthalpy $(\mathrm{J} / \mathrm{kg})$ & $h_{g, a}\left(T_{a}, \boldsymbol{\alpha}\right)$ & $a_{0 g}+a_{1 g} T_{a}$ \\
\hline $\mathrm{C}_{\mathrm{p}}(\mathrm{T})=$ specific heat of dry air $(\mathrm{J} / \mathrm{kg} \mathrm{K})$ & $C_{p}(T, \alpha)$ & $a_{0, c p a}+\left(a_{1, c p a}+a_{2, c p a} T\right) T$ \\
\hline $\mathrm{P}_{\mathrm{vs}}\left(\mathrm{T}_{\mathrm{w}}\right)=$ saturation pressure $(\mathrm{Pa})$ & $P_{v s}\left(T_{w}, \boldsymbol{\alpha}\right)$ & $P_{c} \cdot e^{a_{0}+\frac{a_{1}}{T_{w}}}$, in which $P_{c}=1.0 \mathrm{~Pa}$ \\
\hline $\mathrm{P}_{\mathrm{vs}}\left(\mathrm{T}_{\mathrm{a}}\right)=$ saturation pressure $(\mathrm{Pa})$ & $P_{v s}\left(T_{a}, \boldsymbol{\alpha}\right)$ & $P_{c} \cdot e^{a_{0}+\frac{a_{1}}{T_{a}}}$, in which $P_{c}=1.0 P a$ \\
\hline
\end{tabular}

Note 1: The measurements of parameters $\alpha_{1}-\alpha_{5}$ (i.e., the dry bulb air temperature, dew point temperature, inlet water temperature, atmospheric pressure and wind speed) were taken at the SRNL site, where the F-area cooling towers are located. Out of the 8079 total benchmark data sets [8], 6717 data sets have been considered in this study, since "unsaturated"; through these data sets the statistical properties (means, variance and covariance, skewness and kurtosis) for these model parameters have been derived, as shown in Figures B1-B5 and Tables B4-B8.

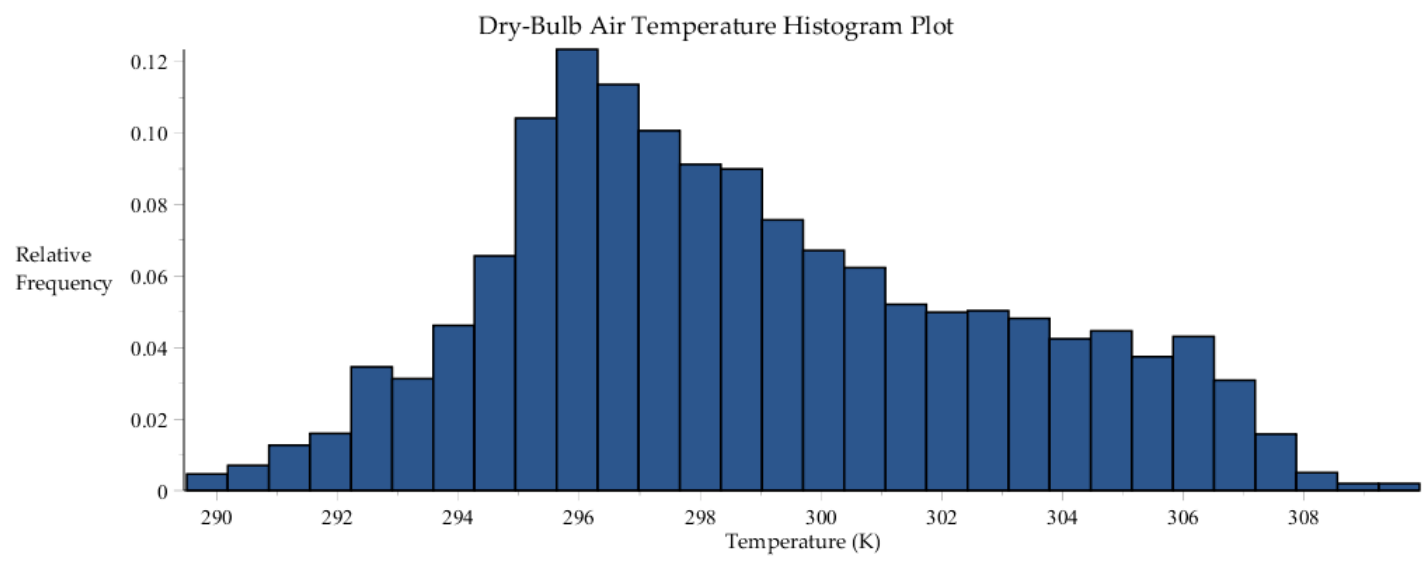

Figure B1. Histogram plot of dry-bulb air temperature data collected by SRNL from F-Area cooling towers. 


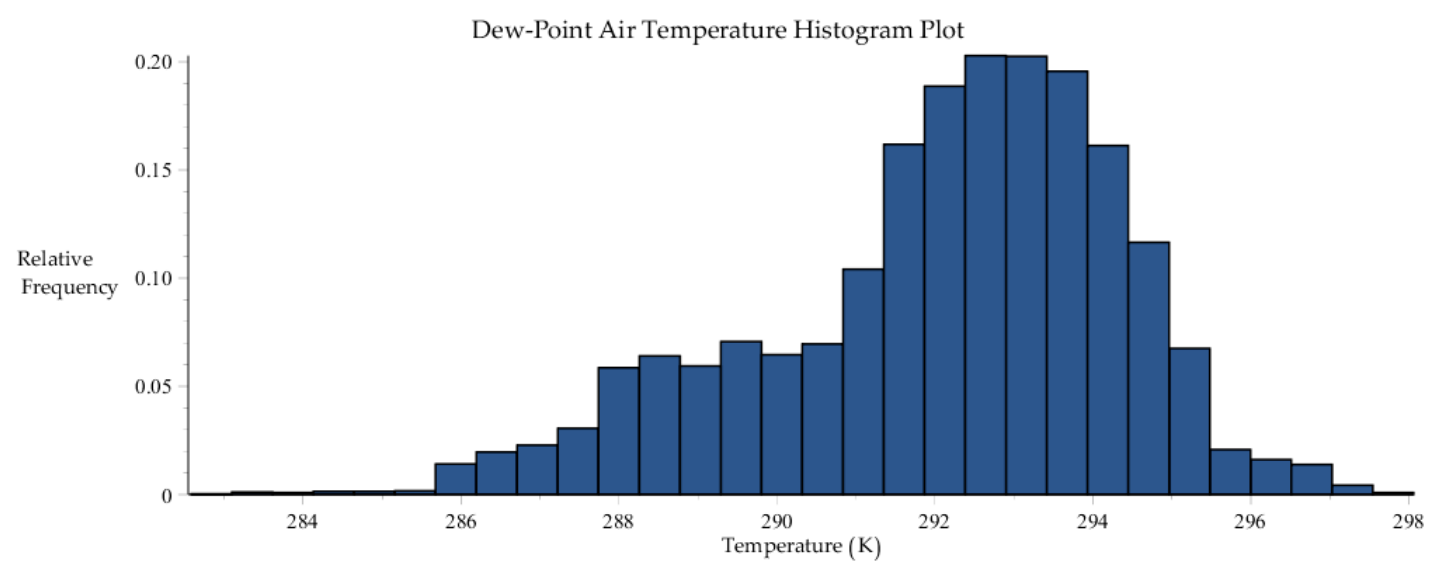

Figure B2. Histogram plot of dew-point air temperature data collected by SRNL from F-Area cooling towers.

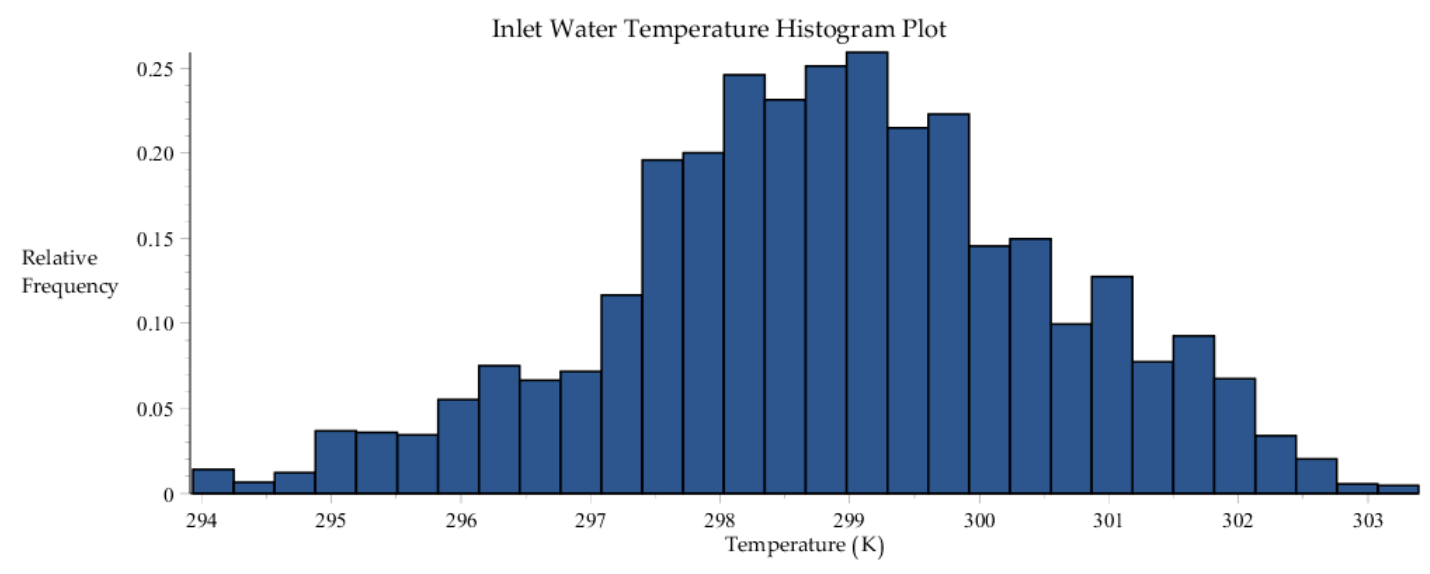

Figure B3. Histogram plot of inlet water temperature data collected by SRNL from F-Area cooling towers.

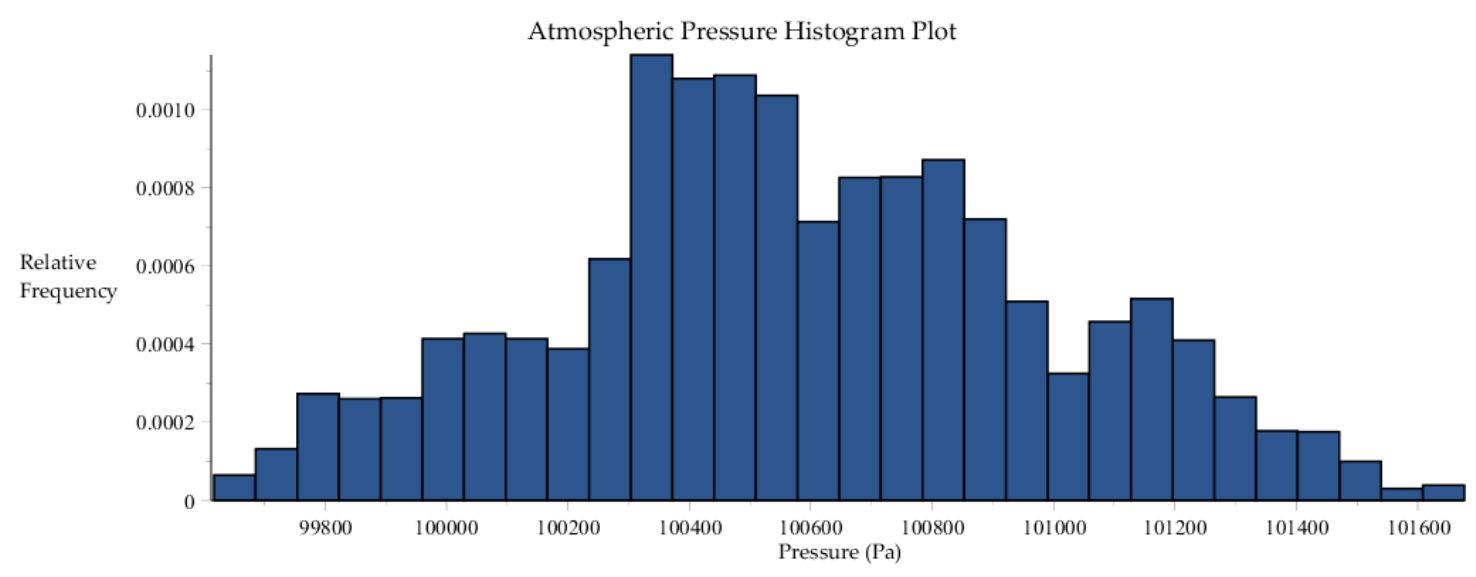

Figure B4. Histogram plot of atmospheric pressure data collected by SRNL from F-Area cooling towers. 


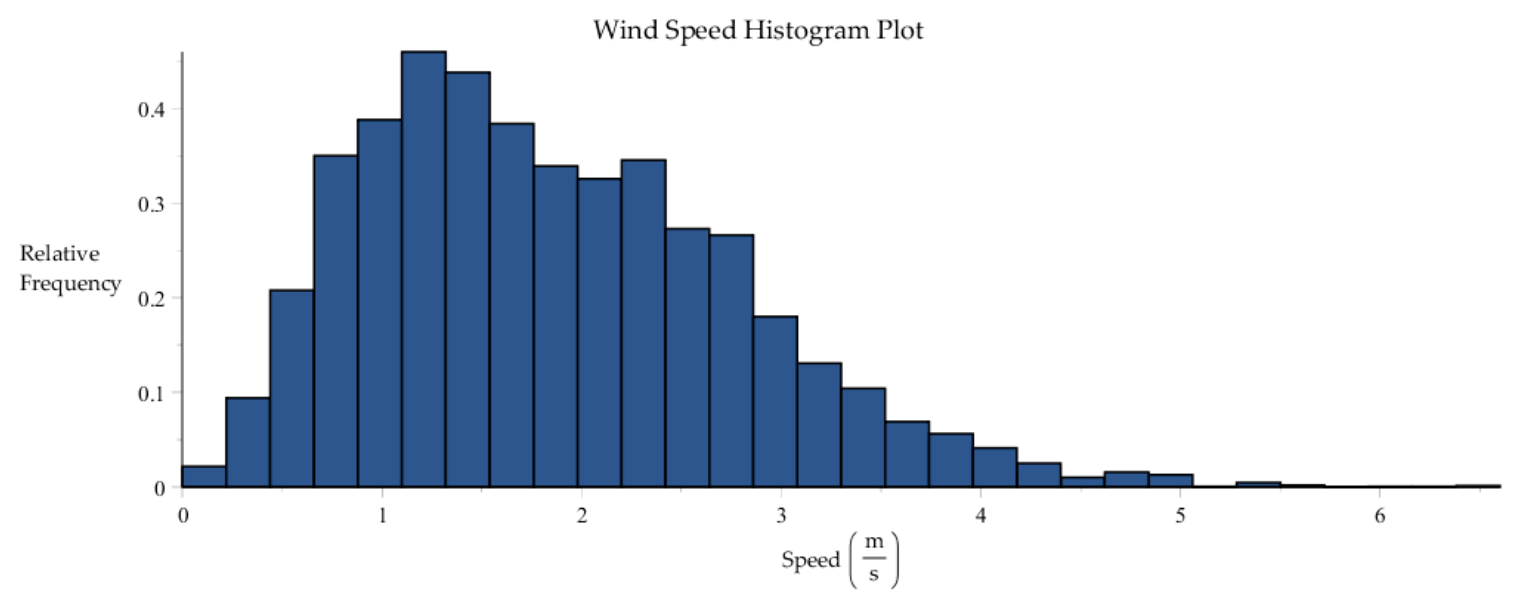

Figure B5. Histogram plot of wind speed data collected by SRNL from F-Area cooling towers.

Table B4. Statistics of the dry-bulb temperature (set to air inlet temperature) distribution [K].

\begin{tabular}{cccccccc}
\hline Minimum & Maximum & Range & Mean & Std. Dev. & Variance & Skewness & Kurtosis \\
\hline 289.50 & 309.91 & 20.41 & 298.88 & 4.03 & 16.27 & 0.36 & 2.38 \\
\hline
\end{tabular}

Table B5. Statistics of the dew-point temperature distribution [K].

\begin{tabular}{cccccccc}
\hline Minimum & Maximum & Range & Mean & Std. Dev. & Variance & Skewness & Kurtosis \\
\hline 282.58 & 298.06 & 15.48 & 292.08 & 2.29 & 5.23 & -0.66 & 3.11 \\
\hline
\end{tabular}

Table B6. Statistics of the inlet water temperature distribution $[\mathrm{K}]$.

\begin{tabular}{cccccccc}
\hline Minimum & Maximum & Range & Mean & Std. Dev. & Variance & Skewness & Kurtosis \\
\hline 293.93 & 303.39 & 9.46 & 298.89 & 1.69 & 2.85 & -0.16 & 2.91 \\
\hline
\end{tabular}

Table B7. Statistics of the atmospheric pressure distribution $[\mathrm{Pa}]$.

\begin{tabular}{cccccccc}
\hline Minimum & Maximum & Range & Mean & Std. Dev. & Variance & Skewness & Kurtosis \\
\hline 99617 & 101,677 & 2060 & 100588 & 408.6 & 166,678 & 0.079 & 2.57 \\
\hline
\end{tabular}

Table B8. Statistics of the wind speed distribution $[\mathrm{m} / \mathrm{s}]$.

\begin{tabular}{cccccccc}
\hline Minimum & Maximum & Range & Mean & Std. Dev. & Variance & Skewness & Kurtosis \\
\hline 0.00 & 6.60 & 6.60 & 1.859 & 0.94 & 0.89 & 0.71 & 3.42 \\
\hline
\end{tabular}

The 5-by-5 covariance matrix for the above experimental data has also been computed and is provided below, with the four model parameters ordered as follows: dry-bulb air temperature $T_{d b}$, dew-point air temperature $T_{d p}$, inlet water temperature $T_{w, i n}$, atmospheric air pressure $P_{a t m}$, and wind speed $V_{w}$.

$$
\operatorname{Cov}\left(T_{d b} ; T_{d p} ; T_{w, i n} ; P_{a t m} ; V_{w}\right)=\left(\begin{array}{ccccc}
16.27 & 3.56 & 2.13 & -494.48 & 2.45 \\
3.56 & 5.23 & 2.22 & -138.46 & 0.28 \\
2.13 & 2.22 & 2.85 & -58.63 & 0.12 \\
-494.48 & -138.46 & -58.63 & 166678.40 & -49.62 \\
2.45 & 0.28 & 0.12 & -49.62 & 0.89
\end{array}\right) .
$$


The covariance matrix (above) neglects the uncertainty associated with sensor readings throughout the data collection period. When combining uncertainties by adding variances, the contribution from the sensors is $0.04 \mathrm{~K}$ for each of the first three parameters, which accounts for a maximum of ca. $1 \%$ of the total variance (for the inlet water temperature, specifically). The uncertainty in the atmospheric pressure sensor is at this time unknown. For these reasons, their contribution to overall uncertainty is considered insignificant at this time.

\section{Appendix C. Derivative Matrix (Jacobian) of the Model Equations with Respect to the State Functions}

As mentioned in Section 2, the Jacobian matrix presents similarities with the Jacobian matrix detailed in [2], Equation (C1). More precisely, the sub-matrices $\left(\mathbf{A}_{i}, \mathbf{B}_{i}, \mathbf{C}_{i}, \mathbf{D}_{i}, \mathbf{E}_{i} ; i=2,3,4,5\right)$ whose elements represents the derivatives of Equations (6)-(14) with respect to the vector valued state function $\mathbf{u} \triangleq\left(\mathbf{m}_{w}, \mathbf{T}_{w}, \mathbf{T}_{a}, \mathbf{w}, m_{a}\right)^{\dagger}$ remain the same as in [2]; for reasons of brevity, they have not been reported in this paper. On the other side, the sub-matrices $\left(\mathbf{A}_{i}, \mathbf{B}_{i}, \mathbf{C}_{i}, \mathbf{D}_{i}, \mathbf{E}_{i} ; i=1\right)$ whose elements represents the derivatives of Equations (2)-(4) with respect to the vector valued state function $\mathbf{u} \triangleq\left(\mathbf{m}_{w}, \mathbf{T}_{w}, \mathbf{T}_{a}, \mathbf{w}, m_{a}\right)^{\dagger}$, are different from their respective formulations in [2], and therefore they will be hereby detailed with the following notation:

$$
\begin{gathered}
a_{1}^{i, j} \equiv \frac{\partial N_{1}^{(i)}}{\partial m_{w}^{(j+1)}} ; \quad i=1, \ldots, I ; j=1, \ldots, I ; \\
b_{1}^{i, j} \equiv \frac{\partial N_{1}^{(i)}}{\partial T_{w}^{(j+1)}} ; \quad i=1, \ldots, I ; j=1, \ldots, I \\
c_{1}^{i, j} \equiv \frac{\partial N_{1}^{(i)}}{\partial T_{a}^{(j)}} ; i=1, \ldots, I ; j=1, \ldots, I \\
d_{1}^{i, j} \equiv \frac{\partial N_{1}^{(i)}}{\partial \omega^{(j)}} ; \quad i=1, \ldots, I ; j=1, \ldots, I \\
e_{1}^{i} \equiv \frac{\partial N_{1}^{(i)}}{\partial m_{a}} ; \quad i=1, \ldots, I .
\end{gathered}
$$

The derivatives of the "liquid continuity equations" (cf., Equations (2)-(4)) with respect to $m_{w}^{(j)}$ are as follows:

$$
\begin{gathered}
\frac{\partial N_{1}^{(i)}}{\partial m_{w}^{(j+1)}} \equiv a_{1}^{i, j}=0 ; i=1, \ldots, I ; j=1, \ldots, I ; j \neq i-1, i \\
\frac{\partial N_{1}^{(i)}}{\partial m_{w}^{(i)}} \equiv a_{1}^{i, i-1}=-1 ; i=2, \ldots, I ; j=i-1 ; \\
\frac{\partial N_{1}^{(i)}}{\partial m_{w}^{(i+1)}} \equiv a_{1}^{i, i}=1 ; i=1, \ldots, I ; j=i .
\end{gathered}
$$

For subsequent use, the above quantities are considered to be the components of the $I \times I$ matrix $\mathbf{A}_{1}$ defined as follows:

$$
\mathbf{A}_{1} \equiv\left(a_{1}^{i, j}\right)_{I \times I}=\left(\begin{array}{ccccc}
1 & 0 & . & 0 & 0 \\
-1 & 1 & . & 0 & 0 \\
. & . & . & . & . \\
0 & 0 & . & 1 & 0 \\
0 & 0 & . & -1 & 1
\end{array}\right)
$$


The derivatives of the "liquid continuity equations" (cf. Equations (2)-(4)) with respect to $T_{w}^{(j)}$ are as follows:

$$
\begin{gathered}
\frac{\partial N_{1}^{(i)}}{\partial T_{w}^{(j+1)}} \equiv b_{1}^{i, j}=0 ; i=1, \ldots, I ; j=1, \ldots, I ; j \neq i ; \\
\frac{\partial N_{1}^{(i)}}{\partial T_{w}^{(i+1)}} \equiv b_{1}^{i, i}=-\frac{M\left(m_{a}, \boldsymbol{\alpha}\right)}{\bar{R}} \frac{P_{v s}^{(i+1)}\left(T_{w}^{(i+1)}, \boldsymbol{\alpha}\right)}{\left[T_{w}^{(i+1)}\right]^{2}}\left\{\frac{a_{1}}{T_{w}^{(i+1)}}+1\right\} ; i=1, \ldots, I ; j=i .
\end{gathered}
$$

For subsequent use, the above quantities are considered to be the components of the $I \times I$ matrix $\mathbf{B}_{1}$ defined as follows:

$$
\mathbf{B}_{1} \equiv\left(b_{1}^{i, j}\right)_{I \times I}=\left(\begin{array}{ccccc}
b_{1}^{1,1} & 0 & \cdot & 0 & 0 \\
0 & b_{1}^{2,2} & \cdot & 0 & 0 \\
\cdot & \cdot & \cdot & \cdot & \cdot \\
0 & 0 & \cdot & b_{1}^{I-1, I-1} & 0 \\
0 & 0 & \cdot & 0 & b_{1}^{I, I}
\end{array}\right) .
$$

The derivatives of the "liquid continuity equations" (cf. Equations (2)-(4)) with respect to $T_{a}^{(j)}$ are as follows:

$$
\begin{gathered}
\frac{\partial N_{1}^{(i)}}{\partial T_{a}^{(j)}} \equiv c_{1}^{i, j}=0 ; i=1, \ldots, I ; j=1, \ldots, I ; j \neq i ; \\
\frac{\partial N_{1}^{(i)}}{\partial T_{a}^{(i)}} \equiv c_{1}^{i, i}=\frac{M\left(m_{a}, \alpha\right)}{\bar{R}} \frac{\omega^{(i)} P_{a t m}}{\left[T_{a}^{(i)}\right]^{2}\left(0.622+\omega^{(i)}\right)} ; i=1, \ldots, I ; j=i .
\end{gathered}
$$

For subsequent use, the above quantities are considered to be the components of the $I \times I$ matrix $\mathrm{C}_{1}$ defined as follows:

$$
\mathbf{C}_{1} \equiv\left(c_{1}^{i, j}\right)_{I \times I}=\left(\begin{array}{ccccc}
c_{1}^{1,1} & 0 & \cdot & 0 & 0 \\
0 & c_{1}^{2,2} & \cdot & 0 & 0 \\
\cdot & \cdot & \cdot & \cdot & \cdot \\
0 & 0 & \cdot & c_{1}^{I-1, I-1} & 0 \\
0 & 0 & \cdot & 0 & c_{1}^{I, I}
\end{array}\right)
$$

The derivatives of the "liquid continuity equations" (cf. Equations (2)-(4)) with respect to $\omega^{(j)}$ are as follows:

$$
\begin{gathered}
\frac{\partial N_{1}^{(i)}}{\partial \omega^{(j)}} \equiv d_{1}^{i, j}=0 ; i=1, \ldots, I ; j=1, \ldots, I ; j \neq i \\
\frac{\partial N_{1}^{(i)}}{\partial \omega^{(i)}} \equiv d_{1}^{i, i}=\frac{M\left(m_{a}, \alpha\right)}{\bar{R}} \frac{P_{a t m}}{\left[0.622+\omega^{(i)}\right] T_{a}^{(i)}}\left\{\frac{\omega^{(i)}}{\left[0.622+\omega^{(i)}\right]}-1\right\} ; i=1, \ldots, I ; j=i .
\end{gathered}
$$

For subsequent use, the above quantities are considered to be the components of the $I \times I$ matrix $\mathbf{D}_{1}$ defined as follows:

$$
\mathbf{D}_{1} \equiv\left(d_{1}^{i, j}\right)_{I \times I}=\left(\begin{array}{ccccc}
d_{1}^{1,1} & 0 & \cdot & 0 & 0 \\
0 & d_{1}^{2,2} & \cdot & 0 & 0 \\
\cdot & \cdot & \cdot & \cdot & \cdot \\
0 & 0 & \cdot & d_{1}^{I-1, I-1} & 0 \\
0 & 0 & \cdot & 0 & d_{1}^{I, I}
\end{array}\right)
$$


The derivatives of the "liquid continuity equations" (cf. Equations (2)-(4)) with respect to $m_{a}$ are as follow follows:

(1) For $\operatorname{Re}_{d}<2300$

$$
\frac{\partial N_{1}^{(i)}}{\partial m_{a}} \equiv e_{1}^{i}=0 ; \quad i=1, \ldots, I
$$

(2) For $2300 \leq \operatorname{Re}_{d} \leq 10,000$

$$
\frac{\partial N_{1}^{(i)}}{\partial m_{a}} \equiv e_{1}^{i}=\left[\frac{P_{v s}\left(T_{w}^{(i+1)}, \boldsymbol{\alpha}\right)}{\bar{R} \cdot T_{w}^{(i+1)}}-\frac{\omega^{(i)} P_{a t m}}{\bar{R} \cdot T_{a}^{(i)}\left(0.622+\omega^{(i)}\right)}\right] \cdot \frac{\partial M_{2}\left(m_{a}, \boldsymbol{\alpha}\right)}{\partial m_{a}} ; i=1, \ldots, I ;
$$

(3) For $\operatorname{Re}_{d}>10,000$

$$
\frac{\partial N_{1}^{(i)}}{\partial m_{a}} \equiv e_{1}^{i}=\left[\frac{P_{v s}\left(T_{w}^{(i+1)}, \boldsymbol{\alpha}\right)}{\bar{R} \cdot T_{w}^{(i+1)}}-\frac{\omega^{(i)} P_{a t m}}{\bar{R} \cdot T_{a}^{(i)}\left(0.622+\omega^{(i)}\right)}\right] \cdot \frac{\partial M_{3}\left(m_{a}, \boldsymbol{\alpha}\right)}{\partial m_{a}} ; i=1, \ldots, I ;
$$

For subsequent use, the above quantities are considered to be the components of the $I$ column vector $\mathbf{E}_{1}$ defined as follows:

$$
\mathbf{E}_{1} \equiv\left(e_{1}^{i}\right)_{I}=\left(\begin{array}{c}
e_{1}^{1} \\
e_{1}^{2} \\
\vdots \\
e_{1}^{I-1} \\
e_{1}^{I}
\end{array}\right)
$$

\section{Appendix D. Derivatives of Cooling Tower Model Equations With Respect to Model Parameters}

The differences between the governing equations for this study and for subcase I in [2] concern only the "liquid continuity equations". Other governing Equations (i.e., liquid energy balance equations; water vapor continuity equations; and the air/water vapor energy balance equations) are the same for both cases.

For this reason, the derivatives of Equations (6)-(14) with respect to the model parameters remain the same as in [3], Equation (A3); for reasons of brevity, they have not been reported in this paper. On the other side, the derivatives of Equations (2)-(4) with respect to the model parameters are different from their respective formulations in [3], and therefore they will be hereby detailed with the following notation:

$$
a_{1}^{i, j} \equiv \frac{\partial N_{1}^{(i)}}{\partial \alpha^{(j)}} ; \quad i=1, \ldots, I ; j=1, \ldots, N_{\alpha} .
$$

For the sake of brevity, only the nonzero derivatives have been reported in this appendix.

The derivatives of the "liquid continuity equations" (cf. Equations (2)-(4)) with respect to the parameter $\alpha^{(1)}: T_{d b}$ are as follows:

$$
\begin{gathered}
\frac{\partial N_{1}^{(i)}}{\partial \alpha^{(1)}}=\frac{\partial N_{1}^{(i)}}{\partial T_{d b}} \equiv a_{1}^{i, 1}=\frac{1}{\bar{R}}\left[\frac{P_{v s}^{(i+1)}\left(T_{w}^{(i+1)}, \boldsymbol{\alpha}\right)}{T_{w}^{(i+1)}}-\frac{\omega^{(i)} P_{a t m}}{\left(0.622+\omega^{(i)}\right) T_{a}^{(i)}}\right] \frac{\partial M\left(m_{a}, \boldsymbol{\alpha}\right)}{\partial D_{a v}\left(T_{d b}, \boldsymbol{\alpha}\right)} \cdot \frac{\partial D_{a v}\left(T_{d b}, \boldsymbol{\alpha}\right)}{\partial T_{d b}} . \\
\ell=1 ; i=1, \ldots, I ; j=1
\end{gathered}
$$

where:

$$
\begin{gathered}
\frac{\partial M\left(m_{a}, \boldsymbol{\alpha}\right)}{\partial D_{a v}\left(T_{d b}, \boldsymbol{\alpha}\right)}=\frac{2}{3} \cdot \frac{M\left(m_{a}, \boldsymbol{\alpha}\right)}{D_{a v}\left(T_{d b}, \boldsymbol{\alpha}\right)} \\
\frac{\partial D_{a v}\left(T_{d b}, \boldsymbol{\alpha}\right)}{\partial T_{d b}}=\frac{1.5 \cdot a_{0 d a v} T_{d b} 0.5-D_{a v}\left(T_{d b}, \boldsymbol{\alpha}\right) \cdot\left(a_{2 d a v}+2 \cdot a_{3 d a v} T_{d b}\right)}{a_{1 d a v}+a_{2 d a v} T_{d b}+a_{3 d a v} T_{d b}{ }^{2}}
\end{gathered}
$$


The derivatives of the "liquid continuity equations" (cf. Equations (2)-(4)) with respect to the parameter $\alpha^{(4)}: P_{\text {atm }}$ are as follows:

$$
\begin{aligned}
\frac{\partial N_{1}^{(i)}}{\partial \alpha^{(4)}}=\frac{\partial N_{1}^{(i)}}{\partial P_{a t m}} & \equiv a_{1}^{i, 4}=-\frac{M\left(m_{a}, \boldsymbol{\alpha}\right)}{\bar{R}} \frac{\omega^{(i)}}{T_{a}^{(i)}\left(0.622+\omega^{(i)}\right)} ; \\
\ell & =1 ; i=1, \ldots, I ; j=4,
\end{aligned}
$$

The derivatives of the "liquid continuity equations" (cf. Equations (2)-(4)) with respect to the parameter $\alpha^{(7)}: \mu$ are as follows:

$$
\begin{gathered}
\frac{\partial N_{1}^{(i)}}{\partial \alpha^{(7)}}=\frac{\partial N_{1}^{(i)}}{\partial \mu} \equiv a_{1}^{i, 7}=\frac{1}{\bar{R}}\left[\frac{P_{v s}^{(i+1)}\left(T_{w}^{(i+1)}, \boldsymbol{\alpha}\right)}{T_{w}^{(i+1)}}-\frac{\omega^{(i)} P_{a t m}}{\left(0.622+\omega^{(i)}\right) T_{a}^{(i)}}\right] \frac{\partial M\left(m_{a}, \boldsymbol{\alpha}\right)}{\partial \mu} ; \\
\ell=1 ; i=1, \ldots, I ; j=7 .
\end{gathered}
$$

where:

$$
\frac{\partial M\left(m_{a}, \boldsymbol{\alpha}\right)}{\partial \mu}= \begin{cases}0 & \operatorname{Re}_{d}<2300 \\ -\frac{a_{1, N} \cdot M\left(m_{a}, \boldsymbol{\alpha}\right) \cdot \operatorname{Re}\left(m_{a}, \boldsymbol{\alpha}\right)}{N u(\operatorname{Re}, \boldsymbol{\alpha}) \cdot \mu} & 2300 \leq \operatorname{Re}_{d} \leq 10,000 \\ -0.8 \cdot \frac{M\left(m_{a}, \boldsymbol{\alpha}\right)}{\mu} & \operatorname{Re}_{d}>10,000\end{cases}
$$

The derivatives of the "liquid continuity equations" (cf. Equations (2)-(4)) with respect to the parameter $\alpha^{(8)}: v$ are as follows:

$$
\begin{gathered}
\frac{\partial N_{1}^{(i)}}{\partial \alpha^{(8)}}=\frac{\partial N_{1}^{(i)}}{\partial v} \equiv a_{1}^{i, 8}=\frac{1}{\bar{R}}\left[\frac{P_{v s}^{(i+1)}\left(T_{w}^{(i+1)}, \boldsymbol{\alpha}\right)}{T_{w w}^{(i+1)}}-\frac{\omega^{(i)} P_{a t m}}{\left(0.622+\omega^{(i)}\right) T_{a}^{(i)}}\right] \frac{\partial M\left(m_{a}, \boldsymbol{\alpha}\right)}{\partial v} ; \\
\ell=1 ; i=1, \ldots, I ; j=8 .
\end{gathered}
$$

where:

$$
\frac{\partial M\left(m_{a}, \boldsymbol{\alpha}\right)}{\partial v}=\frac{1}{3} \frac{M\left(m_{a}, \boldsymbol{\alpha}\right)}{v} .
$$

The derivatives of the "liquid continuity equations" (cf. Equations (A1)-(A4)) with respect to the parameter $\alpha^{(11)}: f_{m t}$ are as follows:

$$
\begin{gathered}
\frac{\partial N_{1}^{(i)}}{\partial \alpha^{(11)}}=\frac{\partial N_{1}^{(i)}}{\partial f_{m t}} \equiv a_{1}^{i, 11}=\frac{1}{\bar{R}}\left[\frac{P_{v s}^{(i+1)}\left(T_{w}^{(i+1)}, \boldsymbol{\alpha}\right)}{T_{w}^{(i+1)}}-\frac{\omega^{(i)} P_{a t m}}{\left(0.622+\omega^{(i)}\right) T_{a}^{(i)}}\right] \frac{\partial M\left(m_{a}, \boldsymbol{\alpha}\right)}{\partial f_{m t}} \\
\ell=1 ; i=1, \ldots, I ; j=11 .
\end{gathered}
$$

where:

$$
\frac{\partial M\left(m_{a}, \boldsymbol{\alpha}\right)}{\partial f_{m t}}=\frac{M_{H 2 O} N u(\operatorname{Re}, \boldsymbol{\alpha})\left(\frac{v}{\operatorname{Pr}}\right)^{\frac{1}{3}}\left[D_{a v}\left(T_{d b}, \boldsymbol{\alpha}\right)\right]^{\frac{2}{3}} w_{t s a} A_{\text {surf }}}{\mathrm{D}_{h} I} .
$$

The derivatives of the "liquid continuity equations" (cf. Equations (2)-(4)) with respect to the parameter $\alpha^{(13)}: a_{0}$ are as follows:

$$
\frac{\partial N_{1}^{(i)}}{\partial \alpha^{(13)}}=\frac{\partial N_{1}^{(i)}}{\partial a_{0}} \equiv a_{1}^{i, 13}=\frac{M\left(m_{a}, \boldsymbol{\alpha}\right)}{\bar{R}} \frac{1}{T_{w}^{(i+1)}} \frac{\partial P_{v s}^{(i+1)}\left(T_{w}^{(i+1)}, \boldsymbol{\alpha}\right)}{\partial a_{0}} ; \ell=1 ; i=1, \ldots, I ; j=13 .
$$

where:

$$
\frac{\partial P_{v s}^{(i+1)}\left(T_{w}^{(i+1)}, \boldsymbol{\alpha}\right)}{\partial a_{0}}=P_{v s}^{(i+1)}\left(T_{w}^{(i+1)}, \boldsymbol{\alpha}\right) .
$$

The derivatives of the "liquid continuity equations" (cf. Equations (2)-(4)) with respect to the parameter $\alpha^{(14)}: a_{1}$ are as follows:

$$
\frac{\partial N_{1}^{(i)}}{\partial \alpha^{(14)}}=\frac{\partial N_{1}^{(i)}}{\partial a_{1}} \equiv a_{1}^{i, 14}=\frac{M\left(m_{a}, \boldsymbol{\alpha}\right)}{\bar{R}} \frac{1}{T_{w}^{(i+1)}} \frac{\partial P_{v s}^{(i+1)}\left(T_{w}^{(i+1)}, \boldsymbol{\alpha}\right)}{\partial a_{1}} ; \ell=1 ; i=1, \ldots, I ; j=14 .
$$


where:

$$
\frac{\partial P_{v s}^{(i+1)}\left(T_{w}^{(i+1)}, \boldsymbol{\alpha}\right)}{\partial a_{1}}=\frac{P_{v s}^{(i+1)}\left(T_{w}^{(i+1)}, \boldsymbol{\alpha}\right)}{T_{w}^{(i+1)}} .
$$

The derivatives of the "liquid continuity equations" (cf. Equations (2)-(4)) with respect to the parameter $\alpha^{(18)}: a_{0, \text { dav }}$ are as follows:

$$
\begin{gathered}
\frac{\partial N_{1}^{(i)}}{\partial \alpha^{(18)}}=\frac{\partial N_{1}^{(i)}}{\partial a_{0, d a v}} \equiv a_{1}^{i, 18}=\frac{1}{\bar{R}}\left[\frac{P_{v s}^{(i+1)}\left(T_{w}^{(i+1)}, \boldsymbol{\alpha}\right)}{T_{w}^{(i+1)}}-\frac{\omega^{(i)} P_{a t m}}{\left(0.622+\omega^{(i)}\right) T_{a}^{(i)}}\right] \frac{\partial M\left(m_{a}, \boldsymbol{\alpha}\right)}{\partial D_{a v}\left(T_{d b}, \boldsymbol{\alpha}\right)} \cdot \frac{\partial D_{a v}\left(T_{d b}, \boldsymbol{\alpha}\right)}{\partial a_{0, d a v}} \\
\ell=1 ; i=1, \ldots, I ; j=18 .
\end{gathered}
$$

where $\frac{\partial M\left(m_{a}, \boldsymbol{\alpha}\right)}{\partial D_{a v}\left(T_{d b}, \boldsymbol{\alpha}\right)}$ was defined previously in Equation (D3), and

$$
\frac{\partial D_{a v}\left(T_{d b}, \boldsymbol{\alpha}\right)}{\partial a_{0, d a v}}=\frac{T_{d b}{ }^{1.5}}{a_{1 d a v}+a_{2 d a v} T_{d b}+a_{3 d a v} T_{d b}{ }^{2}} .
$$

The derivatives of the "liquid continuity equations" (cf. Equations (2)-(4)) with respect to the parameter $\alpha^{(19)}: a_{1, \text { dav }}$ are as follows:

$$
\begin{gathered}
\frac{\partial N_{1}^{(i)}}{\partial \alpha^{(19)}}=\frac{\partial N_{1}^{(i)}}{\partial a_{1, d a v}} \equiv a_{1}^{i, 19}=\frac{1}{\bar{R}}\left[\frac{P_{v s}^{(i+1)}\left(T_{w}^{(i+1)}, \boldsymbol{\alpha}\right)}{T_{w}^{(i+1)}}-\frac{\omega^{(i)} P_{a t m}}{\left(0.622+\omega^{(i)}\right) T_{a}^{(i)}}\right] \frac{\partial M\left(m_{a}, \boldsymbol{\alpha}\right)}{\partial D_{a v}\left(T_{d b}, \boldsymbol{\alpha}\right)} \cdot \frac{\partial D_{a v}\left(T_{d b}, \boldsymbol{\alpha}\right)}{\partial a_{1, d a v}} ; \\
\ell=1 ; i=1, \ldots, I ; j=19 .
\end{gathered}
$$

where $\frac{\partial M\left(m_{a}, \boldsymbol{\alpha}\right)}{\partial D_{a v}\left(T_{d b}, \boldsymbol{\alpha}\right)}$ was defined previously in Equation (D3), and

$$
\frac{\partial D_{a v}\left(T_{d b}, \boldsymbol{\alpha}\right)}{\partial a_{1, d a v}}=-\frac{a_{0 d a v} T_{d b}{ }^{1.5}}{\left(a_{1 d a v}+a_{2 d a v} T_{d b}+a_{3 d a v} T_{d b}\right)^{2}} .
$$

The derivatives of the "liquid continuity equations" (cf. Equations (2)-(4)) with respect to the parameter $\alpha^{(20)}: a_{2, \text { dav }}$ are as follows:

$$
\begin{gathered}
\frac{\partial N_{1}^{(i)}}{\partial \alpha^{(20)}}=\frac{\partial N_{1}^{(i)}}{\partial a_{2, d a v}} \equiv a_{1}^{i, 20}=\frac{1}{R}\left[\frac{P_{v s}^{(i+1)}\left(T_{w}^{(i+1)}, \boldsymbol{\alpha}\right)}{T_{w}^{(i+1)}}-\frac{\omega^{(i)} P_{a t m}}{\left(0.622+\omega^{(i)}\right) T_{a}^{(i)}}\right] \frac{\partial M\left(m_{a}, \boldsymbol{\alpha}\right)}{\partial D_{a v}\left(T_{d b}, \boldsymbol{\alpha}\right)} \cdot \frac{\partial D_{a v}\left(T_{d b}, \boldsymbol{\alpha}\right)}{\partial a_{2, d a v}} ; \\
\ell=1 ; i=1, \ldots, I ; j=20 .
\end{gathered}
$$

where $\frac{\partial M\left(m_{a}, \boldsymbol{\alpha}\right)}{\partial D_{a v}\left(T_{d b}, \boldsymbol{\alpha}\right)}$ was defined previously in Equation (D3), and

$$
\frac{\partial D_{a v}\left(T_{d b}, \boldsymbol{\alpha}\right)}{\partial a_{2, d a v}}=-\frac{a_{0 d a v} T_{d b}^{2.5}}{\left(a_{1 d a v}+a_{2 d a v} T_{d b}+a_{3 d a v} T_{d b}\right)^{2}} .
$$

The derivatives of the "liquid continuity equations" (cf. Equations (2)-(4)) with respect to the parameter $\alpha^{(21)}: a_{3, \text { dav }}$ are as follows:

$$
\begin{gathered}
\frac{\partial N_{1}^{(i)}}{\partial \alpha^{(21)}}=\frac{\partial N_{1}^{(i)}}{\partial a_{3, d a v}} \equiv a_{1}^{i, 21}=\frac{1}{\bar{R}}\left[\frac{P_{v s}^{(i+1)}\left(T_{w}^{(i+1)}, \boldsymbol{\alpha}\right)}{T_{w}^{(i+1)}}-\frac{\omega^{(i)} P_{a t m}}{\left(0.622+\omega^{(i)}\right) T_{a}^{(i)}}\right] \frac{\partial M\left(m_{a}, \boldsymbol{\alpha}\right)}{\partial D_{a v}\left(T_{d b}, \boldsymbol{\alpha}\right)} \cdot \frac{\partial D_{a v}\left(T_{d b}, \boldsymbol{\alpha}\right)}{\partial a_{3, d a v}} ; \\
\ell=1 ; i=1, \ldots, I ; j=21 .
\end{gathered}
$$

where $\frac{\partial M\left(m_{a}, \boldsymbol{\alpha}\right)}{\partial D_{a v}\left(T_{d b}, \boldsymbol{\alpha}\right)}$ was defined previously in Equation (D3), and

$$
\frac{\partial D_{a v}\left(T_{d b}, \boldsymbol{\alpha}\right)}{\partial a_{3, d a v}}=-\frac{a_{0 d a v} T_{d b}{ }^{3.5}}{\left(a_{1 d a v}+a_{2 d a v} T_{d b}+a_{3 d a v} T_{d b}^{2}\right)^{2}} .
$$


The derivatives of the "liquid continuity equations" (cf. Equations (2)-(4)) with respect to the parameter $\alpha^{(26)}: a_{0, N u}$ are as follows:

$$
\begin{gathered}
\frac{\partial N_{1}^{(i)}}{\partial \alpha^{(26)}}=\frac{\partial N_{1}^{(i)}}{\partial a_{0, N u}} \equiv a_{1}^{i, 26}=\frac{1}{\bar{R}}\left[\frac{P_{v s}^{(i+1)}\left(T_{w}^{(i+1)}, \boldsymbol{\alpha}\right)}{T_{w}^{(i+1)}}-\frac{\omega^{(i)} P_{a t m}}{\left(0.622+\omega^{(i)}\right) T_{a}^{(i)}}\right] \frac{\partial M\left(m_{a}, \boldsymbol{\alpha}\right)}{\partial N u(\operatorname{Re}, \boldsymbol{\alpha})} \frac{\partial N u(\operatorname{Re}, \boldsymbol{\alpha})}{\partial a_{0, N u}} ; \\
\ell=1 ; i=1, \ldots, I ; j=26 .
\end{gathered}
$$

where

$$
\begin{gathered}
\frac{\partial M(\operatorname{Re}, \boldsymbol{\alpha})}{\partial N u(\operatorname{Re}, \boldsymbol{\alpha})}=\frac{M\left(m_{a}, \boldsymbol{\alpha}\right)}{N u(\operatorname{Re}, \boldsymbol{\alpha})} \\
\frac{\partial N u(\operatorname{Re}, \boldsymbol{\alpha})}{\partial a_{0, N u}}= \begin{cases}1 & \operatorname{Re}_{d}<2300 \\
0 & 2300 \leq \operatorname{Re}_{d} \leq 10,000 \\
0 & \operatorname{Re}_{d}>10,000\end{cases}
\end{gathered}
$$

The derivatives of the "liquid continuity equations" (cf. Equations (2)-(4)) with respect to the parameter $\alpha^{(27)}: a_{1, \mathrm{~N} u}$ are as follows:

$$
\begin{gathered}
\frac{\partial N_{1}^{(i)}}{\partial \alpha^{(27)}}=\frac{\partial N_{1}^{(i)}}{\partial a_{1, N u}} \equiv a_{1}^{i, 27}=\frac{1}{\bar{R}}\left[\frac{P_{v s}^{(i+1)}\left(T_{w}^{(i+1)}, \boldsymbol{\alpha}\right)}{T_{w}^{(i+1)}}-\frac{\omega^{(i)} P_{a t m}}{\left(0.622+\omega^{(i)}\right) T_{a}^{(i)}}\right] \frac{\partial M\left(m_{a}, \boldsymbol{\alpha}\right)}{\partial N u(\operatorname{Re}, \boldsymbol{\alpha})} \frac{\partial N u(\operatorname{Re}, \boldsymbol{\alpha})}{\partial a_{1, N u}} \\
\ell=1 ; i=1, \ldots, I ; j=27 .
\end{gathered}
$$

where $\frac{\partial M\left(m_{a}, \boldsymbol{\alpha}\right)}{\partial N u(\operatorname{Re}, \boldsymbol{\alpha})}$ was defined previously in Equation (D25), and

$$
\frac{\partial N u(\operatorname{Re}, \boldsymbol{\alpha})}{\partial a_{1, N u}}= \begin{cases}0 & \operatorname{Re}_{d}<2300 \\ \operatorname{Re}\left(m_{a}, \boldsymbol{\alpha}\right) & 2300 \leq \operatorname{Re}_{d} \leq 10,000 \\ 0 & \operatorname{Re}_{d}>10,000\end{cases}
$$

The derivatives of the "liquid continuity equations" (cf. Equations (2)-(4)) with respect to the parameter $\alpha^{(28)}: a_{2, \mathrm{Nu}}$ are as follows:

$$
\begin{gathered}
\frac{\partial N_{1}^{(i)}}{\partial \alpha^{(28)}}=\frac{\partial N_{1}^{(i)}}{\partial a_{2, N u}} \equiv a_{1}^{i, 28}=\frac{1}{\bar{R}}\left[\frac{P_{v s}^{(i+1)}\left(T_{w}^{(i+1)}, \boldsymbol{\alpha}\right)}{T_{w}^{(i+1)}}-\frac{\omega^{(i)} P_{a t m}}{\left(0.622+\omega^{(i)}\right) T_{a}^{(i)}}\right] \frac{\partial M\left(m_{a}, \boldsymbol{\alpha}\right)}{\partial N u(\operatorname{Re}, \boldsymbol{\alpha})} \frac{\partial N u(\operatorname{Re}, \boldsymbol{\alpha})}{\partial a_{2, N u}} ; \\
\ell=1 ; i=1, \ldots, I ; j=28 .
\end{gathered}
$$

where $\frac{\partial M\left(m_{a}, \boldsymbol{\alpha}\right)}{\partial N u(\operatorname{Re}, \boldsymbol{\alpha})}$ was defined previously in Equation (D25), and

$$
\frac{\partial N u(\operatorname{Re}, \boldsymbol{\alpha})}{\partial a_{2, N u}}= \begin{cases}0 & \operatorname{Re}_{d}<2300 \\ 1 & 2300 \leq \operatorname{Re}_{d} \leq 10,000 \\ 0 & \operatorname{Re}_{d}>10,000\end{cases}
$$

The derivatives of the "liquid continuity equations" (cf. Equations (2)-(4)) with respect to the parameter $\alpha^{(29)}: a_{3, \mathrm{Nu}}$ are as follows:

$$
\begin{gathered}
\frac{\partial N_{1}^{(i)}}{\partial \alpha^{(29)}}=\frac{\partial N_{1}^{(i)}}{\partial a_{3, N u}} \equiv a_{1}^{i, 29}=\frac{1}{\bar{R}}\left[\frac{P_{v s}^{(i+1)}\left(T_{i v}^{(i+1)}, \boldsymbol{\alpha}\right)}{T_{w}^{(i+1)}}-\frac{\omega^{(i)} P_{a t m}}{\left(0.622+\omega^{(i)}\right) T_{a}^{(i)}}\right] \frac{\partial M\left(m_{a}, \boldsymbol{\alpha}\right)}{\partial N u(\operatorname{Re}, \boldsymbol{\alpha})} \frac{\partial N u(\operatorname{Re}, \boldsymbol{\alpha})}{\partial a_{3, N u}} ; \\
\ell=1 ; i=1, \ldots, I ; j=29 .
\end{gathered}
$$

where $\frac{\partial M\left(m_{a}, \boldsymbol{\alpha}\right)}{\partial N u(\operatorname{Re}, \boldsymbol{\alpha})}$ was defined previously in Equation (D25), and

$$
\frac{\partial N u(\operatorname{Re}, \boldsymbol{\alpha})}{\partial a_{3, N u}}= \begin{cases}0 & \operatorname{Re}_{d}<2300 \\ 0 & 2300 \leq \operatorname{Re}_{d} \leq 10,000 \\ {\left[\operatorname{Re}\left(m_{a}, \boldsymbol{\alpha}\right)\right]^{0.8} \cdot \operatorname{Pr}^{\frac{1}{3}}} & \operatorname{Re}_{d}>10,000\end{cases}
$$


The derivatives of the "liquid continuity equations" (cf. Equations (2)-(4)) with respect to the parameter $\alpha^{(39)}: D_{h}$ are as follows:

$$
\begin{gathered}
\frac{\partial N_{1}^{(i)}}{\partial \alpha^{(39)}}=\frac{\partial N_{1}^{(i)}}{\partial D_{h}} \equiv a_{1}^{i, 39}=\frac{1}{\bar{R}}\left[\frac{P_{\nu s}^{(i+1)}\left(T_{w}^{(i+1)}, \boldsymbol{\alpha}\right)}{T_{w}^{(i+1)}}-\frac{\omega^{(i)} P_{a t m}}{\left(0.622+\omega^{(i)}\right) T_{a}^{(i)}}\right] \frac{\partial M\left(m_{a}, \boldsymbol{\alpha}\right)}{\partial D_{h}} ; \\
\ell=1 ; i=1, \ldots, I ; j=39 .
\end{gathered}
$$

where

$$
\frac{\partial M\left(m_{a}, \boldsymbol{\alpha}\right)}{\partial D_{h}}= \begin{cases}-M\left(m_{a}, \boldsymbol{\alpha}\right) / D_{h} & \operatorname{Re}_{d}<2300 \\ -\frac{a_{2, N u} M\left(m_{a}, \boldsymbol{\alpha}\right)}{N u(\operatorname{Re}, \boldsymbol{\alpha}) D_{h}} & 2300 \leq \operatorname{Re}_{d} \leq 10,000 \\ -0.2 \cdot M\left(m_{a}, \boldsymbol{\alpha}\right) / D_{h} & \operatorname{Re}_{d}>10,000\end{cases}
$$

The derivatives of the "liquid continuity equations" (cf. Equations (2)-(4)) with respect to the parameter $\alpha^{(40)}: A_{\text {fill }}$ are as follows:

$$
\begin{gathered}
\frac{\partial N_{1}^{(i)}}{\partial \alpha^{(40)}}=\frac{\partial N_{1}^{(i)}}{\partial A_{\text {fill }}} \equiv a_{1}^{i, 40}=\frac{1}{\bar{R}}\left[\frac{P_{v s}^{(i+1)}\left(T_{w}^{(i+1)}, \boldsymbol{\alpha}\right)}{T_{w}^{(i+1)}}-\frac{\omega^{(i)} P_{a t m}}{\left(0.622+\omega^{(i)}\right) T_{a}^{(i)}}\right] \frac{\partial M\left(m_{a}, \boldsymbol{\alpha}\right)}{\partial A_{\text {fill }}} \\
\ell=1 ; i=1, \ldots, I ; j=40 .
\end{gathered}
$$

where

$$
\frac{\partial M\left(m_{a}, \boldsymbol{\alpha}\right)}{\partial A_{\text {fill }}}= \begin{cases}0 & \operatorname{Re}_{d}<2300 \\ -\frac{a_{1, N u} M\left(m_{a}, \boldsymbol{\alpha}\right) \operatorname{Re}\left(m_{a}, \boldsymbol{\alpha}\right)}{N u(\operatorname{Re}, \boldsymbol{\alpha}) A_{\text {fill }}} & 2300 \leq \operatorname{Re}_{d} \leq 10,000 \\ -0.8 \cdot M\left(m_{a}, \boldsymbol{\alpha}\right) / A_{\text {fill }} & \operatorname{Re}_{d}>10,000\end{cases}
$$

The derivatives of the "liquid continuity equations" (cf. Equations (2)-(4)) with respect to the parameter $\alpha^{(41)}: A_{\text {surf }}$ are as follows:

$$
\begin{gathered}
\frac{\partial N_{1}^{(i)}}{\partial \alpha^{(41)}}=\frac{\partial N_{1}^{(i)}}{\partial A_{\text {surf }}} \equiv a_{1}^{i, 41}=\frac{1}{\bar{R}}\left[\frac{P_{v s}^{(i+1)}\left(T_{w}^{(i+1)}, \boldsymbol{\alpha}\right)}{T_{w}^{(i+1)}}-\frac{\omega^{(i)} P_{\text {atm }}}{\left(0.622+\omega^{(i)}\right) T_{a}^{(i)}}\right] \frac{\partial M\left(m_{a}, \boldsymbol{\alpha}\right)}{\partial A_{\text {surf }}} \\
\ell=1 ; i=1, \ldots, I ; j=41 .
\end{gathered}
$$

where

$$
\frac{\partial M\left(m_{a}, \boldsymbol{\alpha}\right)}{\partial A_{\text {surf }}}=\frac{M\left(m_{a}, \boldsymbol{\alpha}\right)}{A_{\text {surf }}}
$$

The derivatives of the "liquid continuity equations" (cf. Equations (2)-(4)) with respect to the parameter $\alpha^{(42)}$ : Pr are as follows:

$$
\begin{gathered}
\frac{\partial N_{1}^{(i)}}{\partial \alpha^{(42)}}=\frac{\partial N_{1}^{(i)}}{\partial \operatorname{Pr}} \equiv a_{1}^{i, 42}=\frac{1}{\bar{R}}\left[\frac{P_{v s}^{(i+1)}\left(T_{w}^{(i+1)}, \boldsymbol{\alpha}\right)}{T_{w}^{(i+1)}}-\frac{\omega^{(i)} P_{a t m}}{\left(0.622+\omega^{(i)}\right) T_{a}^{(i)}}\right] \frac{\partial M\left(m_{a}, \boldsymbol{\alpha}\right)}{\partial \operatorname{Pr}} \\
\ell=1 ; i=1, \ldots, I ; j=42 .
\end{gathered}
$$

where

$$
\frac{\partial M\left(m_{a}, \boldsymbol{\alpha}\right)}{\partial \operatorname{Pr}}= \begin{cases}-M\left(m_{a}, \boldsymbol{\alpha}\right) /(3 \cdot \operatorname{Pr}) & \operatorname{Re}_{d} \leq 10,000 \\ 0 & \operatorname{Re}_{d}>10,000\end{cases}
$$

The derivatives of the "liquid continuity equations" (cf. Equations (2)-(4)) with respect to the parameter $\alpha^{(43)}: w_{t s a}$ are as follows:

$$
\begin{gathered}
\frac{\partial N_{1}^{(i)}}{\partial \alpha^{(43)}}=\frac{\partial N_{1}^{(i)}}{\partial w_{t s a}} \equiv a_{1}^{i, 43}=\frac{1}{\bar{R}}\left[\frac{P_{v s}^{(i+1)}\left(T_{w}^{(i+1)}, \boldsymbol{\alpha}\right)}{T_{w}^{(i+1)}}-\frac{\omega^{(i)} P_{a t m}}{\left(0.622+\omega^{(i)}\right) T_{a}^{(i)}}\right] \frac{\partial M\left(m_{a}, \boldsymbol{\alpha}\right)}{\partial w_{t s a}} \\
\ell=1 ; i=1, \ldots, I ; j=43 .
\end{gathered}
$$


where

$$
\frac{\partial M\left(m_{a}, \boldsymbol{\alpha}\right)}{\partial w_{t s a}}=\frac{M_{H 2 O} f_{m t} N u(\operatorname{Re}, \boldsymbol{\alpha})\left(\frac{v}{\operatorname{Pr}}\right)^{\frac{1}{3}}\left[D_{a v}\left(T_{d b}, \boldsymbol{\alpha}\right)\right]^{\frac{2}{3}} A_{s u r f}}{\mathrm{D}_{h} I} .
$$

The derivatives of the "liquid continuity equations" (cf. Equations (2)-(4)) with respect to the parameter $\alpha^{(44)}: m_{w, \text { in }}$ are as follows:

$$
\begin{gathered}
\frac{\partial N_{1}^{(1)}}{\partial \alpha^{(44)}}=\frac{\partial N_{1}^{(1)}}{\partial m_{w, i n}} \equiv a_{1}^{1,44}=-1 ; \quad \ell=1 ; i=1 ; j=44, \\
\frac{\partial N_{1}^{(i)}}{\partial \alpha(44)}=\frac{\partial N_{1}^{(i)}}{\partial m_{w, i n}} \equiv a_{1}^{i, 44}=0 ; \quad \ell=1 ; i=2, \ldots, I ; j=44 .
\end{gathered}
$$

The derivatives of the "liquid continuity equations" (cf. Equations (2)-(4)) with respect to the parameter $\alpha^{(47)}:$ Sc are as follows:

$$
\begin{gathered}
\frac{\partial N_{1}^{(i)}}{\partial \alpha^{(47)}}=\frac{\partial N_{1}^{(i)}}{\partial S c} \equiv a_{1}^{i, 47}=\frac{1}{\bar{R}}\left[\frac{P_{v s}^{(i+1)}\left(T_{w}^{(i+1)}, \boldsymbol{\alpha}\right)}{T_{w}^{(i+1)}}-\frac{\omega^{(i)} P_{a t m}}{\left(0.622+\omega^{(i)}\right) T_{a}^{(i)}}\right] \frac{\partial M\left(m_{a}, \boldsymbol{\alpha}\right)}{\partial S c} ; \\
\ell=1 ; i=1, \ldots, I ; j=47 .
\end{gathered}
$$

where

$$
\frac{\partial M\left(m_{a}, \boldsymbol{\alpha}\right)}{\partial S c}=\frac{1}{3} \frac{M\left(m_{a}, \boldsymbol{\alpha}\right)}{S c} .
$$

\section{Appendix E. Verification of the Model Adjoint Functions}

This appendix provides a complete display of the procedure followed to verify the numerical accuracy of the adjoint functions computed. Five specific adjoint functions $\left(\mu_{a} ; o^{(49)} ; \tau_{a}^{(49)} ; \tau_{w}^{(1)} ; \mu_{w}^{(1)}\right)$ have been selected for each of the five responses of the model $\left(T_{a}^{(1)} ; T_{w}^{(50)} ; R H^{(1)} ; m_{w}^{(50)} ; m_{a}\right)$ in such a way that, once those have been verified, all the other adjoint functions would be consequently verified as well. For clarity reasons, the adjoint functions have been grouped based on the response they refer to.

Appendix E.1. Verification of the Adjoint Functions for the Outlet Air Temperature Response $T_{a}^{(1)}$

When $R=T_{a}^{(1)}$, the quantities $r_{\ell}^{(i)}$ defined in Equations (21)-(22) all vanish except for a single component, namely: $r_{3}^{(1)} \triangleq \partial R / \partial T_{a}^{(1)}=1$. Thus, the adjoint functions corresponding to the outlet air temperature response $T_{a}^{(1)}$ are computed by solving the adjoint sensitivity system given in Equation (20) using $r_{3}^{(1)} \triangleq \partial R / \partial T_{a}^{(1)}=1$ as the only non-zero source term; for this case, the solution of Equation (20) has been depicted in Figure 8.

(a) Verification of the adjoint function $\mu_{a}$

Note that the value of the adjoint function $\mu_{a}$ obtained by solving the adjoint sensitivity system given in Equation (20) is $\mu_{a}=-0.12651\left[\mathrm{~K} /\left(\mathrm{J} / \mathrm{m}^{3}\right)\right]$, as indicated in Figure 8. Now select a variation $\delta V_{w}$ in the wind speed $V_{w}$, and note that Equation (27) yields the following expression for the sensitivity of the response $R=T_{a}^{(1)}$ to $V_{w}$ :

$$
\begin{aligned}
& S_{5} \triangleq \frac{\partial R}{\partial V_{w}}-\left[\sum_{i=1}^{49}\left(\mu_{w}^{(i)} \frac{\partial N_{1}^{(i)}}{\partial V_{w}}+\tau_{w}^{(i)} \frac{\partial N_{2}^{(i)}}{\partial V_{w}}+\tau_{a}^{(i)} \frac{\partial N_{3}^{(i)}}{\partial V_{w}}+o^{(i)} \frac{\partial N_{4}^{(i)}}{\partial V_{w}}\right)+\mu_{a} \frac{\partial N_{5}}{\partial V_{w w}}\right] \\
& =0-\mu_{a} \frac{\partial N_{5}}{\partial V_{w}}=-\left(\mu_{a}\right)\left[-V_{w} \cdot \rho\left(T_{t d b}, \boldsymbol{\alpha}\right)\right] \text {. }
\end{aligned}
$$


Re-writing Equation (E1) in the form

$$
\mu_{a}=-\frac{S_{5}}{\frac{\partial N_{5}}{\partial V_{w}}}
$$

indicates that the value of the adjoint function $\mu_{a}$ could be computed independently if the sensitivity $S_{5}$ were available, since the quantity $\partial N_{5} / \partial V_{w}=-2.1795\left[\mathrm{~J} /\left(\mathrm{m}^{4} / \mathrm{s}\right)\right]$ is known. To first-order in the parameter perturbation, the finite-difference formula given in Equation (28) can be used to compute the approximate sensitivity $S_{5}^{F D}$; subsequently, this value can be used in conjunction with Equation (E2) to compute a "finite-difference sensitivity" value, denoted as $\left[\mu_{a}\right]^{S F D}$, for the respective adjoint, which would be accurate up to second-order in the respective parameter perturbation:

$$
\left[\mu_{a}\right]^{S F D}=-\frac{S_{5}^{F D}}{\partial N_{5} / \partial V_{w}}=-\left[\frac{T_{a, \text { pert }}^{(1)}-T_{a, \text { nom }}^{(1)}}{\delta V_{w}}\right]\left[\frac{\partial N_{5}}{\partial V_{w}}\right]^{-1}
$$

Numerically, the wind speed $V_{w}$ has the nominal ("base-case") value of $V_{w}^{0}=1.859[\mathrm{~m} / \mathrm{s}]$. The corresponding nominal value $T_{a, n o m}^{(1)}$ of the response $T_{a}^{(1)}$ is $T_{a, n o m}^{(1)}=298.7979[\mathrm{~K}]$. Consider next a perturbation $\delta T_{a, \text { in }}=(0.01) V_{w}^{0}$, for which the perturbed value of the inlet air temperature becomes $V_{w}^{\text {pert }}=V_{w}^{0}-\delta V_{w}=1.84041[\mathrm{~m} / \mathrm{s}]$. Re-computing the perturbed response by solving Equations (2)-(14) with the value of $V_{w}^{\text {pert }}$ yields the "perturbed response" value $T_{a, p e r t}^{(1)}=298.8029[\mathrm{~K}]$. Using now the nominal and perturbed response values together with the parameter perturbation in the finite-difference expression given in Equation (28) yields the corresponding "finite-difference-computed sensitivity" $S_{5}^{F D} \triangleq \frac{T_{a, p e r t}^{(1)}-T_{a, n o m}^{(1)}}{\delta V_{w}}=-0.27219\left[\frac{\mathrm{K}}{\mathrm{m} / \mathrm{s}}\right]$. Using this value together with the nominal values of the other quantities appearing in the expression on the right side of Equation (E3) yields $\left[\mu_{a}\right]^{S F D}=-0.12489\left[\mathrm{~K} /\left(\mathrm{J} / \mathrm{m}^{3}\right)\right]$. This result compares well with the value $\mu_{a}=-0.12651\left[\mathrm{~K} /\left(\mathrm{J} / \mathrm{m}^{3}\right)\right]$ obtained by solving the adjoint sensitivity system given in Equation (20), cf., below Figure 8 .

The same parameter perturbation was utilized to perform the same verification procedure for the adjoint function $\mu_{a}$ with respect to the other four responses; Table E1 displays the obtained results, which compare well with the values in the bar plots in Figures 9-12.

Table E1. Verification Table for adjoint function $\mu_{a}$ with respect to the responses $T_{a}^{(1)}, T_{w}^{(50)}, R H^{(1)}$,

\begin{tabular}{|c|c|c|c|c|c|c|}
\hline \multirow{2}{*}{$\begin{array}{l}\text { Response of } \\
\text { Interest }\end{array}$} & & $V_{w}$ & $T_{a}^{(1)}$ & $S_{5}^{F D}$ & {$\left[\mu_{a}\right]^{S F D}$} & $\mu_{a}$ \\
\hline & & {$[\mathrm{m} / \mathrm{s}]$} & {$[\mathrm{K}]$} & {$[\mathrm{K} /(\mathrm{m} / \mathrm{s})]$} & \multicolumn{2}{|c|}{$\left[\mathrm{K} /\left(\mathrm{J} / \mathrm{m}^{3}\right)\right]$} \\
\hline \multirow{2}{*}{$T_{a}^{(1)}$} & Base case & 1.859 & 298.7979 & \multirow{2}{*}{-0.27219} & \multirow{2}{*}{-0.12489} & \multirow{2}{*}{-0.12651} \\
\hline & Perturbed case & 1.84041 & 298.8029 & & & \\
\hline \multirow{2}{*}{$\begin{array}{l}\text { Response of } \\
\text { Interest }\end{array}$} & & $V_{w}$ & $T_{w}^{(50)}$ & $S_{5}^{F D}$ & {$\left[\mu_{a}\right]^{S F D}$} & $\mu_{a}$ \\
\hline & & {$[\mathrm{m} / \mathrm{s}]$} & {$[\mathrm{K}]$} & {$[\mathrm{K} /(\mathrm{m} / \mathrm{s})]$} & \multicolumn{2}{|c|}{$\left[\mathrm{K} /\left(\mathrm{J} / \mathrm{m}^{3}\right)\right]$} \\
\hline \multirow{2}{*}{$T_{w}^{(50)}$} & Base case & 1.859 & 297.4225 & \multirow{2}{*}{-0.95514} & \multirow{2}{*}{-0.43824} & \multirow{2}{*}{-0.43692} \\
\hline & Perturbed case & 1.84041 & 297.4402 & & & \\
\hline \multirow{2}{*}{$\begin{array}{l}\text { Response of } \\
\text { Interest }\end{array}$} & & $V_{w}$ & $R H^{(1)}$ & $S_{5}^{F D}$ & {$\left[\mu_{a}\right]^{S F D}$} & $\mu_{a}$ \\
\hline & & {$[\mathrm{m} / \mathrm{s}]$} & {$[\%]$} & {$\left[(\mathrm{m} / \mathrm{s})^{-1}\right]$} & \multicolumn{2}{|c|}{$\left[\left(\mathrm{J} / \mathrm{m}^{3}\right)^{-1}\right]$} \\
\hline \multirow{2}{*}{$R H^{(1)}$} & Base case & 1.859 & 99.79724 & \multirow{2}{*}{-0.71122} & \multirow{2}{*}{-0.32632} & \multirow{2}{*}{-0.33332} \\
\hline & Perturbed case & 1.84041 & 99.81046 & & & \\
\hline
\end{tabular}
$m_{w}^{(50)}$ and $m_{a}$. 
Table E1. Cont.

\begin{tabular}{|c|c|c|c|c|c|c|}
\hline \multirow{2}{*}{$\begin{array}{l}\text { Response of } \\
\text { Interest }\end{array}$} & & $V_{w}$ & $m_{w}^{(50)}$ & $S_{5}^{F D}$ & {$\left[\mu_{a}\right]^{S F D}$} & $\mu_{a}$ \\
\hline & & {$[\mathrm{m} / \mathrm{s}]$} & {$[\mathrm{kg} / \mathrm{s}]$} & {$\left[\frac{(\mathrm{kg} / \mathrm{s})}{(\mathrm{m} / \mathrm{s})}\right]$} & \multicolumn{2}{|c|}{$\left[(\mathrm{kg} / \mathrm{s}) /\left(\mathrm{J} / \mathrm{m}^{3}\right)\right]$} \\
\hline \multirow{2}{*}{$m_{w}^{(50)}$} & Base case & 1.859 & 43.90797 & \multirow{2}{*}{-0.073996} & \multirow{2}{*}{-0.033951} & \multirow{2}{*}{-0.033873} \\
\hline & Perturbed case & 1.84041 & 43.90934 & & & \\
\hline \multirow{2}{*}{$\begin{array}{l}\text { Response of } \\
\text { Interest }\end{array}$} & & $V_{w}$ & $m_{a}$ & $S_{5}^{F D}$ & {$\left[\mu_{a}\right]^{S F D}$} & $\mu_{a}$ \\
\hline & & {$[\mathrm{m} / \mathrm{s}]$} & {$[\mathrm{kg} / \mathrm{s}]$} & {$\left[\frac{(\mathrm{kg} / \mathrm{s})}{(\mathrm{m} / \mathrm{s})}\right]$} & \multicolumn{2}{|c|}{$\left[(\mathrm{kg} / \mathrm{s}) /\left(\mathrm{J} / \mathrm{m}^{3}\right)\right]$} \\
\hline \multirow{2}{*}{$m_{a}$} & Base case & 1.859 & 15.83980 & \multirow{2}{*}{11.63149} & \multirow{2}{*}{5.33677} & \multirow{2}{*}{5.34064} \\
\hline & Perturbed case & 1.84041 & 15.62357 & & & \\
\hline
\end{tabular}

(b) Verification of the adjoint function $o^{(49)}$

Note that the value of the adjoint function $o^{(49)}$ obtained by solving the adjoint sensitivity system given in Equation (20) is $o^{(49)}=-1.313 \times 10^{-5}[\mathrm{~K} /(\mathrm{J} / \mathrm{kg})]$, as indicated in Figure 8. Now select a variation $\delta T_{a, i n}$ in the inlet air temperature $T_{a, i n}$, and note that Equation (27) yields the following expression for the sensitivity of the response $R=T_{a}^{(1)}$ to $T_{a, i n}$ :

$$
\begin{aligned}
& S_{45} \triangleq \frac{\partial R}{\partial T_{a, i n}}-\left[\sum_{i=1}^{49}\left(\mu_{w}^{(i)} \frac{\partial N_{1}^{(i)}}{\partial T_{a, i n}}+\tau_{w}^{(i)} \frac{\partial N_{2}^{(i)}}{\partial T_{a, i n}}+\tau_{a}^{(i)} \frac{\partial N_{3}^{(i)}}{\partial T_{a, i n}}+o^{(i)} \frac{\partial N_{4}^{(i)}}{\partial T_{a, i n}}\right)+\mu_{a} \frac{\partial N_{5}}{\partial T_{a, i n}}\right] \\
& =0-\left[o^{(49)} \frac{\partial N_{4}^{(49)}}{\partial T_{a, i n}}+\mu_{a} \frac{\partial N_{5}}{\partial T_{a, i n}}\right] \\
& =-\left(o^{(49)}\right)\left(C p\left(\frac{T_{a}^{(49)}+t K}{2}\right)+\omega_{\text {in }} \alpha_{1 g}\right)- \\
& \left(\mu_{a}\right)\left[\frac{R_{\text {air }}}{2 \cdot P_{\text {atm }}} \cdot\left|m_{a}\right| \cdot m_{a} \cdot\left[\left(\frac{1}{A_{\text {out }}^{2}}-\frac{1}{A_{\text {in }}^{2}}+\frac{k_{\text {sum }}}{A_{\text {fill }}^{2}}\right)+\frac{96 f}{\operatorname{Re}} \cdot \frac{L_{\text {fill }}}{A_{\text {fill }}^{2} D_{h}}\right]+\frac{g \cdot P_{\text {atm }}}{R_{\text {air }} \cdot T_{a, i n}^{2}} \cdot\left(Z+\frac{V_{w w}^{2}}{2 g}-\Delta z_{\text {rain }}-\frac{\Delta z}{2}\right)\right] .
\end{aligned}
$$

Re-writing Equation (E4) in the form

$$
o^{(49)}=-\frac{S_{45}+\mu_{a} \frac{\partial N_{5}}{\partial T_{a, i n}}}{\frac{\partial N_{4}^{(49)}}{\partial T_{a, i n}}}
$$

indicates that the value of the adjoint function $o^{(49)}$ could be computed independently if the sensitivity $S_{45}$ were available, since the quantities $\partial N_{4}^{(49)} / \partial T_{a, i n}=1.0309 \times 10^{3}[\mathrm{~J} /(\mathrm{kg} \cdot \mathrm{K})]$ and $\partial N_{5} / \partial T_{a, i n}=0.40491\left[\mathrm{~J} /\left(\mathrm{m}^{3} \cdot \mathrm{K}\right)\right]$ are known. To first-order in the parameter perturbation, the finite-difference formula given in Equation (28) can be used to compute the approximate sensitivity $S_{45}^{F D}$; subsequently, this value can be used in conjunction with Equation (E5) to compute a "finite-difference sensitivity" value, denoted as $\left[o^{(49)}\right]^{S F D}$, for the respective adjoint, which would be accurate up to second-order in the respective parameter perturbation:

$$
\left[o^{(49)}\right]^{S F D}=-\frac{S_{45}^{F D}+\mu_{a} \frac{\partial N_{5}}{\partial T_{a, i n}}}{\frac{\partial N_{4}^{(49)}}{\partial T_{a, i n}}}=-\left[\frac{T_{a, p e r t}^{(1)}-T_{a, n o m}^{(1)}}{\delta T_{a, i n}}+\mu_{a} \frac{\partial N_{5}}{\partial T_{a, i n}}\right]\left[\frac{\partial N_{4}^{(49)}}{\partial T_{a, i n}}\right]^{-1}
$$

Numerically, the inlet air temperature $T_{a, i n}\left(=T_{d b}\right)$ has the nominal ("base-case") value of $T_{a, i n}^{0}=298.882[\mathrm{~K}]$. The corresponding nominal value $T_{a, n o m}^{(1)}$ of the response $T_{a}^{(1)}$ is $T_{a, n o m}^{(1)}=298.7979[\mathrm{~K}]$. Consider next a perturbation $\delta T_{a, i n}=(0.0001) T_{a, i n}^{0}$, for which the perturbed value of the inlet air temperature becomes $T_{a, i n}^{\text {pert }}=T_{a, i n}^{0}-\delta T_{a, i n}=298.852[\mathrm{~K}]$. Re-computing the perturbed response by solving Equastions (2)-(14) with the value of $T_{a, i n}^{\text {pert }}$ yields the "perturbed 
response" value $T_{a, p e r t}^{(1)}=298.7960[\mathrm{~K}]$. Using now the nominal and perturbed response values together with the parameter perturbation in the finite-difference expression given in Equation (28) yields the corresponding “finite-difference-computed sensitivity" $S_{45}^{F D} \triangleq \frac{T_{a, p e r t}^{(1)}-T_{a, n o m}^{(1)}}{\delta T_{a, \text { in }}}=0.06555$. Using this value together with the nominal values of the other quantities appearing in the expression on the right side of Equation (E6) yields $\left[o^{(49)}\right]^{S F D}=-1.391 \times 10^{-5}[\mathrm{~K} /(\mathrm{J} / \mathrm{kg})]$. This result compares well with the value $o^{(49)}=-1.313 \times 10^{-5}[\mathrm{~K} /(\mathrm{J} / \mathrm{kg})]$ obtained by solving the adjoint sensitivity system given in Equation (20), cf., Figure 8. When solving this adjoint sensitivity system, the computation of $o^{(49)}$ depends on the previously computed adjoint functions $o^{(i)}, \quad i=1, \ldots, I-1$; hence, the forgoing verification of the computational accuracy of $o^{(49)}$ also provides an indirect verification that the functions $o^{(i)}, \quad i=1, \ldots, I-1$, were also computed accurately.

The same parameter perturbation was utilized to perform the same verification procedure for the adjoint function $o^{(49)}$ with respect to the other four responses; Table E2 displays the obtained results, which compare well with the values in the bar plots in Figures 9-12.

Table E2. Verification Table for adjoint function $o^{(49)}$ with respect to the responses $T_{a}^{(1)}, T_{w}^{(50)}, R H^{(1)}$, $m_{w}^{(50)}$ and $m_{a}$.

\begin{tabular}{|c|c|c|c|c|c|c|}
\hline \multirow{2}{*}{$\begin{array}{l}\text { Response of } \\
\text { Interest }\end{array}$} & & $T_{a, i n}$ & $T_{a}^{(1)}$ & $S_{45}^{F D}$ & {$\left[o^{(49)}\right]^{S F D}$} & $o^{(49)}$ \\
\hline & & {$[\mathrm{K}]$} & {$[\mathrm{K}]$} & {$[-]$} & \multicolumn{2}{|c|}{$[\mathrm{K} /(\mathrm{J} / \mathrm{kg})]$} \\
\hline \multirow{2}{*}{$T_{a}^{(1)}$} & Base case & 298.882 & 298.7979 & \multirow{2}{*}{0.06555} & \multirow{2}{*}{$-1.39 \times 10^{-5}$} & \multirow{2}{*}{$-1.31 \times 10^{-5}$} \\
\hline & Perturbed case & 298.852 & 298.7960 & & & \\
\hline \multirow{2}{*}{$\begin{array}{l}\text { Response of } \\
\text { Interest }\end{array}$} & & $T_{a, i n}$ & $T_{w}^{(50)}$ & $S_{45}^{F D}$ & {$\left[o^{(49)}\right]^{S F D}$} & $o^{(49)}$ \\
\hline & & {$[\mathrm{K}]$} & {$[\mathrm{K}]$} & {$[-]$} & \multicolumn{2}{|c|}{$[\mathrm{K} /(\mathrm{J} / \mathrm{kg})]$} \\
\hline \multirow{2}{*}{$T_{w}^{(50)}$} & Base case & 298.882 & 297.4225 & \multirow{2}{*}{0.25125} & \multirow{2}{*}{$-7.21 \times 10^{-5}$} & \multirow{2}{*}{$-7.28 \times 10^{-5}$} \\
\hline & Perturbed case & 298.852 & 297.4149 & & & \\
\hline \multirow{2}{*}{$\begin{array}{l}\text { Response of } \\
\text { Interest }\end{array}$} & & $T_{a, i n}$ & $R H^{(1)}$ & $S_{45}^{F D}$ & {$\left[o^{(49)}\right]^{S F D}$} & $o^{(49)}$ \\
\hline & & {$[\mathrm{K}]$} & {$[\%]$} & {$\left[\mathrm{K}^{-1}\right]$} & \multicolumn{2}{|c|}{$\left[(\mathrm{J} / \mathrm{kg})^{-1}\right]$} \\
\hline \multirow{2}{*}{$R H^{(1)}$} & Base case & 298.882 & 99.79724 & \multirow{2}{*}{0.09039} & \multirow{2}{*}{$4.32 \times 10^{-5}$} & \multirow{2}{*}{$5.02 \times 10^{-5}$} \\
\hline & Perturbed case & 298.852 & 99.79453 & & & \\
\hline \multirow{2}{*}{$\begin{array}{c}\text { Response of } \\
\text { Interest }\end{array}$} & & $T_{a, i n}$ & $m_{w}^{(50)}$ & $S_{45}^{F D}$ & {$\left[o^{(49)}\right]^{S F D}$} & $o^{(49)}$ \\
\hline & & {$[\mathrm{K}]$} & {$[\mathrm{kg} / \mathrm{s}]$} & {$\left[\frac{\mathrm{kg} / \mathrm{s}}{\mathrm{K}}\right]$} & {$[(\mathrm{kg} / \mathrm{s}$} & $(\mathrm{J} / \mathrm{kg})]$ \\
\hline \multirow{2}{*}{$m_{w}^{(50)}$} & Base case & 298.882 & 43.90797 & \multirow{2}{*}{0.012694} & \multirow{2}{*}{$9.91 \times 10^{-7}$} & \multirow{2}{*}{$9.18 \times 10^{-7}$} \\
\hline & Perturbed case & 298.852 & 43.90758 & & & \\
\hline \multirow{2}{*}{$\begin{array}{l}\text { Response of } \\
\text { Interest }\end{array}$} & & $T_{a, i n}$ & $m_{a}$ & $S_{45}^{F D}$ & {$\left[o^{(49)}\right]^{S F D}$} & $o^{(49)}$ \\
\hline & & {$[\mathrm{K}]$} & {$[\mathrm{kg} / \mathrm{s}]$} & {$\left[\frac{\mathrm{kg} / \mathrm{s}}{\mathrm{K}}\right]$} & \multicolumn{2}{|c|}{$[(\mathrm{kg} / \mathrm{s}) /(\mathrm{J} / \mathrm{kg})]$} \\
\hline \multirow{2}{*}{$m_{a}$} & Base case & 298.882 & 15.83890 & \multirow{2}{*}{-2.03711} & \multirow{2}{*}{$-1.22 \times 10^{-4}$} & \multirow{2}{*}{$-1.18 \times 10^{-4}$} \\
\hline & Perturbed case & 298.852 & 15.90091 & & & \\
\hline
\end{tabular}

(c) Verification of the Adjoint Function $\tau_{a}^{(49)}$

Note that the value of the adjoint function $\tau_{a}^{(49)}$ obtained by solving the adjoint sensitivity system given in Equation (20) is $\tau_{a}^{(49)}=21.555[\mathrm{~K}]$, as indicated in Figure 8. Now select a variation $\delta \omega_{\text {in }}$ in 
the inlet air humidity ratio $\omega_{i n}$, and note that Equation (27) yields the following expression for the sensitivity of the response $R=T_{a}^{(1)}$ to $\omega_{i n}$ :

$$
\begin{aligned}
S_{46} & \triangleq \frac{\partial R}{\partial \omega_{i n}}-\left[\sum_{i=1}^{49}\left(\mu_{w w}^{(i)} \frac{\partial N_{1}^{(i)}}{\partial \omega_{i n}}+\tau_{w}^{(i)} \frac{\partial N_{2}^{(i)}}{\partial \omega_{i n}}+\tau_{a}^{(i)} \frac{\partial N_{3}^{(i)}}{\partial \omega_{i n}}+o^{(i)} \frac{\partial N_{4}^{(i)}}{\partial \omega_{i n}}\right)+\mu_{a} \frac{\partial N_{5}}{\partial \omega_{i n}}\right] \\
& =0-\left(\tau_{a}^{(49)} \frac{\partial N_{3}^{(49)}}{\partial \omega_{i n}}+o^{(49)} \frac{\partial N_{4}^{(49)}}{\partial \omega_{i n}}\right)=-\left[\tau_{a}^{(49)} \cdot(1)+o^{(49)} \cdot h_{g, a}^{(50)}\left(T_{a, i n}, \boldsymbol{\alpha}\right)\right] .
\end{aligned}
$$

Re-writing Equation (E7) in the form

$$
\tau_{a}^{(49)}=-S_{46}-o^{(49)} \cdot h_{g, a}^{(50)}\left(T_{a, i n}, \boldsymbol{\alpha}\right)
$$

indicates that the value of the adjoint function $\tau_{a}^{(49)}$ could be computed independently if the sensitivity $S_{46}$ were available, since the $o^{(49)}$ has been verified in (the previous) Appendix E.1 (b) and the quantity $h_{g, a}^{(50)}\left(T_{a, i n}, \boldsymbol{\alpha}\right)$ is known. To first-order in the parameter perturbation, the finite-difference formula given in Equation (28) can be used to compute the approximate sensitivity $S_{46}^{F D}$; subsequently, this value can be used in conjunction with Equation (E8) to compute a "finite-difference sensitivity" value, denoted as $\left[\tau_{a}^{(49)}\right]^{S F D}$, for the respective adjoint, which would be accurate up to second-order in the respective parameter perturbation:

$$
\left[\tau_{a}^{(49)}\right]^{S F D}=-S_{46}^{F D}-o^{(49)} \cdot h_{g, a}^{(50)}\left(T_{a, i n}, \boldsymbol{\alpha}\right)
$$

Numerically, the inlet air humidity ratio $\omega_{\text {in }}$ has the nominal ("base-case") value of $\omega_{\text {in }}^{0}=0.0137976$. The corresponding nominal value $T_{a, n o m}^{(1)}$ of the response $T_{a}^{(1)}$ is $T_{a, n o m}^{(1)}=298.7979[\mathrm{~K}]$. Consider next a perturbation $\delta \omega_{i n}=(0.00125) \omega_{i n}^{0}$, for which the perturbed value of the inlet air humidity ratio becomes $\omega_{i n}^{\text {pert }}=\omega_{i n}^{0}-\delta \omega_{i n}=0.0137803$. Re-computing the perturbed response by solving Eqsuations (2)-(14) with the value of $\omega_{i n}^{\text {pert }}$ yields the "perturbed response" value $T_{a, p e r t}^{(1)}=298.7977[\mathrm{~K}]$. Using now the nominal and perturbed response values together with the parameter perturbation in the finite-difference expression given in Equation (28) yields the corresponding "finite-difference-computed sensitivity" $S_{46}^{\mathrm{FD}} \triangleq \frac{T_{a, p e r}^{(1)}-T_{a, n o m}^{(1)}}{\delta \omega_{\text {in }}}=11.878[\mathrm{~K}]$. Using this value together with the nominal values of the other quantities appearing in the expression on the right side of Equation (E9) yields $\left[\tau_{a}^{(49)}\right]^{S F D}=21.5697[\mathrm{~K}]$. This result compares well with the value $\tau_{a}^{(49)}=21.555[\mathrm{~K}]$ obtained by solving the adjoint sensitivity system given in Equation (20), cf. Figure 8 . When solving this adjoint sensitivity system, the computation of $\tau_{a}^{(49)}$ depends on the previously computed adjoint functions $\tau_{a}^{(i)}, \quad i=1, \ldots, I-1$; hence, the forgoing verification of the computational accuracy of $\tau_{a}^{(49)}$ also provides an indirect verification that the functions $\tau_{a}^{(i)}, \quad i=1, \ldots, I-1$ were also computed accurately.

The same parameter perturbation was utilized to perform the same verification procedure for the adjoint function $\tau_{a}^{(49)}$ with respect to the other four responses; Table E3 displays the obtained results, which compare well with the values in the bar plots in Figures 9-12. 
Table E3. Verification Table for adjoint function $\tau_{a}^{(49)}$ with respect to the responses $T_{a}^{(1)}, T_{w}^{(50)}, R H^{(1)}$, $m_{w}^{(50)}$ and $m_{a}$.

\begin{tabular}{|c|c|c|c|c|c|c|}
\hline \multirow{2}{*}{$\begin{array}{l}\text { Response of } \\
\text { Interest }\end{array}$} & & $\omega_{\text {in }}$ & $T_{a}^{(1)}$ & $S_{46}^{F D}$ & {$\left[\tau_{a}^{(49)}\right]^{S F D}$} & $\tau_{a}^{(49)}$ \\
\hline & & {$[\%]$} & {$[\mathrm{K}]$} & {$[\mathrm{K}]$} & \multicolumn{2}{|c|}{$[\mathrm{K}]$} \\
\hline \multirow{2}{*}{$T_{a}^{(1)}$} & Base case & 0.0137976 & 298.7979 & \multirow{2}{*}{11.878} & \multirow{2}{*}{21.569} & \multirow{2}{*}{21.555} \\
\hline & Perturbed case & 0.0137803 & 298.7977 & & & \\
\hline \multirow{2}{*}{$\begin{array}{l}\text { Response of } \\
\text { Interest }\end{array}$} & & $\omega_{\text {in }}$ & $T_{w}^{(50)}$ & $S_{46}^{F D}$ & {$\left[\tau_{a}^{(49)}\right]^{S F D}$} & $\tau_{a}^{(49)}$ \\
\hline & & {$[\%]$} & {$[\mathrm{K}]$} & {$[\mathrm{K}]$} & \multicolumn{2}{|c|}{$[\mathrm{K}]$} \\
\hline \multirow{2}{*}{$T_{w}^{(50)}$} & Base case & 0.0137976 & 297.4225 & \multirow{2}{*}{201.180} & \multirow{2}{*}{-15.593} & \multirow{2}{*}{-15.799} \\
\hline & Perturbed case & 0.0137803 & 297.4190 & & & \\
\hline \multirow{2}{*}{$\begin{array}{l}\text { Response of } \\
\text { Interest }\end{array}$} & & $\omega_{\text {in }}$ & $R H^{(1)}$ & $S_{46}^{F D}$ & {$\left[\tau_{a}^{(49)}\right]^{S F D}$} & $\tau_{a}^{(49)}$ \\
\hline & & {$[\%]$} & {$[\%]$} & {$[-]$} & \multicolumn{2}{|c|}{$[-]$} \\
\hline \multirow{2}{*}{$R H^{(1)}$} & Base case & 0.0137976 & 99.79724 & \multirow{2}{*}{24.4676} & \multirow{2}{*}{-152.46} & \multirow{2}{*}{-152.50} \\
\hline & Perturbed case & 0.0137803 & 99.79681 & & & \\
\hline \multirow{2}{*}{$\begin{array}{l}\text { Response of } \\
\text { Interest }\end{array}$} & & $\omega_{\text {in }}$ & $m_{w}^{(50)}$ & $S_{46}^{F D}$ & {$\left[\tau_{a}^{(49)}\right]^{S F D}$} & $\tau_{a}^{(49)}$ \\
\hline & & {$[\%]$} & {$[\mathrm{kg} / \mathrm{s}]$} & {$[\mathrm{kg} / \mathrm{s}]$} & \multicolumn{2}{|c|}{$[\mathrm{kg} / \mathrm{s}]$} \\
\hline \multirow{2}{*}{$m_{w}^{(50)}$} & Base case & 0.0137976 & 43.90797 & \multirow{2}{*}{15.1936} & \multirow{2}{*}{-17.533} & \multirow{2}{*}{-17.549} \\
\hline & Perturbed case & 0.0137803 & 43.90770 & & & \\
\hline \multirow{2}{*}{$\begin{array}{l}\text { Response of } \\
\text { Interest }\end{array}$} & & $\omega_{\text {in }}$ & $m_{a}$ & $S_{46}^{F D}$ & {$\left[\tau_{a}^{(49)}\right]^{S F D}$} & $\tau_{a}^{(49)}$ \\
\hline & & {$[\%]$} & {$[\mathrm{kg} / \mathrm{s}]$} & {$[\mathrm{kg} / \mathrm{s}]$} & \multicolumn{2}{|c|}{$[\mathrm{kg} / \mathrm{s}]$} \\
\hline \multirow{2}{*}{$m_{a}$} & Base case & 0.0137976 & 15.83890 & \multirow{2}{*}{43.92139} & \multirow{2}{*}{256.109} & \multirow{2}{*}{256.059} \\
\hline & Perturbed case & 0.0137803 & 15.83903 & & & \\
\hline
\end{tabular}

(d) Verification of the adjoint functions $\tau_{w}^{(1)}$

Note that the values of the adjoint function $\tau_{w}^{(1)}$ obtained by solving the adjoint sensitivity system given in Equation (20) is as follows: $\tau_{w}^{(1)}=-4.98 \times 10^{-6}[\mathrm{~K} /(\mathrm{J} / \mathrm{s})]$, as indicated in Figure 8. Now select a variation $\delta T_{w, i n}$ in the inlet water temperature $T_{w, i n}$, and note that Equation (27) yields the following expression for the sensitivity of the response $R=T_{a}^{(1)}$ to $T_{w, i n}$ :

$$
\begin{aligned}
S_{3} & \triangleq \frac{\partial R}{\partial T_{w, i n}}-\left[\sum_{i=1}^{49}\left(\mu_{w}^{(i)} \frac{\partial N_{1}^{(i)}}{\partial T_{w, i n}}+\tau_{w}^{(i)} \frac{\partial N_{2}^{(i)}}{\partial T_{w, i n}}+\tau_{a}^{(i)} \frac{\partial N_{3}^{(i)}}{\partial T_{w, i n}}+o^{(i)} \frac{\partial N_{4}^{(i)}}{\partial T_{w, i n}}\right)+\mu_{a} \frac{\partial N_{5}}{\partial T_{w, i n}}\right] \\
& =0-\tau_{w}^{(1)} \frac{\partial N_{2}^{(1)}}{\partial T_{w, i n}}=0-\tau_{w}^{(1)} \cdot\left(m_{w, i n} a_{1} f\right) .
\end{aligned}
$$

Re-writing Equation (E10) in the form

$$
\tau_{w}^{(1)}=-\frac{S_{3}}{\left(m_{w, \text { in }} a_{1 f}\right)}
$$

indicates that the value of the adjoint function $\tau_{w}^{(1)}$ could be computed independently if the sensitivity $S_{3}$ were available, since the quantity $m_{w, i n} a_{1 f}$ is known. To first-order in the parameter perturbation, the finite-difference formula given in Equation (28) can be used to compute the approximate sensitivity $S_{3}^{F D}$; subsequently, this value can be used in conjunction with Equation (E11) to compute a "finite-difference sensitivity" value, denoted as $\left[\tau_{w}^{(1)}\right]^{S F D}$, for the respective adjoint, which would be accurate up to second-order in the respective parameter perturbation: 


$$
\left[\tau_{w}^{(1)}\right]^{S F D}=-\frac{S_{3}^{F D}}{\left(m_{w, i n} a_{1 f}\right)}
$$

Numerically, the inlet water temperature, $T_{w, i n}$, has the nominal ("base-case") value of $T_{w, i n}^{0}=298.893[\mathrm{~K}]$. As before, the corresponding nominal value $T_{a, n o m}^{(1)}$ of the response $T_{a}^{(1)}$ is $T_{a, n o m}^{(1)}=298.7979[\mathrm{~K}]$. Consider now a perturbation $\delta T_{w, \text { in }}=(0.000067) T_{w, i n}^{0}$, for which the perturbed value of the inlet air temperature becomes $T_{w, i n}^{p e r t}=T_{w, \text { in }}^{0}-\delta T_{w, \text { in }}=298.873[\mathrm{~K}]$. Re-computing the perturbed response by solving Equations (2)-(14) with the value of $T_{w, \text { in }}^{\text {pert }}$ yields the "perturbed response" value $T_{a, p e r t}^{(1)}=298.7795[\mathrm{~K}]$. Using now the nominal and perturbed response values together with the parameter perturbation in the finite-difference expression given in Equation (28) yields the corresponding "finite-difference-computed sensitivity" $S_{3}^{F D} \triangleq \frac{T_{a, p e r t}^{(1)}-T_{a, n o m}^{(1)}}{\delta T_{w, i n}}=0.91889$. Using this value together with the nominal values of the other quantities appearing in the expression on the right side of Equation (E12) yields $\left[\tau_{w}^{(1)}\right]^{S F D}=-4.99 \times 10^{-6}[\mathrm{~K} /(\mathrm{J} / \mathrm{s})]$. This result compares well with the value $\tau_{w}^{(1)}=-4.98 \times 10^{-6}[\mathrm{~K} /(\mathrm{J} / \mathrm{s})]$ obtained by solving the adjoint sensitivity system given in Equation (20), cf. Figure 8.

The same parameter perturbation was utilized to perform the same verification procedure for the adjoint function $\tau_{w}^{(1)}$ with respect to the other four responses; Table E4 displays the obtained results, which compare well with the values in the bar plots in Figures 9-12.

Table E4. Verification Table for adjoint function $\tau_{w}^{(1)}$ with respect to the responses $T_{a}^{(1)}, T_{w}^{(50)}, R H^{(1)}$, $m_{w}^{(50)}$ and $m_{a}$.

\begin{tabular}{|c|c|c|c|c|c|c|}
\hline \multirow{2}{*}{$\begin{array}{l}\text { Response of } \\
\text { Interest }\end{array}$} & & $T_{w, i n}$ & $T_{a}^{(1)}$ & $S_{3}^{F D}$ & {$\left[\tau_{w}^{(1)}\right]^{S F D}$} & $\tau_{w}^{(1)}$ \\
\hline & & {$[\mathrm{K}]$} & {$[\mathrm{K}]$} & {$[-]$} & \multicolumn{2}{|c|}{$[\mathrm{K} /(\mathrm{J} / \mathrm{s})]$} \\
\hline \multirow{2}{*}{$T_{a}^{(1)}$} & Base case & 298.893 & 298.7979 & \multirow{2}{*}{0.91889} & \multirow{2}{*}{$-4.99 \times 10^{-6}$} & \multirow{2}{*}{$-4.98 \times 10^{-6}$} \\
\hline & Perturbed case & 298.873 & 298.7795 & & & \\
\hline \multirow{2}{*}{$\begin{array}{l}\text { Response of } \\
\text { Interest }\end{array}$} & & $T_{w, i n}$ & $T_{w}^{(50)}$ & $S_{3}^{F D}$ & {$\left[\tau_{w}^{(1)}\right]^{S F D}$} & $\tau_{w}^{(1)}$ \\
\hline & & {$[\mathrm{K}]$} & {$[\mathrm{K}]$} & {$[-]$} & \multicolumn{2}{|c|}{$[\mathrm{K} /(\mathrm{J} / \mathrm{s})]$} \\
\hline \multirow{2}{*}{$T_{w}^{(50)}$} & Base case & 298.893 & 297.4225 & \multirow{2}{*}{0.50358} & $-273 \times 10^{-6}$ & \multirow{2}{*}{$-2.73 \times 10^{-6}$} \\
\hline & Perturbed case & 298.873 & 297.4124 & & $2.80 \wedge 10$ & \\
\hline \multirow{2}{*}{$\begin{array}{l}\text { Response of } \\
\text { Interest }\end{array}$} & & $T_{w, i n}$ & $R H^{(1)}$ & $S_{3}^{F D}$ & {$\left[\tau_{w}^{(1)}\right]^{S F D}$} & $\tau_{w}^{(1)}$ \\
\hline & & {$[\mathrm{K}]$} & {$[\%]$} & {$\left[\mathrm{K}^{-1}\right]$} & \multicolumn{2}{|c|}{$\left[(\mathrm{J} / \mathrm{s})^{-1}\right]$} \\
\hline \multirow{2}{*}{$R H^{(1)}$} & Base case & 298.893 & 99.79724 & \multirow{2}{*}{-0.10693} & \multirow{2}{*}{$5.77 \times 10^{-7}$} & \multirow{2}{*}{$5.78 \times 10^{-7}$} \\
\hline & Perturbed case & 298.873 & 99.7994 & & & \\
\hline \multirow{2}{*}{$\begin{array}{l}\text { Response of } \\
\text { Interest }\end{array}$} & & $T_{w, i n}$ & $m_{w}^{(50)}$ & $S_{3}^{F D}$ & {$\left[\tau_{w}^{(1)}\right]^{S F D}$} & $\tau_{w}^{(1)}$ \\
\hline & & {$[\mathrm{K}]$} & {$[\mathrm{kg} / \mathrm{s}]$} & {$\left[\frac{\mathrm{kg} / \mathrm{s}}{\mathrm{K}}\right]$} & \multicolumn{2}{|c|}{$\left[(\mathrm{J} / \mathrm{kg})^{-1}\right]$} \\
\hline \multirow{2}{*}{$m_{w}^{(50)}$} & Base case & 298.893 & 43.90797 & \multirow{2}{*}{-0.031364} & \multirow{2}{*}{$1.70 \times 10^{-7}$} & \multirow{2}{*}{$1.70 \times 10^{-7}$} \\
\hline & Perturbed case & 298.873 & 43.90859 & & & \\
\hline \multirow{2}{*}{$\begin{array}{l}\text { Response of } \\
\text { Interest }\end{array}$} & & $T_{w, \text { in }}$ & $m_{a}$ & $S_{3}^{F D}$ & {$\left[\tau_{w}^{(1)}\right]^{S F D}$} & $\tau_{w}^{(1)}$ \\
\hline & & {$[\mathrm{K}]$} & {$[\mathrm{kg} / \mathrm{s}]$} & {$\left[\frac{\mathrm{kg} / \mathrm{s}}{\mathrm{K}}\right]$} & \multicolumn{2}{|c|}{$\left[(\mathrm{J} / \mathrm{kg})^{-1}\right]$} \\
\hline \multirow{2}{*}{$m_{a}$} & Base case & 298.893 & 15.83980 & \multirow{2}{*}{1.91042} & \multirow{2}{*}{$-1.037 \times 10^{-5}$} & \multirow{2}{*}{$-1.035 \times 10^{-5}$} \\
\hline & Perturbed case & 298.873 & 15.80159 & & & \\
\hline
\end{tabular}


(e) Verification of the adjoint function $\mu_{w}^{(1)}$

Note that the values of the adjoint function $\mu_{w}^{(1)}$ obtained by solving the adjoint sensitivity system given in Equation (20) is as follows: $\mu_{w}^{(1)}=10.30109[\mathrm{~K} /(\mathrm{kg} / \mathrm{s})]$, as indicated in Figure 8. Now select a variation $\delta m_{w, i n}$ in the inlet water mass flow rate $m_{w, i n}$, and note that Equation (27) yields the following expression for the sensitivity of the response $R=T_{a}^{(1)}$ to $m_{w, i n}$ :

$$
\begin{aligned}
S_{44} & \triangleq \frac{\partial R}{\partial m_{w, i n}}-\left[\sum_{i=1}^{49}\left(\mu_{w}^{(i)} \frac{\partial N_{1}^{(i)}}{\partial m_{w, i n}}+\tau_{w}^{(i)} \frac{\partial N_{2}^{(i)}}{\partial m_{w, i n}}+\tau_{a}^{(i)} \frac{\partial N_{3}^{(i)}}{\partial m_{w, i n}}+o^{(i)} \frac{\partial N_{4}^{(i)}}{\partial m_{w, i n}}\right)+\mu_{a} \frac{\partial N_{5}}{\partial m_{w, i n}}\right] \\
& =0-\left(\mu_{w}^{(1)} \frac{\partial N_{1}^{(1)}}{\partial m_{w, i n}}+\tau_{w}^{(1)} \frac{\partial N_{2}^{(1)}}{\partial m_{w, i n}}+\tau_{a}^{(1)} \frac{\partial N_{3}^{(1)}}{\partial m_{w, i n}}+o^{(1)} \frac{\partial N_{4}^{(1)}}{\partial m_{w, i n}}\right) \\
& =-\left(\mu_{w}^{(1)} \cdot(-1)+\tau_{w}^{(1)} \cdot\left(T_{w, \text { in }} a_{1 f}-a_{1} T_{w}^{(2)}+a_{0}-a_{0} g\right)+\tau_{a}^{(1)} \cdot\left(\frac{1}{m_{a}}\right)+o^{(1)} \cdot\left(\frac{a_{1 g} T_{w w}^{(2)}+a_{0 g}}{m_{a}}\right)\right) .
\end{aligned}
$$

Since the adjoint functions $\tau_{a}^{(49)}$ and $o^{(49)}$ have been already verified as described in Appendix E.1 (b) and (c), it follows that the computed values of adjoint functions $\tau_{a}^{(1)}=2128.24[\mathrm{~K}] o^{(1)}=$ $-8.4254 \times 10^{-4}[\mathrm{~K} /(\mathrm{J} / \mathrm{kg})]$ can also be considered as being accurate, since they constitute the starting point for solving the adjoint sensitivity system in Equation (20); $\tau_{w}^{(1)}$ was proved being accurate in Appendix E.1 (d).

Re-writing Equation (E13) in the form

$$
\mu_{w}^{(1)}=S_{44}+\tau_{w}^{(1)} \cdot\left(T_{w, i n} a_{1 f}-a_{1 g} T_{w}^{(2)}+a_{0 f}-a_{0 \mathrm{~g}}\right)+\tau_{a}^{(1)} \cdot\left(\frac{1}{m_{a}}\right)+o^{(1)} \cdot\left(\frac{a_{1 g} T_{w}^{(2)}+a_{0 g}}{m_{a}}\right)
$$

indicates that the value of the adjoint function $\mu_{w}^{(1)}$ could be computed independently if the sensitivity $S_{44}$ were available, since all the other quantities are known. To first-order in the parameter perturbation, the finite-difference formula given in Equation (28) can be used to compute the approximate sensitivity $S_{44}^{F D}$; subsequently, this value can be used in conjunction with Equation (E14) to compute a "finite-difference sensitivity" value, denoted as $\left[\mu_{w}^{(1)}\right]^{S F D}$, for the respective adjoint, which would be accurate up to second-order in the respective parameter perturbation:

$$
\left[\mu_{w}^{(1)}\right]^{S F D}=\mu_{w}^{(1)}=S_{44}^{F D}+\tau_{w}^{(1)} \cdot\left(T_{w, i n} a_{1 f}-a_{1 g} T_{w}^{(2)}+a_{0 f}-a_{0 \mathrm{~g}}\right)+\tau_{a}^{(1)} \cdot\left(\frac{1}{m_{a}}\right)+o^{(1)} \cdot\left(\frac{a_{1 g} T_{w}^{(2)}+a_{0 g}}{m_{a}}\right)
$$

Numerically, the inlet water mass flow rate, $m_{w, i n}$, has the nominal ("base-case") value of $m_{w, \text { in }}^{0}=44.0193[\mathrm{~kg} / \mathrm{s}]$. As before, the corresponding nominal value $T_{a, \text { nom }}^{(1)}$ of the response $T_{a}^{(1)}$ is $T_{a, n o m}^{(1)}=298.7979[\mathrm{~K}]$. Consider now a perturbation $\delta m_{w, \text { in }}=(0.00068) m_{w, \text { in }}^{0}$, for which the perturbed value of the inlet air temperature becomes $m_{w, \text { in }}^{\text {pert }}=m_{w, \text { in }}^{0}-\delta m_{w, \text { in }}=43.9893[\mathrm{~kg} / \mathrm{s}]$. Re-computing the perturbed response by solving Equations (2)-(14) with the value of $m_{w, \text { in }}^{\text {pert }}$ yields the "perturbed response" value $T_{a, p e r t}^{(1)}=298.7960[\mathrm{~K}]$. Using now the nominal and perturbed response values together with the parameter perturbation in the finite-difference expression given in Equation (28) yields the corresponding "finite-difference-computed sensitivity" $S_{44}^{F D} \triangleq \frac{T_{a, p e r t}^{(1)}-T_{a, n o m}^{(1)}}{\delta m_{w, i n}}=0.00328\left[\frac{\mathrm{K}}{\mathrm{kg} / \mathrm{s}}\right]$. Using this value together with the nominal values of the other quantities appearing in the expression on the right side of Equation (E15) yields $\left[\mu_{w}^{(1)}\right]^{S F D}=10.9768[\mathrm{~K} /(\mathrm{kg} / \mathrm{s})]$. This result compares well with the value $\mu_{w}^{(1)}=10.30109[\mathrm{~K} /(\mathrm{kg} / \mathrm{s})]$ obtained by solving the adjoint sensitivity system given in Equation (20), cf. Figure 8.

The same parameter perturbation was utilized to perform the same verification procedure for the adjoint function $\mu_{w}^{(1)}$ with respect to the other four responses; Table E5 displays the obtained results, which compare well with the values in the bar plots in Figures 9-12. 
Table E5. Verification Table for adjoint function $\mu_{w}^{(1)}$ with respect to the responses $T_{a}^{(1)}, T_{w}^{(50)}, R H^{(1)}$, $m_{w}^{(50)}$ and $m_{a}$.

\begin{tabular}{|c|c|c|c|c|c|c|}
\hline \multirow{2}{*}{$\begin{array}{l}\text { Response of } \\
\text { Interest }\end{array}$} & & $m_{w, i n}$ & $T_{a}^{(1)}$ & $S_{3}^{F D}$ & {$\left[\mu_{w}^{(1)}\right]^{S F D}$} & $\mu_{w}^{(1)}$ \\
\hline & & {$[\mathrm{kg} / \mathrm{s}]$} & {$[\mathrm{K}]$} & {$\left[\frac{\mathrm{K}}{\mathrm{kg} / \mathrm{s}}\right]$} & \multicolumn{2}{|c|}{$\left[\frac{\mathrm{K}}{\mathrm{kg} / \mathrm{s}}\right]$} \\
\hline \multirow{2}{*}{$T_{a}^{(1)}$} & Base case & 44.0193 & 298.7979 & \multirow{2}{*}{0.00328} & \multirow{2}{*}{10.977} & \multirow{2}{*}{10.301} \\
\hline & Perturbed case & 43.9893 & 298.7978 & & & \\
\hline \multirow{2}{*}{$\begin{array}{l}\text { Response of } \\
\text { Interest }\end{array}$} & & $m_{w, i n}$ & $T_{w}^{(50)}$ & $S_{3}^{F D}$ & {$\left[\mu_{w}^{(1)}\right]^{S F D}$} & $\mu_{w}^{(1)}$ \\
\hline & & {$[\mathrm{kg} / \mathrm{s}]$} & {$[\mathrm{K}]$} & {$\left[\frac{\mathrm{K}}{\mathrm{kg} / \mathrm{s}}\right]$} & \multicolumn{2}{|c|}{$\left[\frac{\mathrm{K}}{\mathrm{kg} / \mathrm{s}}\right]$} \\
\hline \multirow{2}{*}{$T_{w}^{(50)}$} & Base case & 44.0193 & 297.4225 & \multirow{2}{*}{0.03142} & \multirow{2}{*}{6.0444} & \multirow{2}{*}{6.0443} \\
\hline & Perturbed case & 43.9893 & 297.4215 & & & \\
\hline \multirow{2}{*}{$\begin{array}{l}\text { Response of } \\
\text { Interest }\end{array}$} & & $m_{w, i n}$ & $R H^{(1)}$ & $S_{3}^{F D}$ & {$\left[\mu_{w}^{(1)}\right]^{S F D}$} & $\mu_{w}^{(1)}$ \\
\hline & & {$[\mathrm{kg} / \mathrm{s}]$} & {$[\%]$} & {$\left[(\mathrm{kg} / \mathrm{s})^{-1}\right]$} & \multicolumn{2}{|c|}{$\left[(\mathrm{kg} / \mathrm{s})^{-1}\right]$} \\
\hline \multirow{2}{*}{$R H^{(1)}$} & Base case & 44.0193 & 99.79724 & \multirow{2}{*}{-0.001267} & \multirow{2}{*}{-265.511} & \multirow{2}{*}{-265.511} \\
\hline & Perturbed case & 43.9893 & 99.79728 & & & \\
\hline \multirow{2}{*}{$\begin{array}{l}\text { Response of } \\
\text { Interest }\end{array}$} & & $m_{w, i n}$ & $m_{w}^{(50)}$ & $S_{3}^{F D}$ & {$\left[\mu_{w}^{(1)}\right]^{S F D}$} & $\mu_{w}^{(1)}$ \\
\hline & & {$[\mathrm{kg} / \mathrm{s}]$} & {$[\mathrm{kg} / \mathrm{s}]$} & {$[-]$} & \multicolumn{2}{|c|}{$[-]$} \\
\hline \multirow{2}{*}{$m_{w}^{(50)}$} & Base case & 44.0193 & 43.90797 & \multirow{2}{*}{0.99986} & \multirow{2}{*}{0.52753} & \multirow{2}{*}{0.52753} \\
\hline & Perturbed case & 43.9893 & 43.87797 & & & \\
\hline \multirow{2}{*}{$\begin{array}{l}\text { Response of } \\
\text { Interest }\end{array}$} & & $m_{w, i n}$ & $m_{a}$ & $S_{3}^{F D}$ & {$\left[\mu_{w}^{(1)}\right]^{S F D}$} & $\mu_{w}^{(1)}$ \\
\hline & & {$[\mathrm{kg} / \mathrm{s}]$} & {$[\mathrm{kg} / \mathrm{s}]$} & {$[-]$} & \multicolumn{2}{|c|}{$[-]$} \\
\hline \multirow{2}{*}{$m_{a}$} & Base case & 44.0193 & 15.83980 & \multirow{2}{*}{0.010543} & \multirow{2}{*}{22.807} & \multirow{2}{*}{22.807} \\
\hline & Perturbed case & 43.9893 & 15.83948 & & & \\
\hline
\end{tabular}

\section{References}

1. Aleman, S.E.; Garrett, A.J. Operational Cooling Tower Model (CTTool v1.0); SRNL-STI-2015-00039, Revision 0; Savannah River National Laboratory: Savannah River Site, SC, USA, 2015.

2. Cacuci, D.G.; Di Rocco, F. Predictive modeling of a buoyancy-operated cooling tower operating under saturated Conditions. I: Adjoint sensitivity model. Nucl. Sci. Eng. 2016, in press.

3. Di Rocco, F.; Cacuci, D.G.; Badea, M.C. Predictive modeling of a buoyancy-operated cooling tower operating under saturated Conditions. II: Optimal best-estimate results with reduced predicted uncertainties. Nucl. Sci. Eng. 2016, in press.

4. Cacuci, D.G. Sensitivity theory for nonlinear systems: I. Nonlinear functional analysis approach. J. Math. Phys. 1981, 22, 2794-2802. [CrossRef]

5. Cacuci, D.G. Sensitivity and Uncertainty Analysis: Theory; Chapman \& Hall/CRC: Boca Raton, FL, USA, 2003.

6. Cacuci, D.G.; Ionescu-Bujor, M.; Navon, I.M. Sensitivity and Uncertainty Analysis: Applications to Large Scale Systems; Chapman \& Hall/CRC: Boca Raton, FL, USA, 2005.

7. Cacuci, D.G. Predictive modeling of coupled multi-physics systems: I. theory. Ann. Nucl. Energy 2014, 70 , 266-278. [CrossRef]

8. Garrett, A.J.; Parker, M.J.; Villa-Aleman, E. 2004 Savannah River site Cooling Tower Collection; SRNL-DOD-2005-07; Atmospheric Technologies Group, Savannah River National Laboratory: Aiken, SC, USA, 2005.

9. Saad, Y.; Schultz, M.H. GMRES: A generalized minimal residual algorithm for solving nonsymmetric linear systems. SIAM J. Sci. Stat. Comput. 1986, 7, 856-869. [CrossRef] 
10. Oppe, T.C.; Joubert, W.D.; Kincaid, D.R. A Package for Solving Large Sparse Linear Systems by Various Iterative Methods; NSPCG User's Guide, Version 1.0; Center for Numerical Analysis, the University of Texas at Austin: Austin, TX, USA, 1988.

11. Faragó, I.; Havasi, A.; Zlatev, Z. Advanced Numerical Methods for Complex Environmental Models: Needs and Availability; Bentham Science Publishers: Oak Park, IL, USA, 2014.

12. Cacuci, D.G.; Navon, I.M.; Ionescu-Bujor, M. Computational Methods for Data Evaluation and Assimilation; Chapman \& Hall/CRC: Boca Raton, FL, USA, 2014.

13. Cacuci, D.G. Second-order adjoint sensitivity analysis methodology (2nd-ASAM) for large-scale nonlinear Systems: I. Theory. Nucl. Sci. Eng. 2016, 184, 16-30.

14. Cacuci, D.G. Second-Order adjoint sensitivity analysis methodology (2nd-ASAM) for large-scale nonlinear Systems: II. Illustrative application to a paradigm nonlinear heat conduction benchmark. Nucl. Sci. Eng. 2016, 184, 31-52. [CrossRef]

(C) 2016 by the authors; licensee MDPI, Basel, Switzerland. This article is an open access article distributed under the terms and conditions of the Creative Commons Attribution (CC-BY) license (http://creativecommons.org/licenses/by/4.0/). 